\title{
WestVirginiaUniversity
}

THE RESEARCH REPOSITORY @ WVU

Graduate Theses, Dissertations, and Problem Reports

2018

\section{The Policy Dynamics of the Trafficking Victims Protection Act (2000)}

\author{
Samantha E. Godbey
}

Follow this and additional works at: https://researchrepository.wvu.edu/etd

\section{Recommended Citation}

Godbey, Samantha E., "The Policy Dynamics of the Trafficking Victims Protection Act (2000)" (2018). Graduate Theses, Dissertations, and Problem Reports. 5685.

https://researchrepository.wvu.edu/etd/5685

This Dissertation is protected by copyright and/or related rights. It has been brought to you by the The Research Repository @ WVU with permission from the rights-holder(s). You are free to use this Dissertation in any way that is permitted by the copyright and related rights legislation that applies to your use. For other uses you must obtain permission from the rights-holder(s) directly, unless additional rights are indicated by a Creative Commons license in the record and/ or on the work itself. This Dissertation has been accepted for inclusion in WVU Graduate Theses, Dissertations, and Problem Reports collection by an authorized administrator of The Research Repository @ WVU.

For more information, please contact researchrepository@mail.wvu.edu. 
The Policy Dynamics of the Trafficking Victims Protection Act (2000)

Samantha E. Godbey

Dissertation submitted to the Eberly College of Arts and Sciences at West Virginia University in partial fulfillment of the requirements for the degree of

Doctor of Philosophy

in

Political Science

Jeff Worsham, PhD, (Co-Chair)

Christina Fattore, $\mathrm{PhD}$, (Co-Chair)

John Kilwein, PhD

Shauna Fisher, PhD

Karen Culcasi, PhD

Department of Political Science

May 2018

Morgantown, West Virginia

Copyright 2018 Samantha E. Godbey

Keywords: Human Trafficking Policy, Policy Creation 


\author{
Abstract \\ "The Policy Dynamics of the Trafficking Victims Protection Act (2000)" \\ Samantha E. Godbey
}

This study examines the creation and implementation of the Trafficking Victims Protection Act 2000 (TVPA). This research builds on the literature in the area of the policy-making process, specifically focusing on the issue attention cycle, agenda setting, and implementation. This study begins with a focus on the role the media plays in framing the issue, turns to a consideration of Congress and the passage of the TVPA, and concludes with an examination of the implementation of the act through executive branch use of sanctions. I suggest that human trafficking was framed as a criminal justice issue by both the media and Congress, thus shaping the implementation of the policy at home and abroad. 


\section{Dedication}

This dissertation is dedicated to Dr. Neil Berch and The West Virginia University Debate Team Past, Present, and Future. 


\section{Acknowledgments}

When I think back over the events that happened that led to the creation of this document, and subsequent career path, I am not entirely sure how it happened. I did not grow up wishing to be a $\mathrm{PhD}$, or even a teacher and I'm not entirely sure any of this would have happened if I did not find my true calling and love the WVU Debate Team. Post undergrad I did not really have a plan, and in a series of events outside of my control I got offered the debate coach assistantship about 2 weeks before Fall 2008 term started. It was supposed to be a way to bide some time until I figured out what I wanted to do with my life, little did I know this would become it. My life has been consumed with the WVU Debate team since then, guiding almost all of my professional decisions, including the topic of this dissertation. Though being a debate coach was my love, and I let that role consume a majority of my life, and for the past 3 years in particular, this

dissertation and completion of this degree might be the best thing that has come out of it. In all of the madness, I learned that I can do hard things, and have a new found confidence in my role as an educator, researcher, and debate coach. Though those things are true, I did not do this on my own. I hope these words can adequately express the gratitude I have for everyone who has helped me in this process.

Being a member of a dissertation committee is a lot of work, for very little reward. None of this would have been possible without the help of my committee. Thank you to Dr. Kilwein, Dr. Fisher, and Dr. Culcasi for sticking by me over the last three years and giving great feedback and research questions to shape my research in the future. I am very grateful to have mentors like you. 
Since I was combining disciplines, I ended up with two Co-Chairs. Both of these people guided my research and professional careers in their own ways. Both of which it was an absolute honor and privilege to work with.

Dr. Worsham, I think it is rare that one gets to work with someone who so dramatically shaped their view of their discipline. When I look back on my education, particularly in graduate school your courses were the most influential. They made me excited about political science. You challenged me in ways that did not knock me down but elevated my work and research. You are my role model for what I want to be both as a teacher and researcher, being able to work with you in this capacity was one of the greatest privileges of my professional life.

Dr. Fattore, I could go on and on about your accolades, how smart and strategic you and your research are, but you provided me with much more than that. To be a woman in academia is not easy. I know for a fact without your encouragement and never letting me give up even through the tears and the "I'm freaking out emails," I wouldn't have finished. When we talk about changes that need to happen in institutions like higher education, you lead by example. I strive to be as good of a role model to students as you are to not just me, but every student lucky enough to cross paths with you.

Not only did I find support and help from my mentors, I would not have been able to do this without my family. Dad and Maryann, There have never been two more positive and uplifting cheerleaders. Thank you for all of your support and kindness throughout this process, even though it took longer than we all wanted. I am extremely blessed to have you two in my life, and it is one of my life long goals to make you proud.

Mom, you have always provided me with role models from Eleanor Roosevelt to Oprah, never letting me get out of my head that I could be anything I wanted to be. Little did you know, 
all I wanted was to be just like you. I hope to be half the woman you are. I hope this, and all I do makes you proud.

Bobbie, Ryan, and Addie, I feel so lucky to call you all family. You provide me with support, laughter, and love. Bobbie, thank you for being the best sister anyone could ask for, and for always being able to edit and read through something even at the last minute. I have never met someone who works as hard as you do to make the people they loves lives easier. You are kind and generous. Ryan, you are the best brother anyone could ask for. We are all blessed that you are a part of our family, and though not related by blood you are such a strong and central part of the Godbey-Lewis-Imes family. Addie, you are only 2 but the light and laughter you bring us makes me feel better about the future of world everyday. I know you will do great things and I hope to help guide you in whatever your dreams may be.

Last but not least Josh. I'm very glad Binghamton and Cal State Fullerton both preferred us mutually, and our lives collided. There will never be the perfect words to express my gratitude for your support throughout this process. You have loved me when I was not loveable, you never gave up on my ability to finish, and you supported us throughout this entire process. You moved to a new state from the greatest city in the world for me to pursue my dream and we have created such a beautiful life. I have loved every minute of being your partner, you are the best part of everyday. There is not a way I would have gotten through this without your help. I love you endlessly. 
Table of Contents

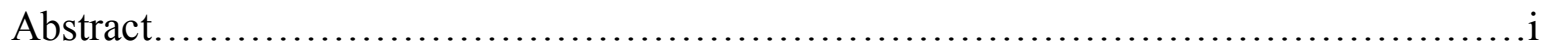

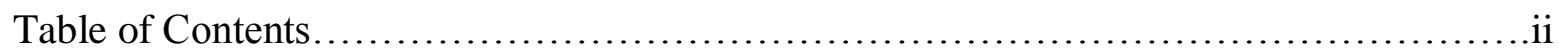

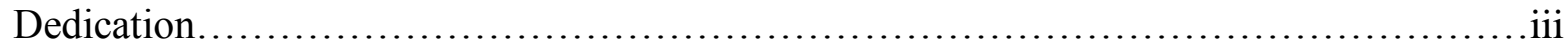

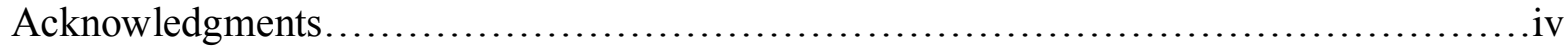

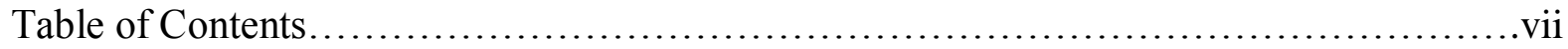

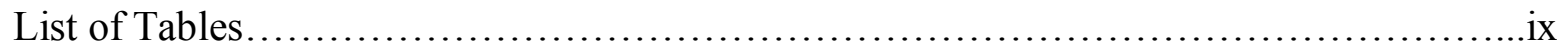

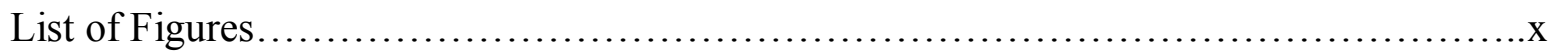

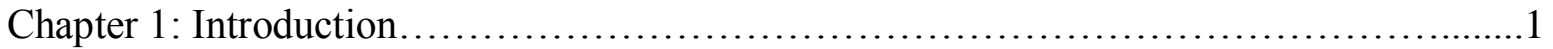

Chapter 2: The Policy Dynamics of the TVPA......................................

Introduction............................................................

Morality Politics and Human Trafficking ...................................... 5

Immigration and Human Trafficking. ......................................... 7

Globalization and Human Trafficking......................................... 8

International Diffusion of Policy............................................9

Conclusion................................................................... 11

Chapter 3: Theoretical Approaches to the Policy Making Process........................ 13

Introduction...............................................................

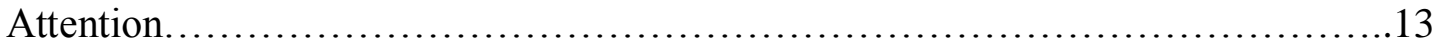

Issue Framing and Agenda Setting ...............................................

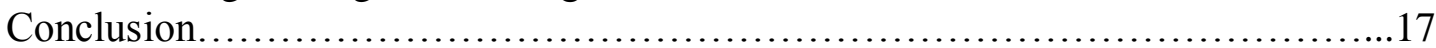

Chapter 4: Media Attention....................................................... 19

Introduction............................................................... 19

Theories of Problem Identification, Agenda Setting, and Target Populations.........20

Data Sources.............................................................. 23

Mapping the Issue Attention Cycle..........................................23

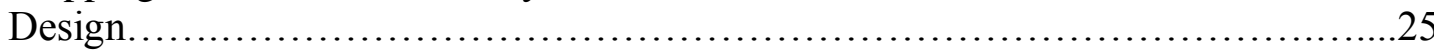

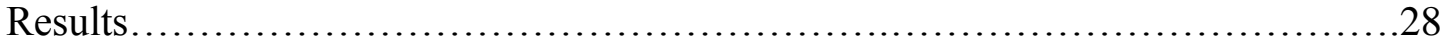

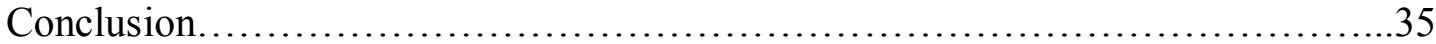

Chapter 5: Human Trafficking and Congressional Attention..............................36

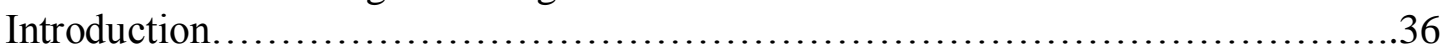

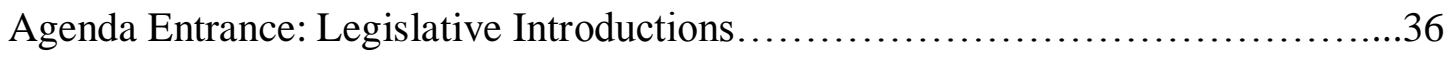

Entrepreneurship ....................................................... 40

Framing the Issue: Hearings and Commissions................................48

Framing the Issue: Topic Discussions at Hearings............................ 54

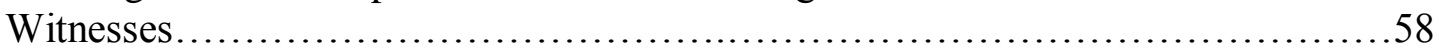

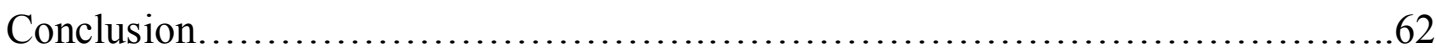

Chapter 6: Sanctions as a Tool to Stop Human Trafficking..........................6 63

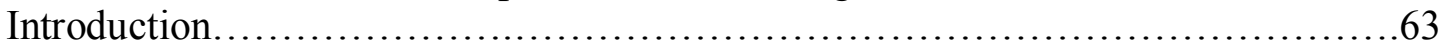

International Diffusion..................................................66

Sanctions as a Punishment for Non-Compliance.............................. 71

Methods..................................................................... 76

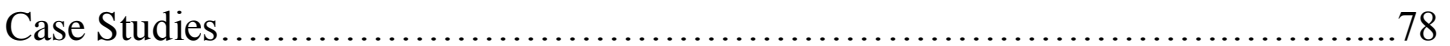

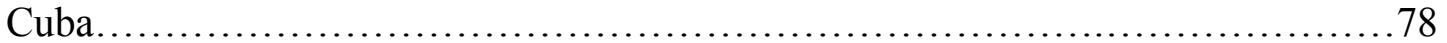

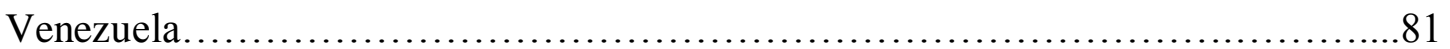


Saudi Arabia............................................................. 83

Sudan/South Sudan......................................................... 86

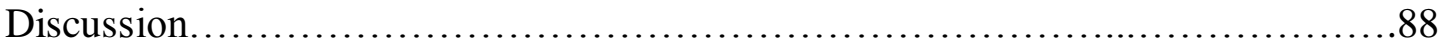

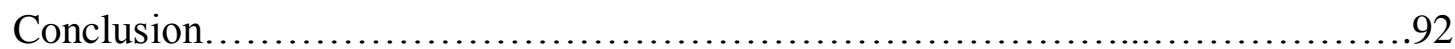

Chapter 7: Conclusion..........................................................94

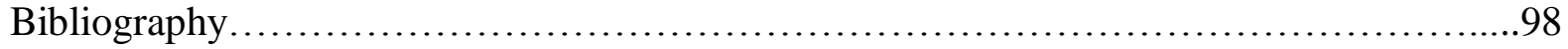

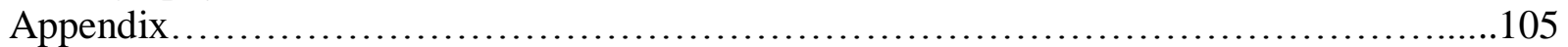




\section{List of Tables}

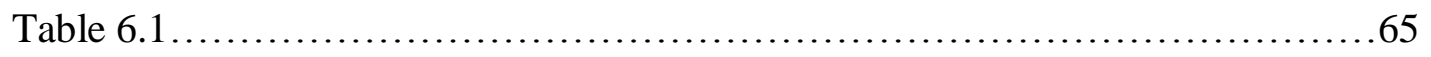

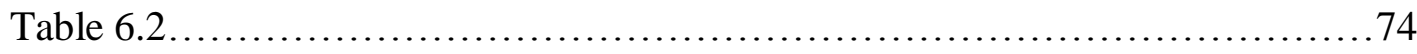


Chapter 4:

\section{List of Figures}

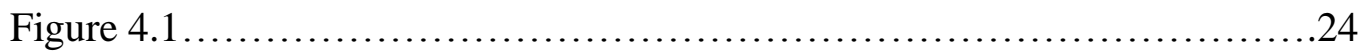

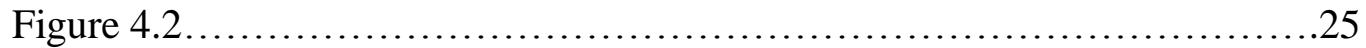

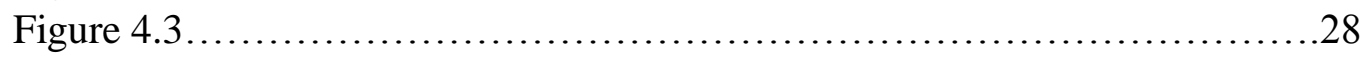

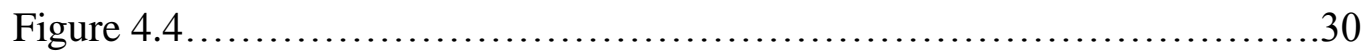

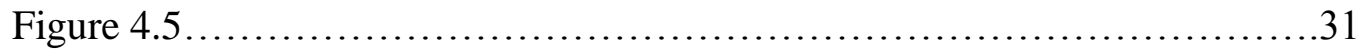

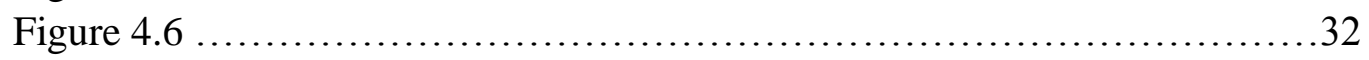

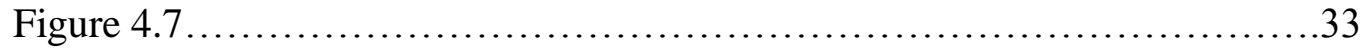

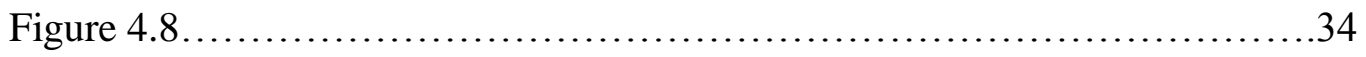

Chapter 5:

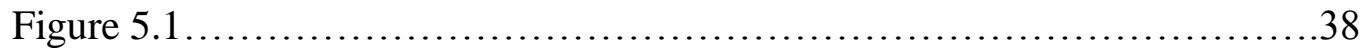

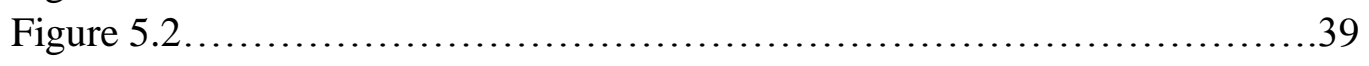

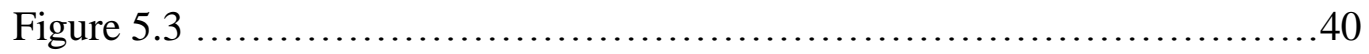

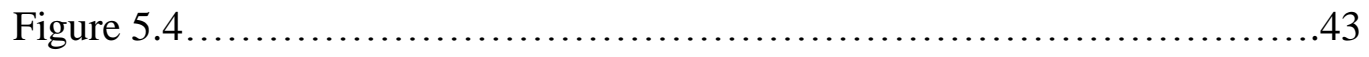

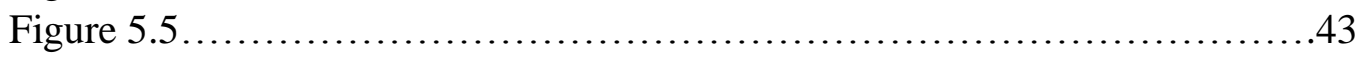

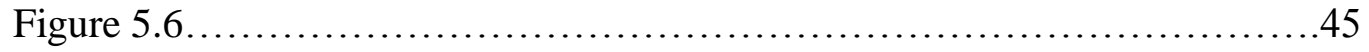

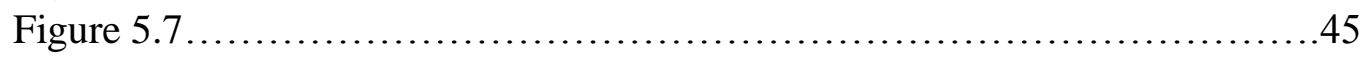

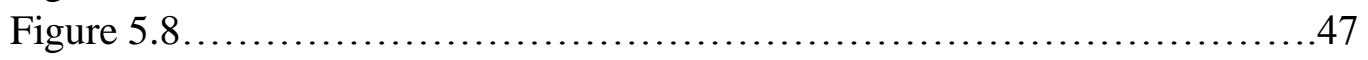

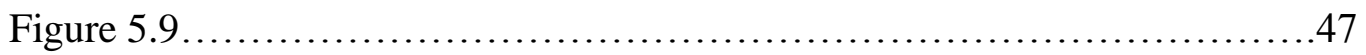

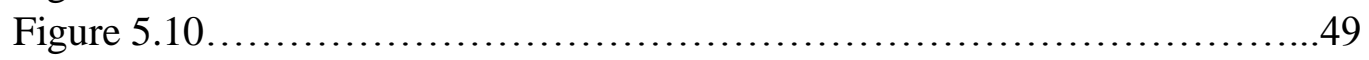

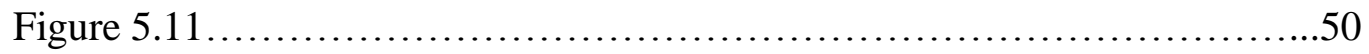

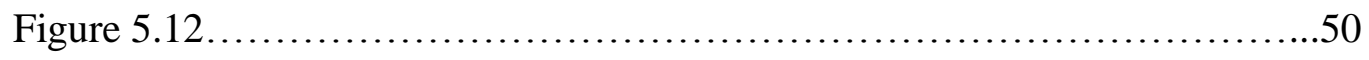

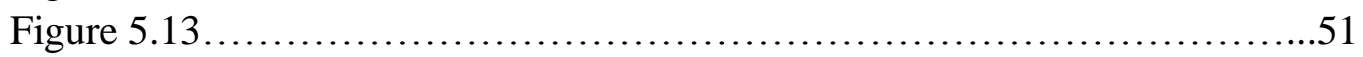

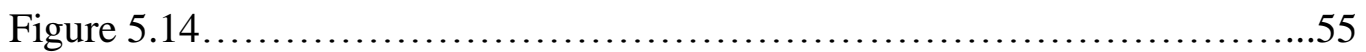

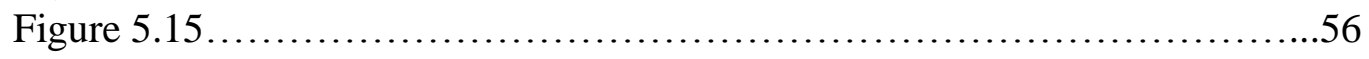

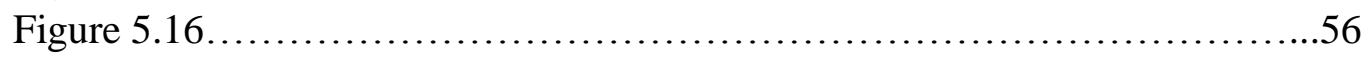

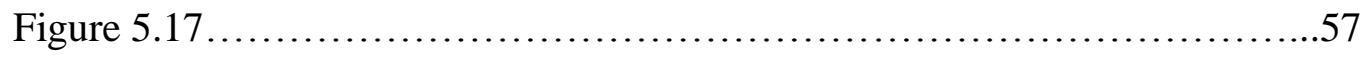

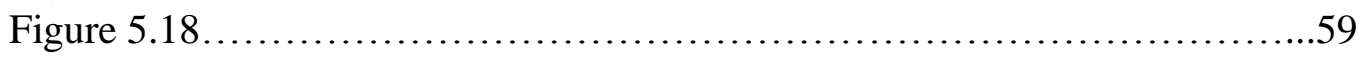

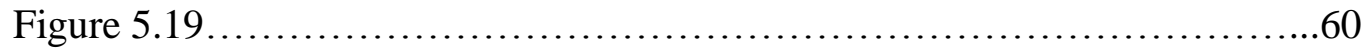

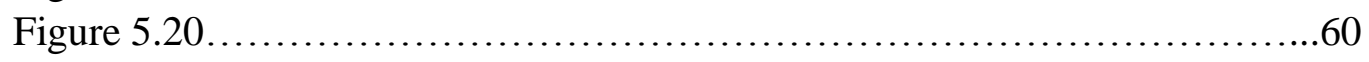

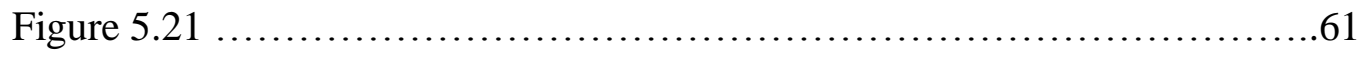




\section{Chapter 1- Introduction}

Human trafficking is not a new phenomenon in the history of humankind. It has existed in practice in a multitude of cultures throughout time. Some of those historical instances of past trafficking, such as the slave trade in the Americas and Europe, still haunt our social and political lives. Human trafficking refers to the act of moving persons both internationally and domestically for the purposes of labor. Trafficking of humans for work can lead to extremely dangerous, illegal, and exploitative working conditions. Although human trafficking can affect all persons no matter their gender, race, or sexual identification, women and girls are especially targeted due to their vulnerable status in society (Samarsinghe, 2008).

The United States State Department claims that 600,000-800,000 persons are trafficked across international borders each year. Approximately $80 \%$ of human trafficking involves sexual exploitation, although women and girls are trafficked at a higher rate, men and boys are exploited for sexual labor as well (United Nationals Organization on Drugs and Crime, 2014; Free the Slaves, 2017; Bales and Soodalter, 2009). According to the 2011 United Nations Trafficking report, women and girls made up $70 \%$ of those trafficked (49\% and $21 \%$ respectively) throughout the world, while men accounted for $18 \%$ and boys made up 12\% of trafficking victims (United Nations Organization on Drugs and Crime, 2015). Although sexual exploitation is a large part of the trafficking of humans across borders, exploitation for other forms of labor is also a large part of the narrative. $70 \%$ of trafficking victims are trafficked into the sex industry each year (United States Department of State, 2005). Out of the 600,000 to 800,000 persons trafficked across international borders it is estimated that 14,500 to 17,500 of those persons are brought into the United States for the exploitation of labor (United States Department of State, 2006; United States Department of State, 2007; Clawson et al, 2006).

Human trafficking does not just target one demographic of the population. Human trafficking victims can be any gender, age, sexual orientation, or economic status. Although victims can be part of any demographic, there are certain criteria that make a person more likely to be trafficked. Young 
persons, impoverished persons, women, unemployed persons, persons that live in countries with high police corruption, persons that live in a place with high crime rates, and those that experience a range of mental and physical health disabilities are all persons that are more likely to become victims (Joshi, 2002; Newman, 2006; Clawson et al, 2009).

Victims of human trafficking are often convinced to go with their traffickers with the promise of high paying jobs in a more economically and politically stable country. Often these victims are then indebted to their traffickers, since they pay for their travel and documentation needed for international travel and legal immigration status. Once victims are in their new country they find that they have little legal recourse to address the abuse they may be facing since they are strangers in a new place and the fact that often their immigration status is not legal, as was promised by their trafficker (International Organization on Migration, 2017; Tuller et al, 2005; Bales, 2004; Clawson et al, 2009).

Human trafficking is a problem, both internationally and domestically. In response to this problem the United States enacted the Trafficking Victims Protection Act (TVPA) on October 28, 2000. The TVPA was the first human trafficking piece of legislation in the world that took on the international battle of human trafficking, as well as providing services for those who have been trafficked within United States' borders. While human trafficking has been practiced all over the world since the beginning of time, agreement on the definition of human trafficking in both the international community and the United States has never been formalized. This study is interested in discovering how trafficking became defined as a recent problem and how that definition shaped the policy response to this long practiced ill.

The research question that drives this dissertation is what shaped the content of the TVPA? Why did the TVPA frame human trafficking the way it did and propose the solutions it did? The answer to this question draws on the literature in public policy, agenda setting, and policy diffusion to tell the story of the origins, passage and reformulation of the TVPA. The answer is developed in three substantive chapters that focus on media attention, congressional action, and international diffusion.

Chapter four is interested in how the media frames human trafficking and whether it shaped the way in which the law was written. I track media attention by content analyzing New York Times articles 
between 1990 and 2010. I find that the media discussed human trafficking employing morality politics, anti-immigrant rhetoric, and a global focus, which both shaped the goals of TVPA and the subsequent efforts to amend it. Chapter five documents the role of Congress in the creation of the TVPA, as well as the efforts to amend it following its passage through 2016. I am interested in the role of policy entrepreneurs, committees, and interests in the formulation and reformulation of human trafficking legislation. The final empirical chapter (six) tracks international diffusion of the TVPA. I am interested in tracking the process and identifying the parts of the act that were adopted by other organizations, states, or actors. 


\section{Chapter 2- The Policy Dynamics of the Trafficking Victims Protection Act}

\section{Introduction}

The TVPA was the first attempt by the United States, or any international actor, to address the problem of modern day slavery and the trafficking of persons across international borders. The TVPA is groundbreaking in its creation because it provides stricter legal repercussions for human traffickers, focusing on both the domestic and international aspects of trafficking (Reiger 2007).

The TVPA defines trafficking in the following terms:

(a) sex trafficking in which a commercial sex act is induced by force, fraud, and coercion, or in which the person induced to perform such act has not attained 18 years of age; or (b) the recruitment, harboring, transportation, provision or obtaining of person for labor or services, through the use of force, fraud or coercion for the purpose of subjection to involuntary servitude, peonage, debt bondage, and/or slavery (H.R. 3244, 2000).

There are three major components to this definition. First, it distinguishes between labor and sex trafficking, although both are illegal they affect their victims in dramatically different ways. Second, it recognizes the presence of force, fraud and coercion involved in trafficking.

This is an important component because is defines the way in which victims can access legal recourse, as well as immigration support. Victims must prove that they were victims of "forceful, fraudulent, and coercion" and did not consent to any activity before they were trafficked. Third, it distinguishes between human smuggling and trafficking. Human trafficking specifically deals with people who are transported to do a job, where smuggling only deals with people being brought across borders (Gozdziak and Collett, 2001).

Many argue that because of these different definitions there exists a built-in tension when it comes to deciding who qualifies for the benefits of the policy. The phrase "severe forms of trafficking" forces victims to have had never consented to any type of sex work. The "severe forms of trafficking," contingent in the bill excludes many human trafficking victims since it only applies to victims who are innocent of any crimes (Chapkis, 2003). An example of this exclusion would be if a person who had decided to work in the sex industry was trafficked while on the job he/she would not have access to any of 
the benefits provided by the TVPA although this person may suffer all the same negative repercussions of human trafficking, such as not getting paid for their work, sexual and physical assault, and unsafe working conditions (Schauer and Wheaton, 2006).

Another criticism of the TVPA is its inability to successfully provide protection to the victims of human trafficking. Scholars claim that for the law to be effective, police and other law enforcement officials must be trained in the sensitive nature of sex trafficking and treat the participants as victims not criminals. Without proper training and understanding of the larger problem of sex trafficking, it mostly ends up going unnoticed as law officials often ignore prostitution-related crimes (Chacon, 2006;

Sadruddin et. al, 2005). Many scholars argue that the TVPA fails to protect the victims of trafficking as it ignores the fact that victims are most of the time fearful of the trafficker's retaliation and that fear will affect their cooperation with the officials (Reiger, 2007). The way the TVPA was written forces victims to "fully cooperate" with the prosecution of their traffickers. Although many would see this as an obvious part of the law, human trafficking victims often have a different relationship with their traffickers. Since most trafficking rings are international, testimony in the United States could result in reprisals directed at family members in the victim's home countries (Sadruddin et. Al, 2005).

The focus of this research to is to attempt to explain why these levels of ambiguity exist in the TVPA. What societal, international, and political pressures existed at the time this legislation was passed that influenced the policy to be written in such a way that excludes most of the victims they are trying to protect? The following discussion will be focused on the different ways in which human trafficking has been framed in the literature to help begin to shed some light on the problems of the TVPA.

\section{Morality Politics and Human Trafficking}

Human trafficking gained a steady presence in media outlets throughout the 1990s with images of women being rescued from underground brothels throughout the United States and abroad. What had previously been viewed as an issue outside of the United States suddenly became one of the most talked about moral controversies throughout the country. As the media began to televise images of women being 
rescued from brothels on national media, a demand to change this immoral act began (Farrell and Fahy, 2009).

When discussing policy making it is important to understand how different actions affect policy creation. Morality is a large driver in many policy reforms. One of the main ways in which morality plays into policy making is that it creates an undeniable evil, something that must be conquered and taken down —in this case it was human trafficking, but most importantly the idea of forced prostitution. "The [TVPA] capitalized on the one of the most powerful symbols in the pantheon of Western imagery, the innocent, young girl dragged off against her will to distant lands to satisfy the insatiable sexual cravings of wanton men" (Weitzer, p. 467, 2007).

Morality politics can take many forms. Abolitionist rhetoric, anti-sex work rhetoric, and human rights rhetoric were the dominant frames used in the process of identifying human trafficking as a problem. Kinney (2006) states that abolitionist rhetoric was essential in forcing there to be antiprostitution legislation when it came to the issue of human trafficking. As stated above, the TVPA makes it difficult for all victims of human trafficking to receive protection and social services. The TVPA provides no protection for an individual who had intentions of working in the sex trade since it violated traditional notions of morality (Kinney, 2006). This becomes particularly true in discussions of "White Slavery," which is often used side by side in discussions of human trafficking. James Morone (2003) notes that the term "White Slave Trade," has a long history in American politics and especially in discussions on immigration. This morality rhetoric is not new to American media or policy creation; the "white slave trade," narrative focuses on the protection of white women from seemingly dangerous others. During the early 1900s, doctors throughout major cities in the United States started claiming the rise in venereal diseases were the fault of immigrants and persons of color. Prostitution was on the rise and while the demand for prostitution rose, reporters began blaming immigrants (mostly from Eastern Europe) for forcing young, white women into prostitution. Citizens viewed the idea that a white woman could choose the path of prostitution without force or coercion was beyond belief and was therefore 
deemed "White Slavery." This ongoing fear of "White Slavery," created immigration policies set out to protect perceived vulnerable women from perceived threats from immigrants (Morone, 2003).

Globally, victims of human trafficking have been portrayed in many ways. Though having roots in historical immigration debates within the United States, "White Slave Trade," has made a comeback in the literature. The rise in immigration, the feminist movement, the AIDS pandemic, and increased attention to child prostitution and child sex tourism, brought about a globalized discussion of the role morality plays in human trafficking. Though the narrative no longer largely focused on American white women, but Eastern European women being held in brothels around the world, the moral outrage of forced sex work flooded human trafficking discourse (Gozdziak and Collett 2005; Doezema 2002; Wijers and Lap-Chew, 1998).

\section{Immigration and Human Trafficking}

Human trafficking, at its heart, is an issue of immigration. No matter the venue-media, congressional, or international--immigration/emigration is an important frame being used to define human trafficking. The desire to emigrate from their native countries is often strong and many victims of human trafficking are confronted with offers for economic prosperity. Often these economic opportunities force debt bondage, making victims work off the debt of the cost of travel to their destination country (Wheaton et al, 2010). Human trafficking and immigration are inextricably linked, which makes the TVPA on face seem like a great policy, since it provides immigration visas to those who meet the qualifications (Chacon, 2006). The disparity of services offered to victims is seen no clearer than when we are discussing the disbursement of T-Visas for human trafficking victims. With 50,000 Visas that have been offered since the creation of the TVPA only 6,206 have been issued to victims and their families ( $\mathrm{Li}$, 2013). This policy failure is rooted in the immigration policies of American politics.

Human trafficking discussions cannot be separated from discussions of immigration and efforts to control who may enter a country (legal immigration) and who cannot (illegal immigration). With millions of persons being trafficking throughout the world, the concern of illegal immigration has become a 
burden for policy makers. Those seeking better economic and social conditions than their native countries can offer, seek passage to prosperity. Though this has been true for a majority of modern American history, immigration policy has always been a highly contested and divisive issue. Though many scholars have different views on the role of immigration in American politics, one of the most important parts of the discussions comes through its link to the welfare state. Immigration involves social welfare and there are certain services they gain when they become citizens that non-citizens cannot access. Social services by definition imply increased cost to communities. As the number of immigrants increase, so does the cost and controversy associated with immigration (Carens, 1988). Carens (1988) suggests that when you add social services that cost money it fuels the anti-immigration policies and sentiments throughout the United States. On top of the idea that there will be more citizens to cover with social services, racist, ethnocentric, and stereotypes of immigrants only fuel this side of the debate (Carens, 1988).

\section{Globalization and Human Trafficking}

The opening of borders for economic globalization is inextricably tied to immigration/emigration. With the rise of poverty and the increase in openness of borders and economies many people who were stuck in poverty decided to leave their economic hardships for better opportunities (Friman and Reich, 2007). Though this can apply to any type of economic pursuit, it also plays a huge role in human trafficking. The need for cheap labor and people willing to do it has led to many persons being trafficked to fill the gaps in certain labor markets (Feingold, 2005). Globalization has led to the opening of economies, borders, technology, and communication (Friman and Reich, 2007). Though there are some parts of the world that have managed to keep up with the globalized world, many developing countries feeling pressured to keep up with Western abundance then attempted to play the same game and ended up failing to keep up. Poverty throughout the world has actually risen — even though the worldwide incomes have increased (Stiglitz, 2003).

To try and facilitate economic growth countries throughout the world have made development plans that call for promoting tourism. Globalization has introduced sex tourism as a globally known 
business and in some cases increasing the gross domestic product (GDP) of countries (Wonders and Michalowski, 2001). Even in countries without legal sex tourism, the increase of visitors in developing areas fuels a side line in the commercial sex business (Bauer and McKercher, 2002). The rise of globalization has created a world in which there is a large abundance of inexpensive sex throughout the world. With the sex industry growing rapidly under the globalized world, human trafficking for the means to meet the supply and demand markets throughout the world has increased (Kara, 2009). Numerous factors associated with the internationalized economy fuels the growth of sex trafficking. Some suggest the rise of Export Processing Zones (EPZs), which are prolific in developing countries, populated by male laborers has increased the demand for prostitution in these areas (Farr, 2005). The rise of the global sex industry also brings into question the concept of morality politics. Prostitution is illegal in many countries throughout the world, making countries that do not have the same restrictions on sex work a prime target for trafficked victims (Kohm and Selwood,2004; Hughes, 2000).

A discussion of globalization is essential to any discussion of human trafficking and the implications it brings to countries around the world. This research will show that both the media and

Congress spent a large amount of time focusing on the international aspect of human trafficking instead of the domestic problems that come with human trafficking. These three different factors, globalization, immigration policy, and morality all played a role in the domestic level discussions of human trafficking. These three frames will be discussed in future chapters on media attention and congressional action. Though these frames were important in telling the story of the TVPA, the TVPA is not just a domestic policy. To completely understand the success and failure of the TVPA it will be necessary to look at the other components surrounding the role it plays in the international arena through diffusion.

\section{International Diffusion of Policy}

The final analytical chapter of this research focuses on how, after it was passed, the TVPA was able to affect human trafficking throughout the world. As mentioned before, the TVPA was the first policy of its kind to attempt to halt the growing human trafficking problem. There has been a lot of 
discussion in this research about the domestic aspects of the policy, but we must not forget it is also has a foreign policy component as well. One of the strongest, most powerful aspects of this policy is that it gives the President the ability to unilaterally sanction (through the removal of non-trade, nonhumanitarian assistance) any country that is deemed to not be meeting anti-trafficking protocol (Chuang, 2006; Trafficking Victims Protection Act H.R. 3244, 2000). To be able to implement these sanctions the State Department starting a rating system for countries throughout the world and how they responded to issues of human trafficking.

Tier 1 countries are countries that fully comply with the TVPA. Tier 2 countries do not fully comply with the TVPA, but are making efforts to meet the standards set. Tier 2 Watchlist is comprised of countries that are attempting to become compliant but are not for one or more of the following reasons. First, they have too many victims of severe forms of trafficking. Second, they have not provided adequate proof of the policy changes they are making to halt human trafficking. Third, they have not made verbal or political commitments to try and stop human trafficking in the year to come. Tier 3 countries are those that do not meet expectations and are also not making any moves to be compliant. Countries that fall into Tier 3 can be sanctioned by the President at his or her discretion (United States State Department, 2015).

The TVPA was the first of its kind, but since then we have seen numerous international actors and states begin to facilitate changes on the international level. How was the TVPA able to influence other countries throughout the world to adopt similar protections? Finnemore and Sikkink (1998) suggest that international relations norm creation involves many of the same processes outlined in agenda setting models. First, entrepreneurs are critical to the changing of norms as they are responsible for dramatizing the issue and creating the frame that comes to dominate the discussion. Entrepreneurs use organizational platforms that include governmental offices, non-governmental organizations, and international institutions to raise salience and sell their framing of the issue. The second stage is marked by a tipping point, which often takes the form of a cascade, in which powerful actors within the system accept and use the frame. 
Examples of this would be when a major actor like the United Nations, the European Union, or the United States adopts the policy. Such action influences others - either through soft or hard power- to also adopt the new norm, which results in a cascade and the norm becomes socialized throughout the world. Norm internalization, the final stage in the cycle, occurs when the new norm becomes engrained in the life of most actors within the system. Those who do not adopt the norm are outsiders and as such are subject to penalties and ostracism sanctioned by most governments and international law (Finnemore and Sikkink 1998; Wood 2006; Jenkins-Smith and Sabatier, 1994).

One of the most influential and dramatic changes in politics has been the influence and adoption of policies from international actors. International policy diffusion has become a much larger part of international politics due to the rise of globalization over the past 30 years (Simmons and Elkins, 2004). Diffusion of public policy across borders happens more frequently when the policy is deemed an inventive or creative way to solve current world challenges. Most of the time diffusion of public policies are influenced greatly by the role of international organizations. Adoption of these policies tend to come out of policy learning, which generally deals with states' ability to learn from other states' endorsement of certain international treaties or policies. Influence by powerful and influential states teaches actors about the harms and consequences of adopting (or in some cases not adopting) certain public policies aimed at protecting the larger good. Another factor that plays strongly in international policy diffusion is the desire for actors to be like their cultural and political allies. Adopting public policy that mirrors their international peers, actors are able to stay strongly within the bounds of the world elite on protective policies (Biesenbender and Tosun, 2014).

\section{Conclusion}

Though there has been a good deal of research by feminist legal scholars, as well as globalization scholars, the overall field of political science lacks any real discussion on the TVPA. Other than criticizing the impact it has had on victims, there is little discussion on the role it plays in combating human trafficking or the creation of the actual policy. To fully understand and comprehend the impact 
TVPA has had on human trafficking, it is critical that we discuss the formation and diffusion of the policy in its earliest stages. Without research that is committed to understanding the factors that shaped TVPA and the later attempts to amend it, we cannot understand the reason for the implementation failure documented by feminist legal and global studies scholars. I argue that there are three main factors that contribute to this failure: morality politics, fear of illegal immigration, and economic globalization. Each analytical chapter will discuss how these factors shape attention in the media, in Congress, and of international actors. In the conclusion I will come back to the argument regarding the inability of TVPA to eradicate human trafficking from the United States and abroad. 


\section{Chapter 3- Theoretical Approaches to the Policy Making Process}

\section{Introduction}

Political science is often focused on how problems are resolved, but often not focused enough on how those problems get defined and the path they take on their way to the public agenda. This research suggests that how human trafficking was identified and the steps it took to make it on the agenda are going to matter a great deal for the success or failure of the TVPA. Thus, this research claims that the passage of TVPA is best understood by referencing the literature on attention, issue framing, and agenda setting - a subject to which I now turn.

The dominant theme in the literature studying human trafficking is that the TVPA is ineffective at providing real, lasting solutions to the problem. As such, the TVPA presents a classic problem of implementation (Pressman and Wildavsky 1973). One of the main concerns throughout this research project is identifying the factors that played a role in the creation of the TVPA, since implementation problems are often at their heart associated with earlier stages of the policy process (VanMeter and VanHorn 1975; Rein and Rabinovitz 1978; Mazmanian and Sabatier 1983). Through an examination of the agenda setting process that resulted in passage of the TVPA, I track how attention to the issue was both shaped by and affected the policy subsystems engaged in the formulation of policy associated with human trafficking. Before I engage in that task, I offer a brief review of the policy literature that will inform my research design.

\section{Attention}

Policy studies grew out of the realization that a good deal of the discipline focused on the macrolevel of the polity, portraying politics as the stuff of party rivalries, institutional clashes between Congress, the President (and occasionally the Courts), or similar. While on the macro level, the focus on large-scale politics' drama offered a good deal of insight, some suggested the meso level is where most of 
the policy drama often unfolds. ${ }^{1}$ Meso level politics are characterized by a low level of visibility, a narrow scope of conflict, and few participants (Thurber, 1991). Studying the meso level of the polity involves the study of subsystems or policy monopolies. Policy subsystems are defined as a multitude of political actors from both governmental and nongovernmental forces that shape and create public policies. Subsystems typically consist of a set of actors that interact to change a specific area of public policy. These subsystems focus on the actions between congressional actors, interest groups, and members of the executive bureaucracy. Due to the nature of many actors within the policy subsystems, public policy creation takes considerable time (McCool, 1998). This means that on a day-to-day basis policy does not change dramatically, but rather at the margins; therefore giving rise to the idea that politics and policy are incremental (Baumgartner et al 2009). Thus, subsystem politics produce long periods of equilibrium that favor powerful entities that prefer policies the way they are. At times there are rapid and dramatic changes in each political and policy equilibrium, a situation that gives rise to the notion of punctuated equilibrium or change in status quo politics. Baumgartner and Jones (2004) suggest such change is often the result of exogenous factors - such as change in party control of government, disasters, and similar all which force change within policy subsystems. For Baumgartner and Jones (2004), attention is a major source of challenge to policy monopolies. Attention shapes both problem definition and the dynamics of agenda setting (Baumgartner and Jones 1993, 2004).

Most researchers suggest the moment of punctuation can be identified by tracking media attention to issues over time and looking for an increased public consideration and debate of the problem at hand. In addition, by tracking media attention over time one can learn something about the staying power of particular issues on the media/public agenda (Nelson, 1984). For Cobb, et al (1976) tracking salience on the public agenda is a first step in a process that traces how issues move from the public agenda to the government agenda and if successful, to a decision agenda. Barbara Nelson (1984) goes a step further

\footnotetext{
${ }^{1}$ The micro-level has an individual focus that characterizes the behavioral bent.
} 
outlining four stages that lead to successful agenda setting. The four stages of agenda setting according to Nelson are issue recognition, issue adoption, priority setting, and issue maintenance.

Issue recognition deals with the entrance of a problem into the policy arena. The issue in question does not have to be a new societal phenomenon, but solely new to the public policy agenda. After the problem is recognized, the second stage in agenda setting is issue adoption. Issue adoption refers to the process in which policy makers decide to act upon the problem recognized. Issue adoption happens when two criteria are met, policy makers decide that the problem is something that the government should intervene in, and that there is a possible solution to the problem outlined. The third stage in agenda setting and deals with the setting of priorities. For the new issue identified in stage one to make it on the agenda it must be made a priority by law makers. Law makers make issues a priority by placing them higher on the docket and therefore making sure that the problem and solution is up for discussion. The final stage in agenda setting deals with issue maintenance. Issue maintenance is a twostep process. First, initial maintenance which refers to the first attempt and agreement to acknowledge and solve the problem identified. The second stage of issue maintenance is recurring maintenance, which refers to the continued attention the problem gets overtime through reexamination of the problems and effectiveness of the policy. If a problem does not continue to be examined or changed overtime then it is no longer on the government's agenda (Nelson, 1984).

While the media certainly plays an important role in setting the public agenda, Schattschneider argues that organized interests are equally important in raising salience and shaping the contours of policy debates. Because such interests are more likely to get attention than unorganized interests, agenda setting is a game played by those with resources. For Schattschneider, choosing the definition of a problem is the ultimate exercise of power on solutions (Schattschneider, 1960).

\section{Issue Framing and Agenda Setting}

The framing process involves three steps. First there is naming, which is simply giving a name to a problem. While this may look like symbolic politics, naming is more than that. It involves identifying 
some condition as a public ill or identifying the shortcomings of existing policy. Second there is blaming, which suggests that the problems must involve a culprit; that is, one needs to assign blame to someone or something. Last there is claiming, which is when the actors make demands on the government regarding the nature of the fix (Felstiner, et al, 1980). Issue definition then is concerned with why some definitions of a problem, or frames, are adopted as opposed to others.

Issue framing rhetoric can come in many different forms. One form of issue framing deals with the macro level actors' definition of a problem. A second form deals with the severity of the problemhow long it will last and what major effects it has on society. The final form deals with the way in which stories, images, and non-typical forms of rhetoric can help frame an issue to either keep it on or off the agenda (Stone, 1998). Deborah Stone (1998) refers to this last form of issue framing as causal stories. Policy makers use these causal stories to promote images that bring the issue to the public in ways in which gain their support for the issue. Causal stories typically go beyond other forms of issue framing by inducing a morality component to the issue. These causal stories are used to make the general public feel compelled to get behind the issue to address the problem. Policy entrepreneurs create these stories to garner both public and Congressional support (Stone, 1998).

While attention is an important first step in gaining access to the public and government agendas, if one hopes to alter the status quo an issue needs to gain access to the decision agenda (Cobb, Ross, and Ross, 1976). The decision agenda is where formulation occurs; that is, where solutions are attached to problems (Kingdon,1995). When it comes to public policy creation, Kingdon (1995) is interested in how different institutions affect the outcomes of policies. Institutions and government officials try to measure the degree of consensus around particular issues and balance them out as a means to remain in power. Throughout this balancing there are times of success and failure. There is also a large amount of bargaining and compromise as a means to promote certain goals and interests (Kingdon, 1995). Institutions like the Senate can create and change policy as a means to satisfy public mood and also to maintain control over a certain policy and its outcome. One way this can happen is through the role of the policy entrepreneur (Wawro, 2000). 
Most political actors prefer the status quo since it is known and changes can lead to dramatic and unforeseen consequences. Though this is a general tendency, not everyone favors incrementalism and the status quo all the time (Baumgartner et al, 2009). Policy entrepreneurs are members of the policy community who often seek radical change in the status quo. Schneider and Teske (1992) define a political entrepreneur as someone who dramatically alters the direction of politics. To be considered a policy entrepreneur one must find problems that are not being fixed or on the agenda to be fixed. The entrepreneur must also have some sort of solution to the problems identified. Policy entrepreneurs are typically successful in their entrepreneurship when they can promote their ideas. Policy entrepreneurs are the most successful when they are the ones that frame the problem, network within policy circles, shape debates, and build coalitions. The entrepreneur must then be able to accept the extreme risk involved in advocating for a dramatic shift in policy. Finally, an entrepreneur must coordinate groups of individuals and organizations that have the ability to create and implement the change of policy (Schneider et al, 1995, Schneider and Teske, 1992, Mintrom, 1997).

Policy entrepreneurs can change the status quo by employing strategic rhetoric to shift the focus from the dominant frame to other possibilities. This type of rhetoric provides linkages and insights into the policy opportunities and obstacles that are present. These linkages are extremely important because they provide more access to information often denied other actors (Jones and Jenkins-Smith, 2009).

Legislative entrepreneurs compile information and distribute it in a way that allows them to assemble coalitions that challenge the status-quo (Wawro, 2000). Policy entrepreneurs-when successful— can change the status quo by employing strategic rhetoric in order to shift the focus from the dominant image or frame to other possibilities. Entrepreneurs provide linkages to other frames and new insights into the origins of a problem and solutions to same. Entrepreneurship involves providing access to information, links to other actors, and coalition formation in support of policy change (Wawro, 2000; Worsham, 2006; Jones and Jenkins-Smith, 2009).

Legislative entrepreneurs assemble packages that consist of general information on the policy in question, how it resonates with particular interests (and constituents), as well as the likelihood of its 
passage in respect to the legislative climate. Legislative packages are used by entrepreneurs to assemble coalitions, as well as gain the attention of committee chairs. Committee chairs are the key to scheduling hearings and moving an issue to the government agenda (Wawro, 2000). Baumgartner and Jones suggest that hearings (the legislative version of the government agenda) can take two forms: legislative hearings are those which are held to consider an actual piece of legislation and non- legislative hearings are those in which no actual legislation is being considered, rather the committee is in a kind of search mode (Baumgartner and Jones, 2004). During this "search mode" committees battle over turf or who gets to legislate on the issue in question. These battles over who gets to legislate on which issue can change the focus and frames used to discuss a problem and the solutions by sometimes widening the scope of debate (positive feedback) and other times narrowing it (negative feedback) (Baumgartner and Jones 1993;

Worsham 2012). The battle for turf is a critical part of moving to the decision agenda and to understanding the legislative process (Talbert, Baumgartner, and Jones 1995).

\section{Conclusion}

This research is focused on how the problem of human trafficking has been identified and defined throughout the issue attention cycle and agenda setting. Particularly how did actors become interested in, and therefore promote policy change in the area of human trafficking. Chapter 4 on media attention will focus strongly on issue attention and how human trafficking was defined by the media. Chapter 5 on Congressional action will focus on the formal agenda, how the issue of human trafficking moved from being an interest to a major public policy. In Chapter 6 I will see how the definition of the problem, as well as the way it became a part of the agenda influenced other countries to adopt similar policies. In each section I will investigate how actors defined the issue, legislated the issue, formalized the issue, and then kept the issue on the agenda for years to come. 


\section{Chapter 4- Human Trafficking and the Media}

\section{Introduction}

How did human trafficking become a public issue? What changed in the rhetoric of international relations and American public policy to focus attention to the problems surrounding the increase of human trafficking throughout the world? The outside initiative model of agenda setting suggests that there is a process in which nongovernmental groups are able to increase attention to an issue that reaches the public and then impacts the political agenda (Cobb, Ross, and Ross, 1976, 127). This research demonstrates how the media influenced public attention, which in turn shaped government attention on this specific policy issues. According to this approach, the media's main function is to bring issues to the attention of the average citizen, in effect acting as the "fourth estate" and the public conscious. Barbara Nelson $(1984,51)$ argues that media's “task is to discover, unveil, and create what is 'public.' To do so they often wrench 'private deviance' from the confines of the home." Thus, media attention to human trafficking brought a problem much of the public viewed as a problem in other parts of the world, into their own community (Wilson and Dalton, 2008).

This chapter has several goals. First, to track media attention to the issue over time in an effort to determine the level of influence the media had on bringing attention to the issue of human trafficking into the public and political eye. If the TVPA involved a case of outside initiative one would expect media attention to serve as a spark that resulted in government attention. Related to tracking media attention, this research focuses on the pattern that attention assumes. Anthony Down's seminal work on the "issueattention cycle" suggested that mass media attention operates in short bursts characterized by large amounts of attention to a particular issue until a new issue takes the limelight and it begins to occupy the agenda (Downs, 1972).

The second goal of this chapter is to develop a more nuanced measure of media attention. A central problem with some of the earlier studies of media attention (Downs 1972; Kingdon 1984) is their focus on the news media. Although the news media is important, solely looking at human trafficking 
through news sources would only provide a partial picture of the dynamics of media attention. Nelson (1984) and Walker (1977) suggest professional journals are an important source of attention that can shape both the popular media and decision-makers attention to an issue. This chapter documents the role of professional journals in maintaining attention. What is revealed throughout this research is that professional journals and the media are invested and prevalent in the discussion of human trafficking. They further indicate that particular professional journals shape the discussion and tie them back to larger, more pressing issues of the time (Nelson, 1984; Walker, 1977).

Finally this chapter examines the frames used by media outlets when discussing the issue of human trafficking. Tracking the frames used by both the mass media and professional journals, allows one to get a feel for the multiple ways in which the issue of trafficking is defined, as well as identifying who is promoting which frame. The role the media plays in influencing policy largely depends on how they frame the issue. Media portrayals are socially constructed, what is determined "newsworthy" reflects and shapes social and political values, which in turn often shapes public policy. The specific frame used by the media to tell a particular story is often chosen in order to promote a particular image and solution to the issue (Baumgartner and Jones 2009; Schneider and Ingram 1993).

\section{Theories of Problem Identification, Agenda Setting, and Target Populations}

Downs (1972) suggests that before an issue can make it to the public agenda, it has to gain public attention, often going through the "issue-attention cycle." The issue-attention cycle has five distinct stages that explain the life cycle of an issue. First, the pre-problem stage, which defines the period in which the problem in question exists but has little public attention. During this stage the problem is only known to a few, often experts and organized interests groups. He was a bit amorphous regarding what sparked the second stage of the issue attention cycle, which is explained as alarmed discovery and euphoric enthusiasm. He suggested the second stage was triggered by a dramatic event that gained mass media attention. During this stage the public begins to assess how to best solve the problem that has been identified. The urgency of the problem is felt within the population and many begin to demand action for 
a timely resolution to the identified harm. During the process of trying to find a solution to the problem, the population begins to realize the costs and difficulties of a viable solution. Realizing the cost and difficulty of significant progress solving the issue, pushes the issue into the third stage where citizens are deterred from actively pursuing change, since the issue they want to change is both costly and has many more obstacles than expected. In the fourth stage of the issue attention cycle, citizens have realized the high costs and obstacles in solving the issue and are likely to move on to the next issue in the public eye. Finally, in the post problem stage the issue is simply replaced with another. Although this often results in the issue receiving less and less public attention, it is still possible that during the life cycle, politicians and organized groups created relevant polices or programs in order to address the problem. When this happens it means that the issue is never fully eliminated from the public agenda, just that the public's attention acknowledged that issues in which vested interests become involved, as well as those characterized by ambiguity, or changing definitions of the problem and solutions, can remain salient longer than the normal cycle allows (Downs, 1972 49).

Ambiguity is often associated with valence issues (Baumgartner and Jones 2009; Nelson, 1984). Valence issues are defined as "problems in which only one side of the debate is legitimate" (Baumgartner and Jones, 2009, p.150). Valence issues are often referred to as issues that the electorate have a common opinion on and there is not much deviation from that opinion no matter their political views. Examples include child abuse, drug and alcohol abuse, elder care, and access to child care (Fridkin, 1999). Human trafficking would meet all the criteria for a valence issue as a majority of the population views it as a problem in need of government attention. In an opinion poll published by the College of Mount Saint Vincent, $63 \%$ of those polled identified human trafficking as a "very important" issue within the United States, while in the same poll $61 \%$ deemed it a "very serious" issue. Not only has the issue of human trafficking been deemed important, government intervention in this issue was also deemed necessary (College of Mount Saint Vincent Fishlinger Center for Public Policy Research, 2015). In an opinion poll conducted by Southern Illinois University Carbondale, $86 \%$ of respondents agreed that human trafficking training should be mandatory for all law enforcement officials (Paul Simon Public Policy Institute at SIU 
Carbondale, 2017). Although valence issues are often politically salient, they are not easy to solve (Baumgartner and Jones, 2009).

News media has a significant role in two stages of the Downsian life cycle of an issue-- problem identification and moving a problem onto the public agenda. Professional journals are scholarly, often peer reviewed publications that are written by and for professionals in a certain field. These academic journals are often written in language and jargon that is specific to a field of study and follow strict academic norms (Addleman and Verbrugge, 2000). Professional journals play an important role in keeping an issue salient among policy communities and in generating solutions (Nelson 1984; Walker 1977). The professional media's focus on a particular issue can push and encourage the news media to take up the issue or keep an issue alive — either through professional relationships and encouragement or an overarching journalistic interest (Nelson, 1984). Walker (1977) suggests experts are able to maintain issue salience absent focusing events that so often provoke news media attention. Professional journals and experts debate and discuss the best way to enact policies to solve the problem and can greatly affect the way in which policies are handled once they make it to the public agenda. Leadership on issues is mostly seen throughout professional media; therefore, making the role of professional journals invaluable to the discussion of problem identification and framing.

Baumgartner and Jones (2009) suggest the framing of an issue is critical to understanding agenda setting. They also found that choosing the right frame was often instrumental in moving an item from the public to the government agenda. This becomes particularly critical in the discussion of human trafficking. Not only does the issue never seem to have a consistent frame, but the multiple, often conflicting, frames make any attempt to attach a solution to the problem difficult. Schneider and Ingram (1993) also suggest that the way in which the media frames an issue and the target population of policy is an important part of setting the agenda. 


\section{Data Sources}

There are many different influences that affect the creation of public policy. The way in which the media identifies a problem can be extremely influential in the creation of the legal response to that problem. Those interested in agenda setting often begin by developing indicators of salience on the public agenda. Like many (Baumgartner and Jones 1994; Nelson, 1984; Fahy and Farrell 2009) this research settles on tracking stories in the New York Times. Using the ProQuest Historical Index and the search terms, "human trafficking," "sex trafficking," "human smuggling," and "child trafficking," media attention is tracked between 1990 and 2010. Due to the way the ProQuest Historical Index search engine queries the database, there had to be more specific terms used in order to obtain a more accurate count of human trafficking stories. In addition to researching mass media's attention to human trafficking this research is also interested in the role professional media had in the issue creation of human trafficking discourse. Using EbscoHost Academic Search Complete and the search term "human trafficking," this research looked for human trafficking stories in the academic and professional press. The first academic journal to cover the issue of human trafficking, Jewish Social Studies, focused on "white slavery" in Argentina. Other professional journals that have covered this issue over time have been Anthropology Today, Gender and Development, the European Journal of Crime, Criminal Law, and Criminal Justice.

\section{Mapping the Issue Attention Cycle}

Human trafficking occupied little space on the public agenda through 1992. Media attention picks up dramatically after the passage of the TVPA in 2000. Although there are dips at some points, it is clear that media attention does not fade over time, suggesting little support for Downs' issue attention cycle. The second stage of the issue attention cycle, alarmed discovery and euphoric enthusiasm, never transitions into the third stage - perhaps because human trafficking is a valence issue (Baumgartner and Jones, 2009). Figure 4.1 tracks media attention from 1950 to 2010. 


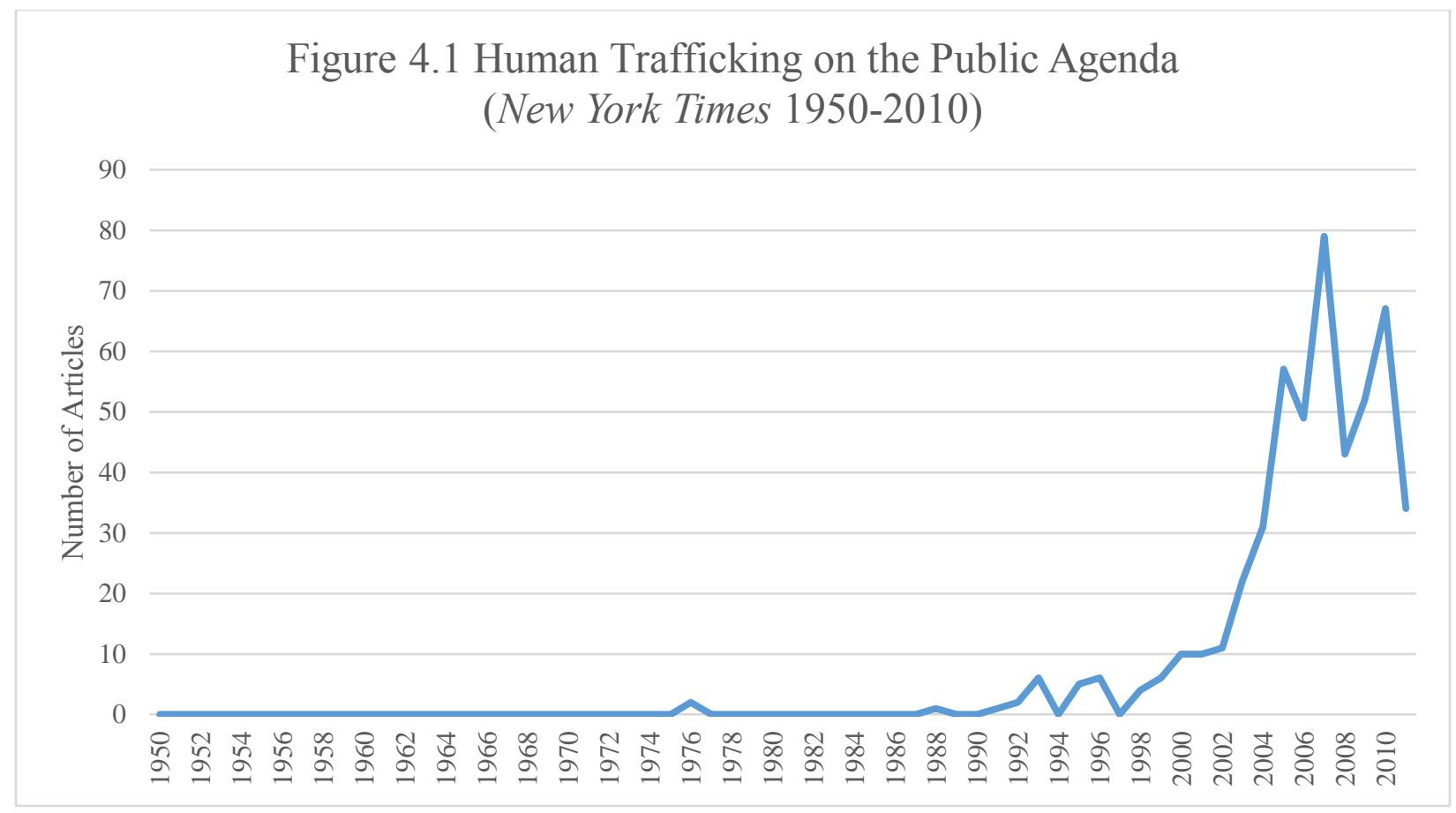

Human trafficking in the professional media such as Anthropology Today, Gender and Development, The European Journal of Crime, Criminal Law, and Criminal Justice mimics the attention paid to human trafficking by the popular media, similar to the case of child abuse documented by Barbara Nelson (1984). Since the news media often takes its cue regarding important issues from professional media sources (Nelson, 1984), it could be that the continued attention to human trafficking in the professional media kept the news media focused on the problem as well, rather than moving elsewhere as Downs predicts. The attention paid to human trafficking by both forms of media appear to run in unison, albeit the issue experiences a higher level of in salience professional journals, suggesting once an issue gains a foothold among policy experts it remains salient (see Figure 4.2). 


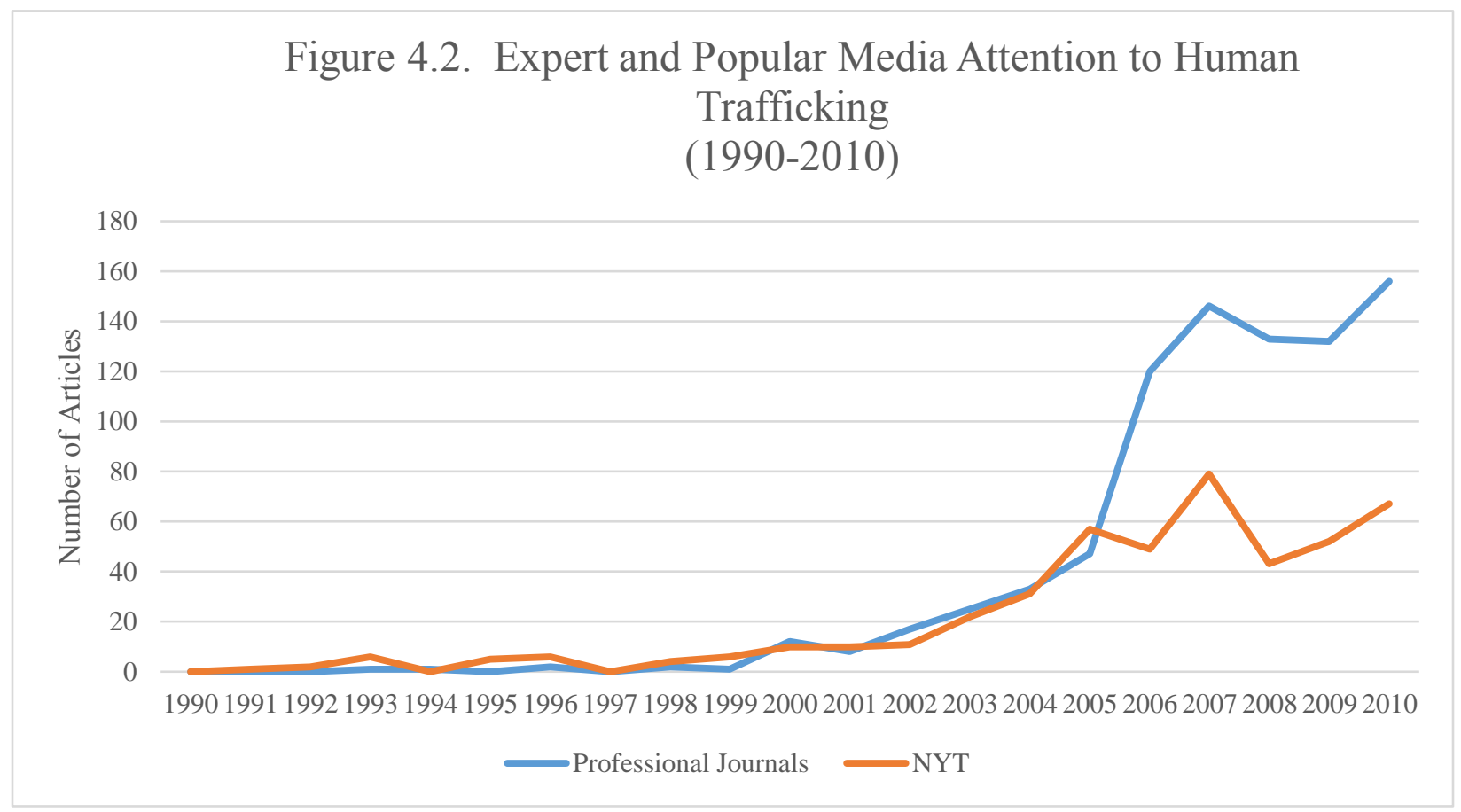

\section{Design}

As stated previously there are two components to this research. First, it will map the issue attention cycle of human trafficking in the popular media and professional journals, which will demonstrate the attention given to human trafficking in both realms, as well as compare attention across realms. Second, mapping both will allow for the analysis of what form the discussion took in the two different realms, as well as looking for evidence of any "cross-pollination." The bulk of the chapter deals with this second task, to document the frames utilized by both the news media and professional journals. The first frame of distinction deals with domestic trafficking and international trafficking.

This research will separate the human trafficking stories into domestic and international frames. This distinction is important because it provides an indication of the view of human trafficking by the media, and therefore the public as a domestic or international issue. In addition, this research coded all stories from 1966-2010 that shaped the problem as either domestic or international. Two examples of an international frame were "Bosnia Policeman Fired for Aiding Sex Traffic," written by Daniel Simpson on October 18, 2002 and "Somalis in Twin Cities Shaken by Charges of Sex Trafficking," written by Erik 
Eckholm on November 23, 2010. Examples of stories that were coded under a domestic frame did not provide distinct titles identifying them as addressing domestic trafficking. In "U.S. Tells of Ocean Transfer in Smuggling of Immigrants," written by Alan Feuer on June 14, 2005, it explains how the United States criminal justice system stopped the transfer of human trafficking victims from other countries. However in "Girls on our Streets," written by Nicholas Kristoff on May 6, 2009, the mass media presents its first discussion of domestic trafficking within the United States. As explained within this research this distinction is critical to how the problem is presented by the media which impacts the views of the public and ultimately the policy agenda. Shaping the problem as an international issue or a domestic issue dramatically changes who constitutes a victim and the target population of policy (Baumgartner and Jones 2009; Schneider and Ingram, 1993).

In addition to coding the media attention within either an international or domestic frame, this research conducts a second level of coding. Story frames are going to matter in how the problem is identified and how the media is framing the issue of human trafficking. Understanding the frames used by the media in the case of human trafficking is an important step in understanding the policy dynamics underlying the issue (Farrell and Fahy 2009). This research adds to Farrell and Fahy's research in which they track New York Times articles on human trafficking and separate them into three frames: crime, human rights, and national security — suggesting that the frames used by the media defined human trafficking as something that needed to be criminalized. In addition, they claim that the frame used by the media set up the possibility for the TVPA to pass with strict criminal provisions for both the victims and those perpetuating the crime. Although Farrell and Fahy's research added to the literature on the role the media played in the creation of the TVPA, this research demonstrates that there are other frames that are equally as important, if not more so, and provide better insight into the role of the media in human trafficking legislation.

Throughout this research it became clear that the media was using more than just three frames to discuss human trafficking. This research shows that there were five different frames used by the media. 
1.) Policy and Law Enforcement which are stories that frame the issue in a way in which problematizes human trafficking as a violation of the law. This frame also focuses on the use of the legal system as a remedy for those that have been victims of trafficking. Two examples of these stories are "A Crackdown on the Traffic of Humans," written by Christopher Marquis on February 26, 2003 and “Two Groups Charged With Abuse of Witness Law," written by Eric Lichtblau on June 27, 2005.

2.) Immigration or Emigration is a frame that focuses the issue of human trafficking on the migration and politicization of that migration on human trafficking victims. These stories are often based on the response from the receiving country on how their immigration politics will be affected by human trafficking. Two examples of these stories are "Arizona-Mexico Discussion Focuses on Border Violence," written by Randall Archibold on June 16, 2007 and "Many Indigent Refugees to Lose Federal Assistance,” written by Robert Pear on July 31, 2010. 3.) Foreign Policy are stories that are framed through the impact they have on national security, international crime, and international agreements all dealing and spinning from the impact of human trafficking. Two examples of these stories are "Take Al Qaeda to Court," written by Kelly Anne Moore on August 21, 2007 and "Bush Assails Castro and Human Trafficking," written by Michael Janofsky on July 7, 2004.

4.) Human Rights frame deals with the rhetoric that places human trafficking and its victims in a violation of basic protections assigned to individuals by natural law. Human Rights issues dealt with a litany of violations that impact human trafficking victims: sexual exploitation, violence, and slavery. Two examples of these stories are "Seduction, Slavery, and Sex," written by Nicholas Kristoff on July 4, 2010 and "Italian Police Free 113 Poles Living in Slave Labor Camps," published with no author credited on July 19, 2006.

5) Economics frame deals with news media that focused the problem of human trafficking as something that could potentially have a negative effect on the economy. Two examples of these 
stories are 'The Ugly Side of Free Trade," written by Steven Greenhouse on May 3, 2006 and

“Terrors Purse Strings,” written by Dana Thomas on August 30, 2007.

\section{Results}

As explained above the main focus of the media prior to 2003 was focused on human trafficking as an international approach. This would suggest that the international frame would dominate media coverage through 2003 and Figure 4.3 illustrates that to be the case. The focus of the media shifts drastically in 2004 with a sharp rise in stories dealing with issues of domestic human trafficking. This increased focus on issues of domestic human trafficking demonstrates a shift to portraying the issue as both an international and domestic problem. Figure 4.3 tracks the domestic and international focus of New York Times coverage between 1990 and 2010. Although Figure 4.3 shows an increase in media attention to domestic human trafficking in 2004 it still maintains a high level of attention to international trafficking through 2010.

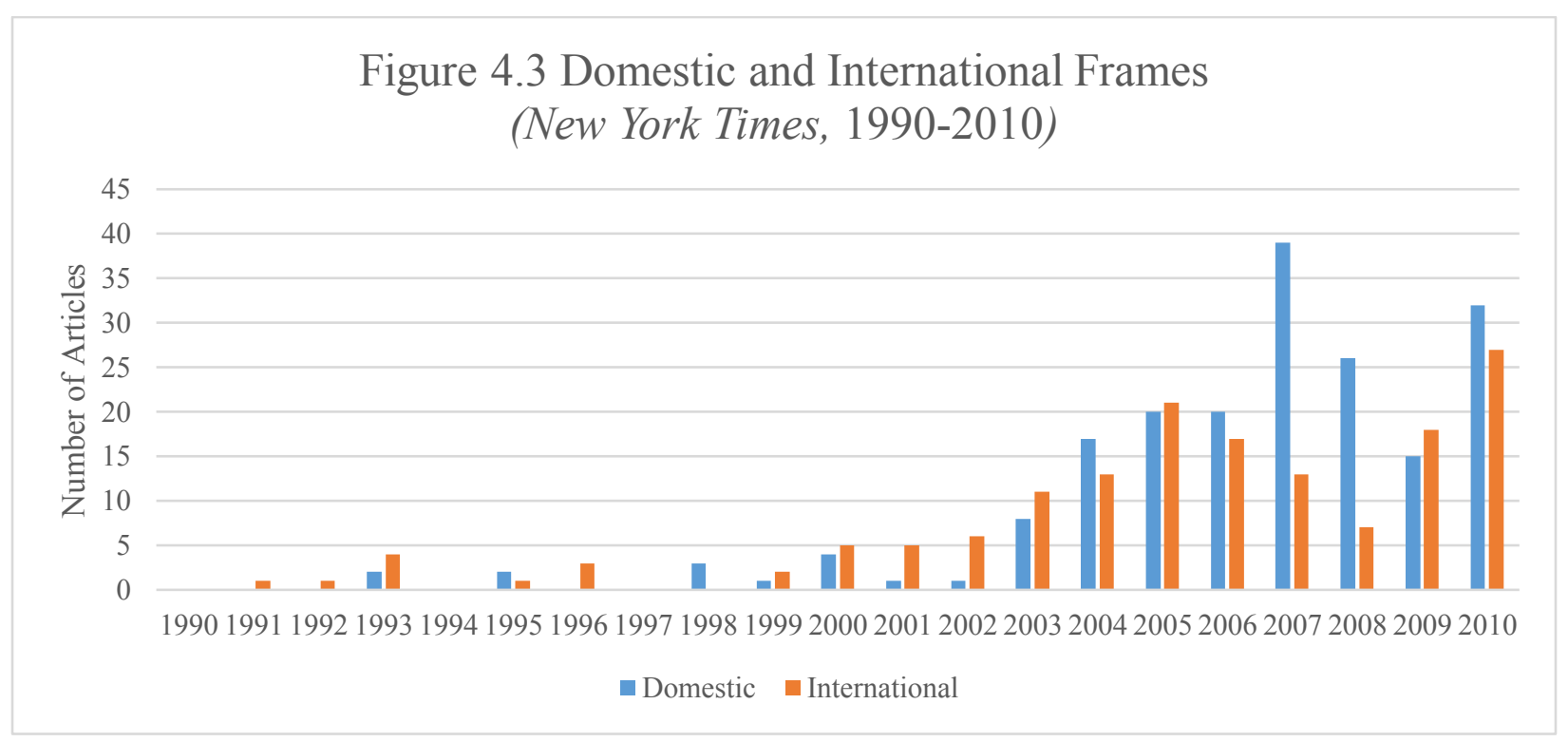

As explained earlier in this research human trafficking is considered a valence issue, Schneider and Ingram (1993) suggest that the way the media frames trafficking and the target population of antitrafficking policy, is critical in setting the agenda. A lack of agreement over whether human trafficking is primarily an international or domestic issue makes an agreement on a viable solution especially difficult. 
Schneider and Ingram (1993) suggest that there are four typologies of populations in which congressional action attempts to solve issues. These typologies are socially constructed, meaning that the way the problem surrounding different populations are defined is often times left to how those populations are viewed throughout society. The four different typologies are advantaged populations, contenders, dependents, and deviants. Advantaged populations are viewed favorably and often times come from a societal position of power. Advantaged populations do not require government intervention and are often assumed to be able to solve problems on their own. Contenders are viewed unfavorably but still have power. Contenders are able to get policies implemented that are beneficial to them but society often times dislikes those policies (i.e. tax breaks for the rich). Dependent populations are seen favorably, but are politically weak. Dependent populations are often considered a population that needs to be protected by the government through social services and social welfare policies. The final typology, deviants, are usually unpopular and possess little power within society. Society views deviants as a menace to society and favor government action to control and police them, if they require government action at all.

This research illustrates that media frames trafficking victims within the dependent typology. In other words, human trafficking is a case of an individual being victimized by an abuser. It is perceived that the Government should step in to protect these victims. Although that idea is popular with most citizens (human trafficking is a valence issue), this construction of the subjects of human trafficking as victims keeps them from being involved in policy creation once the problem makes it to the formal agenda (Schneider and Ingram, 1993). Figure 4.4 demonstrates the focus of framing domestic human trafficking between 1990 and 2010 rest in the dependent typology. 


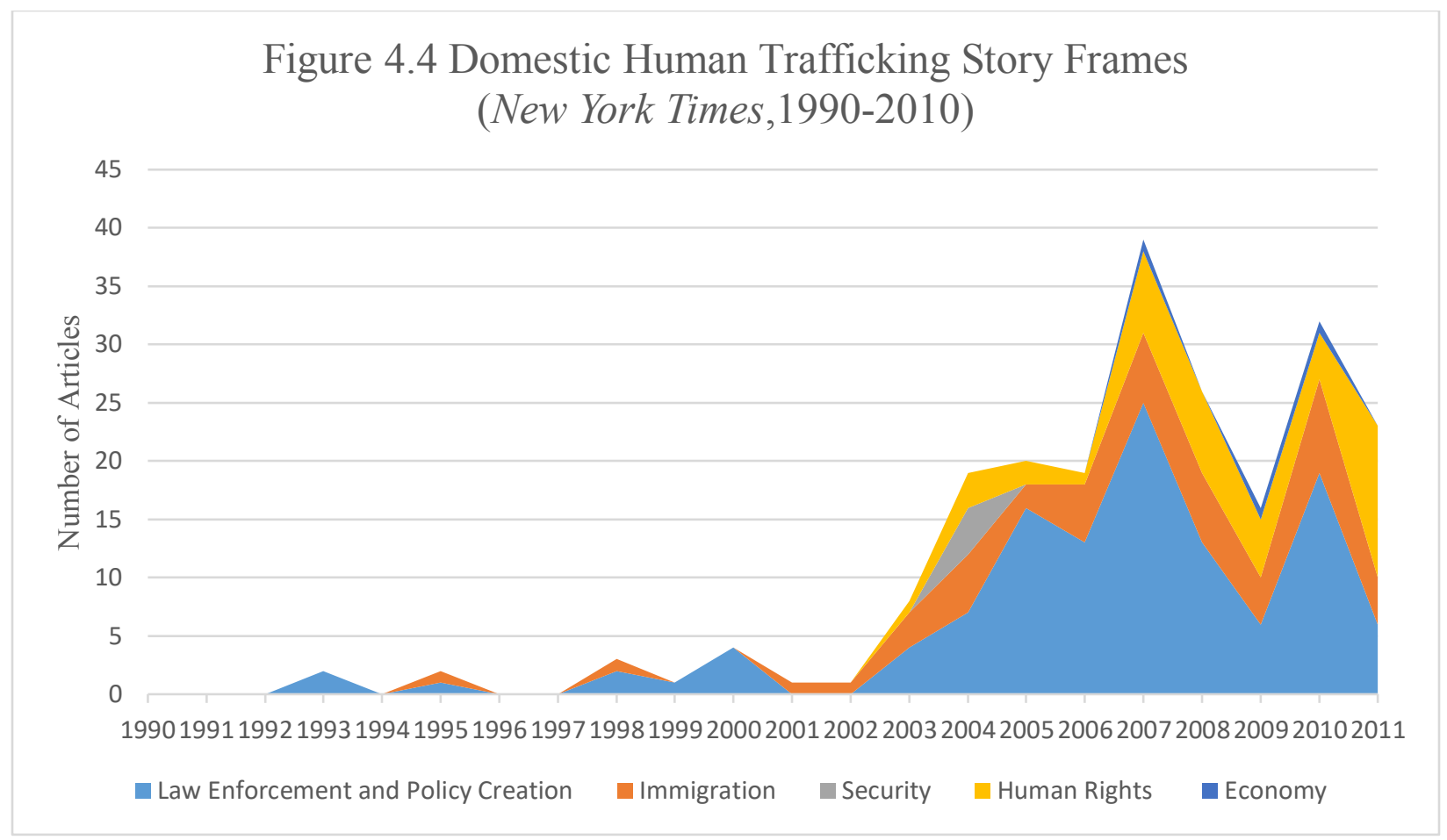

Although domestic human trafficking is framed using the dependent typology, when compared to the international frames a different focus emerges - although ending in the same typology. An overwhelmingly majority of media stories dealt with the human rights issue while focusing on human trafficking victims abroad. The second most popular frame used in international stories dealt with law enforcement and policy. Although the focus was different, the end result was the same-human trafficking victims are framed as dependents on the international level as well. Figure 4.5 illustrates that the main focus of the international frames is different from the domestic frames, however the overall message of the issue remains that human trafficking consists of victims and they are dependent on government intervention. 


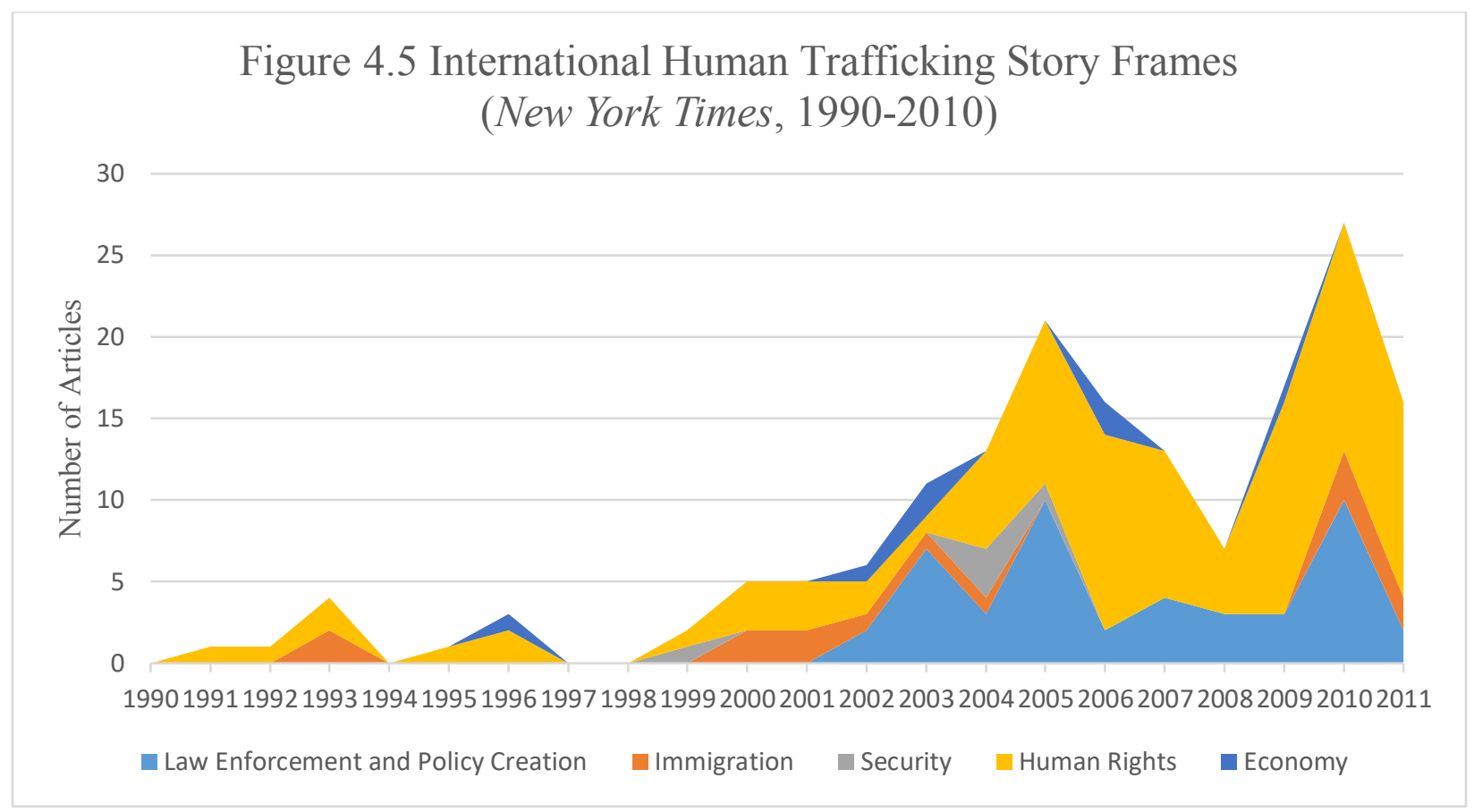

When the frames used by the professional media are examined during this time period one finds that the international focus occupies $82 \%$ of the articles. Experts were focusing on the global impacts of human trafficking versus a concentration on the domestic facet. The specialization of professional journals allowed them to focus on the issue as it developed instead of the minor victories in the human trafficking arrests often covered by the media. Not needing to compete and sell media like news outlets, professional journals are able to focus more on what is developing the issue rather than trying to sell papers (Baumgartner and Jones 2009; Walker, 1977). Figure 4.6 illustrates the dominance of international human trafficking stories during the 1990-2010 time period. 


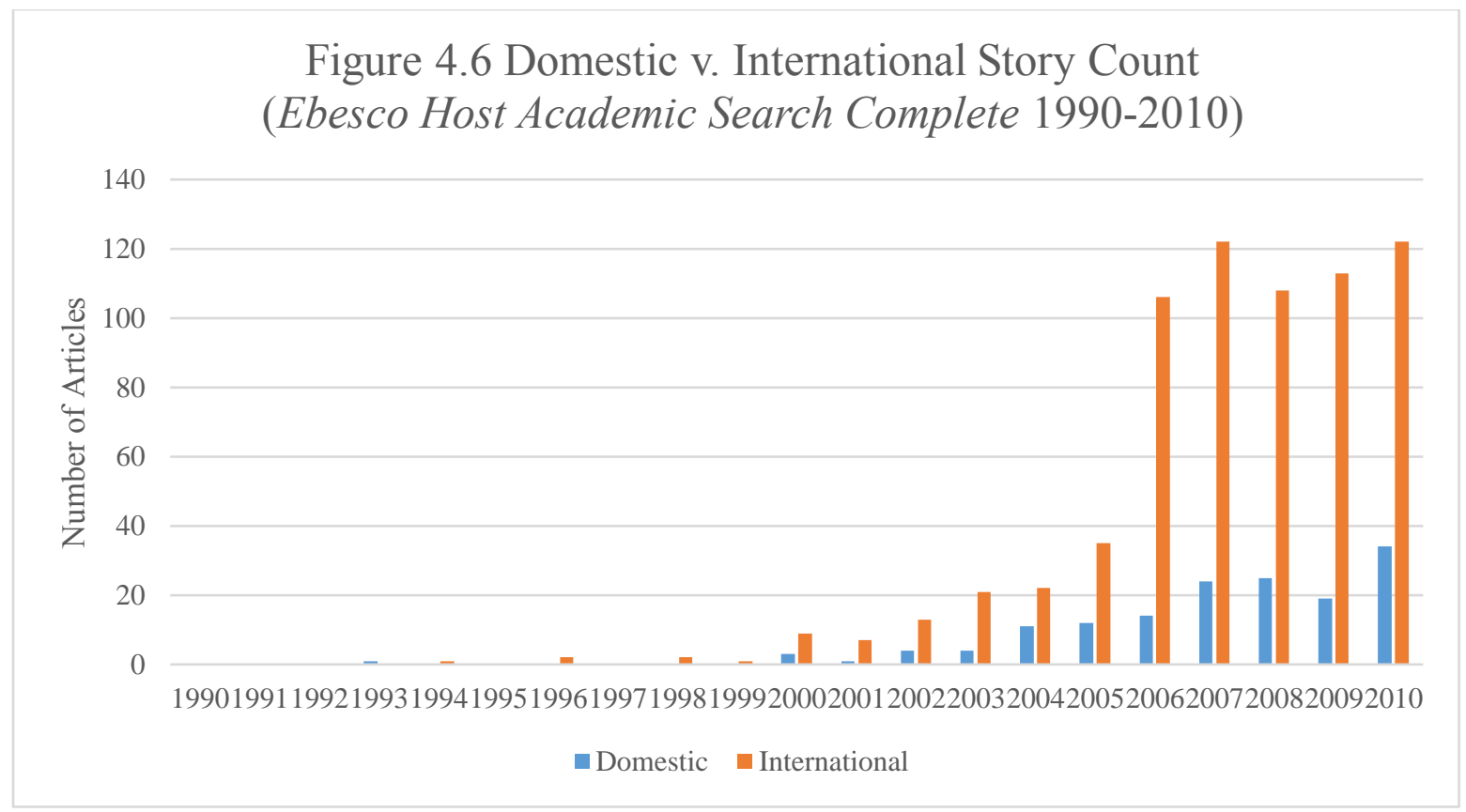

Although professional journals focused the majority of their stories on the international aspects of human trafficking, they did not ignore the domestic front. While coding frames for stories in professional journals was similar to the media frames, there was one difference, there were no stories related to economic issues in the professional journals, although a new frame - health -- is present. The data shows an increase in discussion within the professional journals of the impact of human trafficking on larger health concerns. Specifically, how the rise of international sex trafficking was affecting sexual health throughout the world. Although sexual health was a major theme, the health focus also included the mental health of victims, post- traumatic stress disorder, and similar. While the data from professional journals was limited (there were often fewer than 13 stories relating to domestic human trafficking during the 1990-2010 time period), the data demonstrated similarities with the media in framing the issue of domestic human trafficking. Both the professional journals and the media used law enforcement and policy creation as the most discussed frame followed by human rights. These two frames in the news media and professional journals were very similar in their content by covering the same news that was happening domestically throughout the United States. Figure 4.7 illustrates that although the data is limited and a final conclusion cannot be reached, it is important for this research as it demonstrates that 
the professional media was also involved in the construction of a dependent target population not unlike the news media.

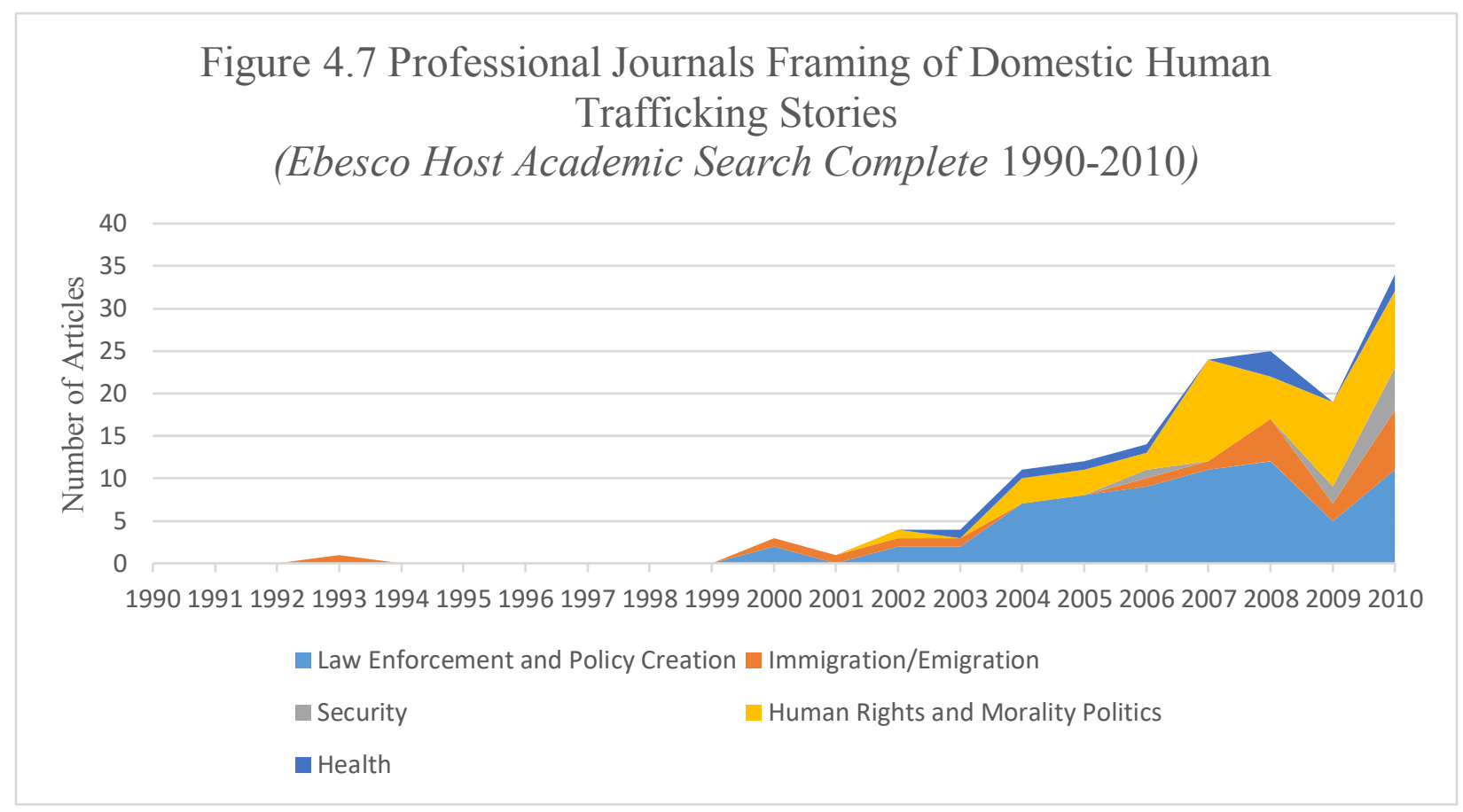

As stated, professional journals focused mainly on international human trafficking issues with a focus on the frame of human rights. Specifically they addressed global conditions that created an environment conducive for the increase in human trafficking. These articles were also much more likely than the news media to discuss the role global inequality, specifically gender and economic inequality had on the issue of human trafficking. Figure 4.8 illustrates that professional journals put out a very consistent frame focusing on the human rights abuses. Again the stories reveal that those involved in human trafficking are framed as victims and dependent and in turn, further defines who should or should not be protected. 


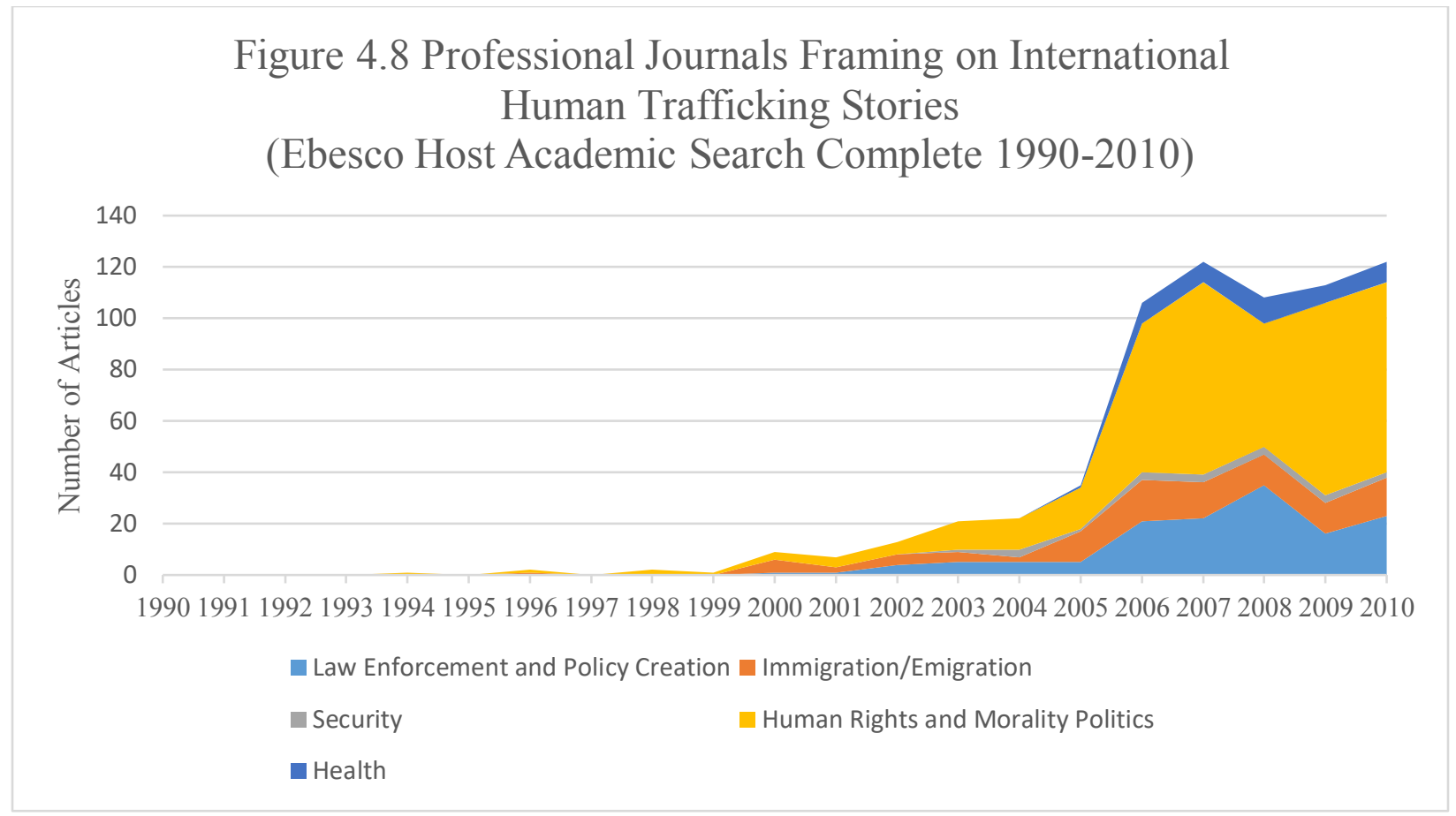

How an issue is defined and framed matters to the success in solving that issue. In a public opinion poll completed by the Southern Illinois University at Carbondale in 2017 it is suggested that $51 \%$ of Americans disagree or strongly disagree that human trafficking occurs or affects their communities (Paul Simon Public Policy Institute at SIU Carbondale, 2017). This result appears to be in direct conflict with the seriousness of human trafficking in the United States. Hardy et al, 2013 suggest that domestic trafficking, particularly youth trafficking, happens at an alarming rate in the United States with approximately 244,000-325,000 persons under the age of 18 trafficked throughout the United States each year (Hardy et al, 2013, 1). This became a problem for the TVPA because it severely limited the ability to effectively combat human trafficking as the result of a historical international focus and problem identification.

Although the focus of the media began to change in 2004 and additional funding was added for youth rehabilitation in the TVPA Reauthorization Act of 2008, it greatly missed the mark in its ability to adequately provide such services (Hardy et al, 2013). How the media frames the problem of human 
trafficking — particular before the TVPA was passed — shaped the TVPA and as media coverage continued, it would also alter later Reauthorization Acts.

\section{Conclusion}

Media attention is extremely influential in setting the public agenda. This chapter explained the role of the media in defining and framing the issue of human trafficking and ultimately its role in the creation of the TVPA. Although at the beginning of the research for this chapter it was assumed that human trafficking would follow the Downsian issue attention cycle, which proved not to be the case. There were two main reasons human trafficking did not follow the attention cycle- human trafficking is a valence issue, as there is no conflict over which is the on the right side of history on this issue the media stays engaged and the role played by professional journals. Professional journals provided a solid, vetted, and reliable source of issues for the news media to cover. Professional journals provide expert analysis in a particular field with the potential of encouraging specific coverage by the media.

This chapter explains the importance of media attention and the role it plays in bringing issues to the forefront of the public agenda. In addition it explains the impact on human trafficking on how the media framed the issue. Human trafficking has many different aspects, the focus of this chapter was to identify the frames used by the news media and its impact on the TVPA. This research as well as Farrell and Fahy (2009) found that domestic stories tend to focus on the criminal aspects, thus promoting law enforcement solutions and protection of the victim as these stories typically highlighted law enforcement agencies' successes in the crackdown of human trafficking. While international stories emphasize the victimization of the target population, the failure of many countries to halt human trafficking, and what policies were best to try and halt the problems of human trafficking (Farrell and Fahy, 2009). 


\section{Chapter 5- Human Trafficking and Congressional Attention}

\section{Introduction}

This chapter will focus on the congressional activity that led to the passage of the Trafficking Victims Protection Act (TVPA) in 2000, as well as the follow up effort to further define and limit trafficking through 2014. As such, this chapter focuses on how human trafficking was placed on the congressional agenda, and how the goals associated with trafficking were altered as the issue moved through the legislative process. I examine the role of policy entrepreneurs who frame the issue via legislation, committees that serve as venues promoting particular frames, and the commission process and oversight activities that further defined and redefined the congressional efforts to end human trafficking.

I model my work on others who have studied congressional agenda setting. Clearly Baumgartner and Jones $(1993,2009)$ set the standard in the field, but in addition to their study, I utilize the approaches of Nelson, Wawro, Walker, and a host of others as discussed below. In order to understand how attention to trafficking shaped the TVPA, one must begin at the beginning, with legislative introductions. The first section of this chapter performs a subject search using Congress.Gov, to identify all legislation introduced between 1970 and 2016. Care was taken to identify the sponsor(s), title, and topic of legislation, as well as the committee(s) to which it was referred, and its fate in committee. The focus of the second section of the chapter is on committees and commissions, with care taken to identify any committee or commission that held hearings on the subject of human trafficking between 1970 and 2016, using Proquest Congressional to identify and examine relevant hearings.

\section{Agenda Entrance: Legislative Introductions}

A variety of scholars have studied how legislative introductions, and control of same, shape the policy process. Legislators that wish to place an issue on the formal agenda often assume the role of policy entrepreneur. Wawro (2001) suggests that policy entrepreneurship involves a four-step process that includes: acquiring information, drafting legislation, building coalitions, and pushing legislation. I focus on the first two steps of this process, acquiring information and drafting legislation. I used the subject 
search function on Congress.gov employing the search term "human trafficking" (as suggested by the glossary) to track all legislation dealing with human trafficking. The search identified 490 bills introduced between 2000 and 2017 (Congress.gov 2017). Forty-four of these were eventually adopted as public law, suggesting the issue received not only congressional attention, but resulted in congressional action. That said, the first thing that stands out is that the subject of human trafficking is a recent arrival on the congressional agenda. While my search included the period between 1970 and 2017, Figure 5.1 and the figures that follow only include 2000-2017 given the lack of activity prior to 2000. The lack of legislation prior to 2000 suggests the congressional concern with human trafficking was relatively new, seemingly became an issue overnight, and resulted in the immediate passage of legislation intended to deal with the problem. To say this is unusual is an understatement. Very few issues move to the decision agenda with the speed of human trafficking did, especially without the accompaniment of a punctuating event. While human trafficking was discussed relatively frequently in the media from the mid 1990s on (see Chapter 4), it does not actually move onto the congressional agenda until some five years later, and then has a solution attached to it in relatively short order. Figure 5.1 suggests the issue garnered little attention, even during the process of enshrining a solution into law, marking the passage of TVPA as unusual. That said, after passage of the act the topic slowly builds momentum, really taking off after 2010, when it becomes increasingly salient. 


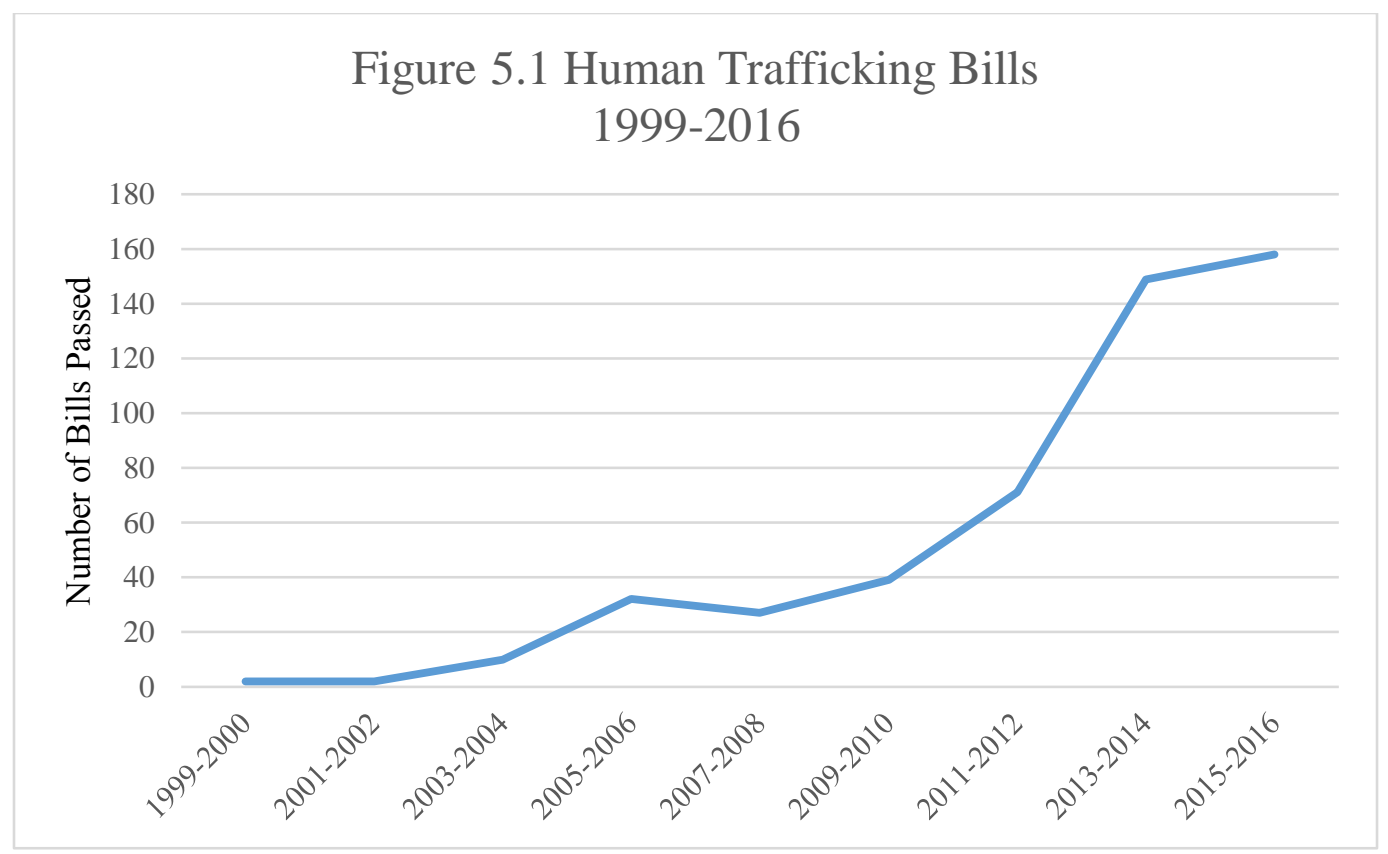

Apparently trafficking was a prime example of a valence issue, that is, an issue that has little to no controversy over the need for a solution, giving it unusual agenda access. As Nelson (1984) demonstrates in the case of child abuse, such issues are rare, but not unheard of. Baumgartner and Jones (1993) suggest such issues present would be opponents no room for cover, are highly salient, and come with ready-made solutions that all can agree on. In the case of human trafficking, as demonstrated in Chapter 4, citizens are overwhelmingly opposed to human trafficking, it was salient on the public agenda for a good half decade before Congress took it up, and the solution on the surface is simple, the government should have procedures in place to criminalize trafficking.

The 2000 Act originated as an anti-sex trafficking legislation when it passed the House International Relations Committee. Although the first draft of this legislation was passed via a voice vote a year before the final legislation made its way to the floor, it was the first action on human trafficking by either chamber. Christopher H. Smith (R-NJ) was crucial in changing the language to include other forms of trafficking such as labor, and debt bondage, from the original focus on sexual trafficking, thus broadening the type of activity included in the definition of trafficking (Barron, 1999). 
As figure 5.2 makes clear, not only did trafficking remain on the congressional agenda, the original solution enshrined in the TVPA has been revisited in every session since its passage (a topic I revisit in the final portion of this chapter).

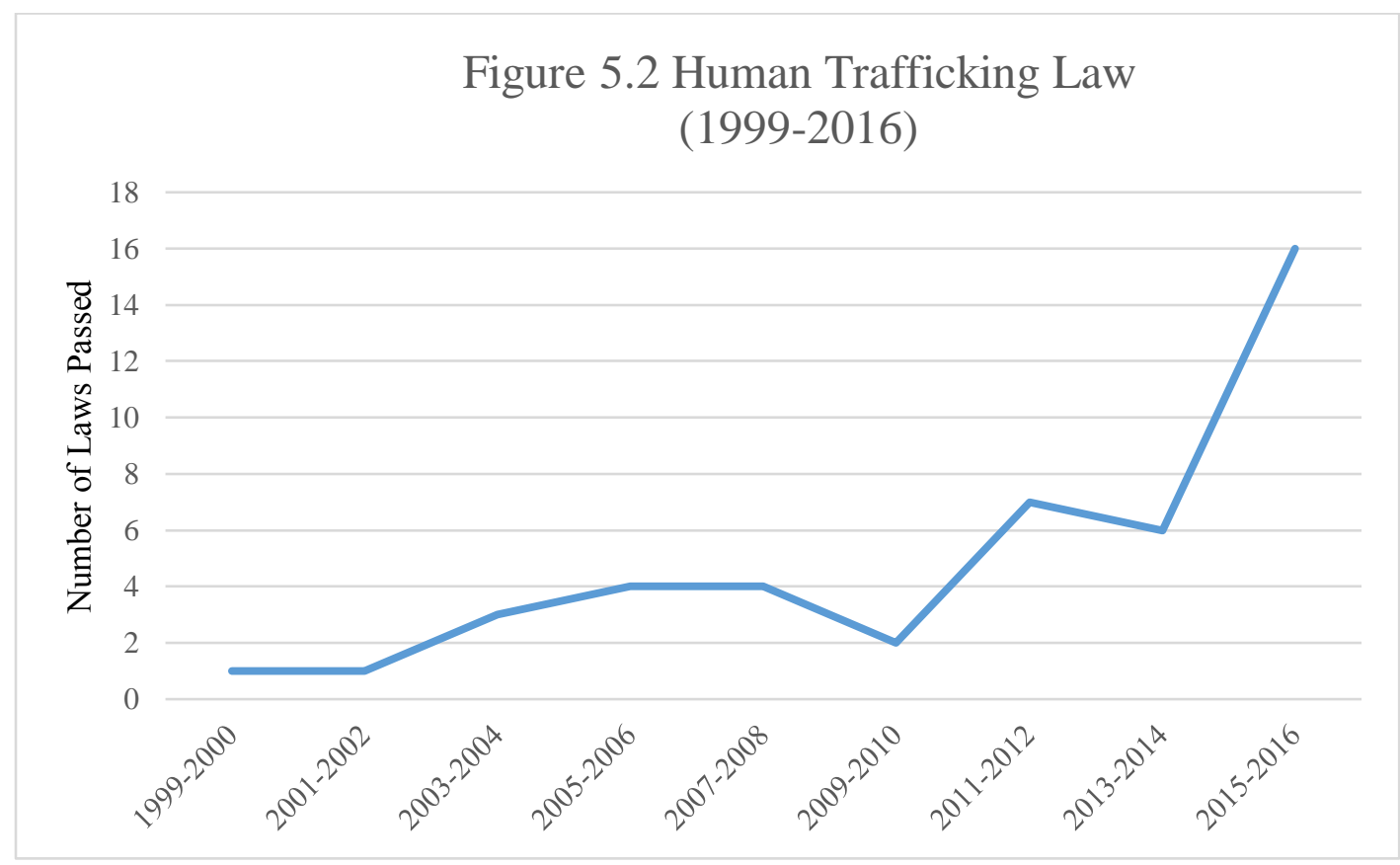

Those who study the legislative process suggest the most interesting dynamic often involves inter-chamber differences in the treatment of issues and legislation. In order to get at that dynamic I broke the bill introductions down by chamber. Figure 5.3 shows that the House dominates the introduction of legislation, no surprise since they have four times the number of potential entrepreneurs than the other chamber. Sheer numbers aside, the House was the first to take up the issue of human trafficking in 1999 and as time went on they dominated the discussion and framing of the problem. 


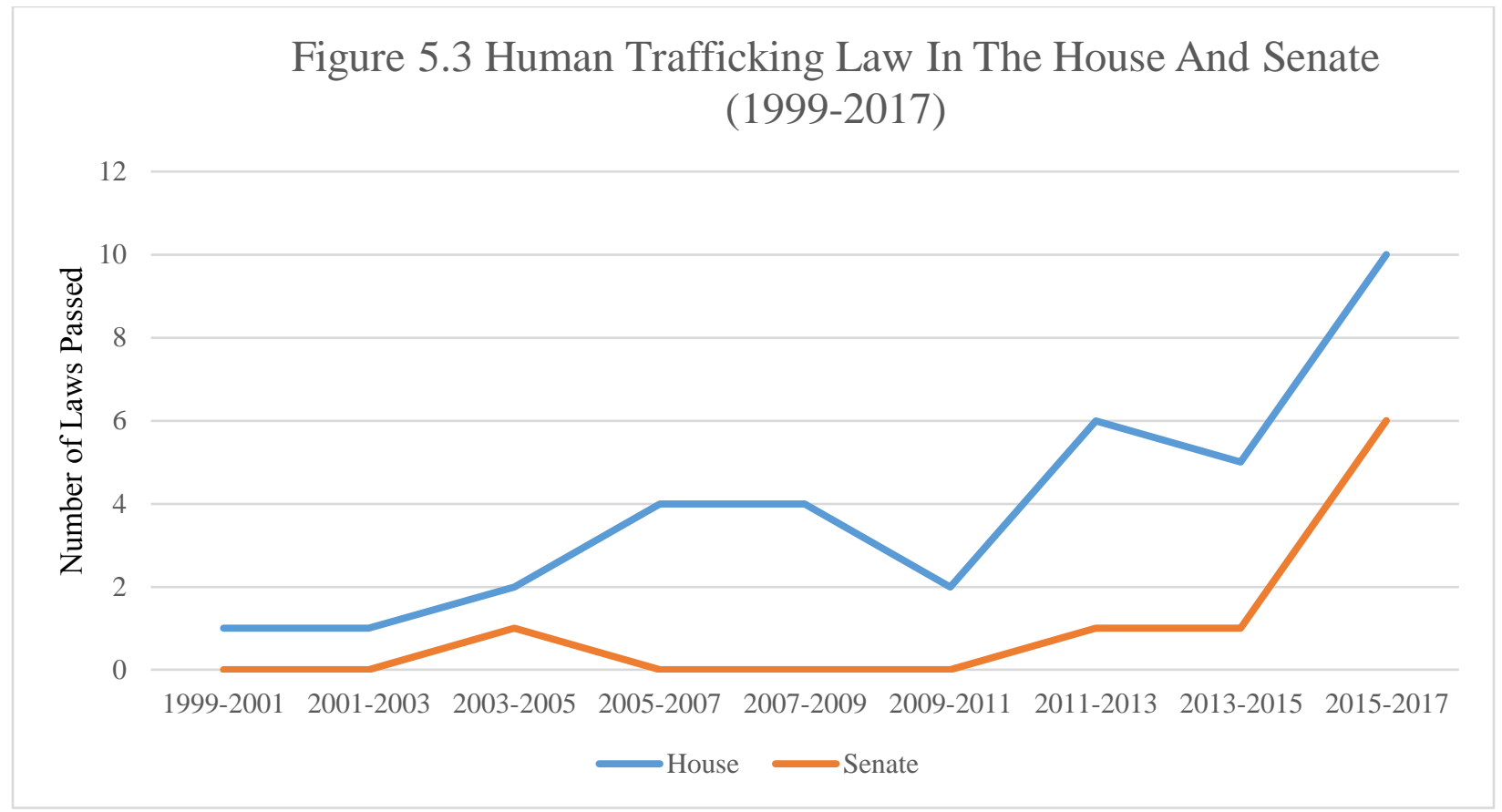

Simply focusing on legislative introductions tells the reader something about congressional attention, but it does not provide a complete picture of agenda setting dynamics. In order to gain a fuller understanding of the process one needs to understand who is introducing legislation, as well as the content of legislation, which take us into the realm of entrepreneurship and issue framing.

\section{Entrepreneurship}

To fully understand how an issue moves onto the public agenda, it is important to understand the dynamics of entrepreneurship. Schneider and Teske (1992) define a political entrepreneur as someone who dramatically alters the direction of politics by introducing and selling a new understanding of some problem or phenomena. Michael Mintrom (1997) adds to the discussion with an emphasis on how entrepreneurship involves framing the problem, networking within policy circles, shaping policy debates, and building coalitions. Gregory Wawro $(2001,27)$ argues that a legislator must be willing, and able, to "invest time, staff, and other resources to acquire [the] knowledge" that allows them to both author solutions and assemble coalitions necessary to engage in entrepreneurship 
The legislator as entrepreneur must focus on not only crafting legislation, but on the congress and political environment in which the legislation is to be passed. Information gathering is extremely important when creating new legislation given the uncertainty in how other legislators feel about an issue, as well the difficulty of finding space on the crowded congressional agenda (Wawro, 2001). Thus, entrepreneurs need to become specialists in the area they are legislating, but more than that they need to become expert in the legislative process. This becomes even more important the more complex and intersectional the policy issue to be addressed. Gathering this "political intelligence" is imperative for successful entrepreneurship (Wawro, 2001).

Entrepreneurs are typically long-serving members of the legislative branch, this, combined with their expertise provides them with the acumen necessary to draft legislation that appeals to a majority of members. Successful entrepreneurs identify problems and write legislation in a way that makes it difficult for their colleagues to reject their preferred solution. Entrepreneurs do this by either making it clear the problem is something that should be acted upon, or framing the issue so that the only way to combat the problem is through legislation.

Certain issues become attractive to policy entrepreneurs to be placed on the agenda for three main reasons. First, the issue effects a large portion of the population, and citizens would be interested in potential policy change. Second, the problem identified is serious, and can be defined in such a way that the public understands the gravity of the situation. Third, there is a easily identified and implemented solution to the problem identified. If an issue has these components it is an attractive candidate to be place on the discretionary agenda (Wawro, 2001; Mintrom 1997; Walker, 1977).

To increase their chances at success, entrepreneurs must draft legislation that could potentially address a multitude of issues. By increasing the "issue dimensions" to include problems with a large or broad scope, they increase the potential size of the coalition that will join in their effort (Wawro, 2001). Entrepreneurs must also be very involved in the policy process- making sure that legislation takes the path of least resistance to passage. Entrepreneurs are not done with the process once the legislation is written, they then must be involved in the process of getting the legislation passed. The first step is to make sure 
that the bill is referred to the appropriate committee (normally one on which the entrepreneur serves, but it could also involve a committee seen as sympathetic to a particular frame or solution). Entrepreneurs write legislation in such a way that the Parliamentarian will refer it to the committee favored by the entrepreneur (King, 1989; Mintrom, 1997; Wawro, 2001; Walker,1977; Davidson and Oleszek, 2004).

In order to get at entrepreneurship on the issue of human trafficking I identified the sponsor, and cosponsors, of the legislation tracked in the previous section. Table 5.1 lists the legislation and sponsors through time (see appendix), while figures 5.4 (House) and 5.5 (Senate) identifies those legislators who introduced legislation between 2000 and 2017. As figure 5.4 reveals, Christopher H. Smith (R-NJ) appears to be the most active legislator, introducing 30 bills on human trafficking, he is a ranking member of the House Committee on Foreign Affairs as well as a founding member of the Joint Commission on Security and Cooperation in Europe and the Congressional Executive Committee on China all three of which of which (as you will see below) were busy in the formulation and discussion of human trafficking policy. Ted Poe (R-TX) is second with 14 bills, he is a member of the, House Committee on Foreign Affairs as well as the House Judiciary Committee. Edward Royce (R-CA) is third with 13 bills, he is a member of the House Committee on Foreign Affairs as well as the House Committee on Financial Services. Sheila Jackson-Lee (D-TX) is fourth with 12 bills, and is a ranking member of the Judiciary Committee, she is also a member of the Committee on Homeland Security and Budget Committee. Finally, Carolyn Maloney (D-NY) is fifth with 8 bills she is a member of the House Committee on Financial Services as well as House Committee on Oversight and Government Reform.

In the Senate the most active member is Patrick Leahy (D-VT) who introduced 12 bills, he is a member of the Appropriations Committee, Judiciary Committee, and Agriculture, Nutrition, and Forestry. Both John Cornyn (R-TX) and Robert Menendez (D-NJ) had 11 bills each. John Cornyn (R-TX) is a member of the Committee on Finance, Judiciary Committee and Select Committee on Intelligence. Robert Menendez (D-NJ), is a member of the Banking, Housing, and Urban Affairs Committee, and the Finance Committee. Barbara Boxer (D-CA) and Bob Corker (R-TN) introduced 7 bills each. Barbara Boxer (D-CA) was a member of the Committee on Commerce, Science, and Transportation, Committee 
on Environment and Public Works, Select Committee on Ethics, and Committee on Foreign Relations. Bob Corker (R-TN) is a member of the Foreign Relations Committee, Banking, Housing, and Urban Affairs Committee, the Budget Committee, and the Special Committee on Aging. Though Figure 5.1 (appendix) will identify the House and the Senate had 165 and 74 (respectively) different members introduce human trafficking legislation, there are clear differences among legislators.

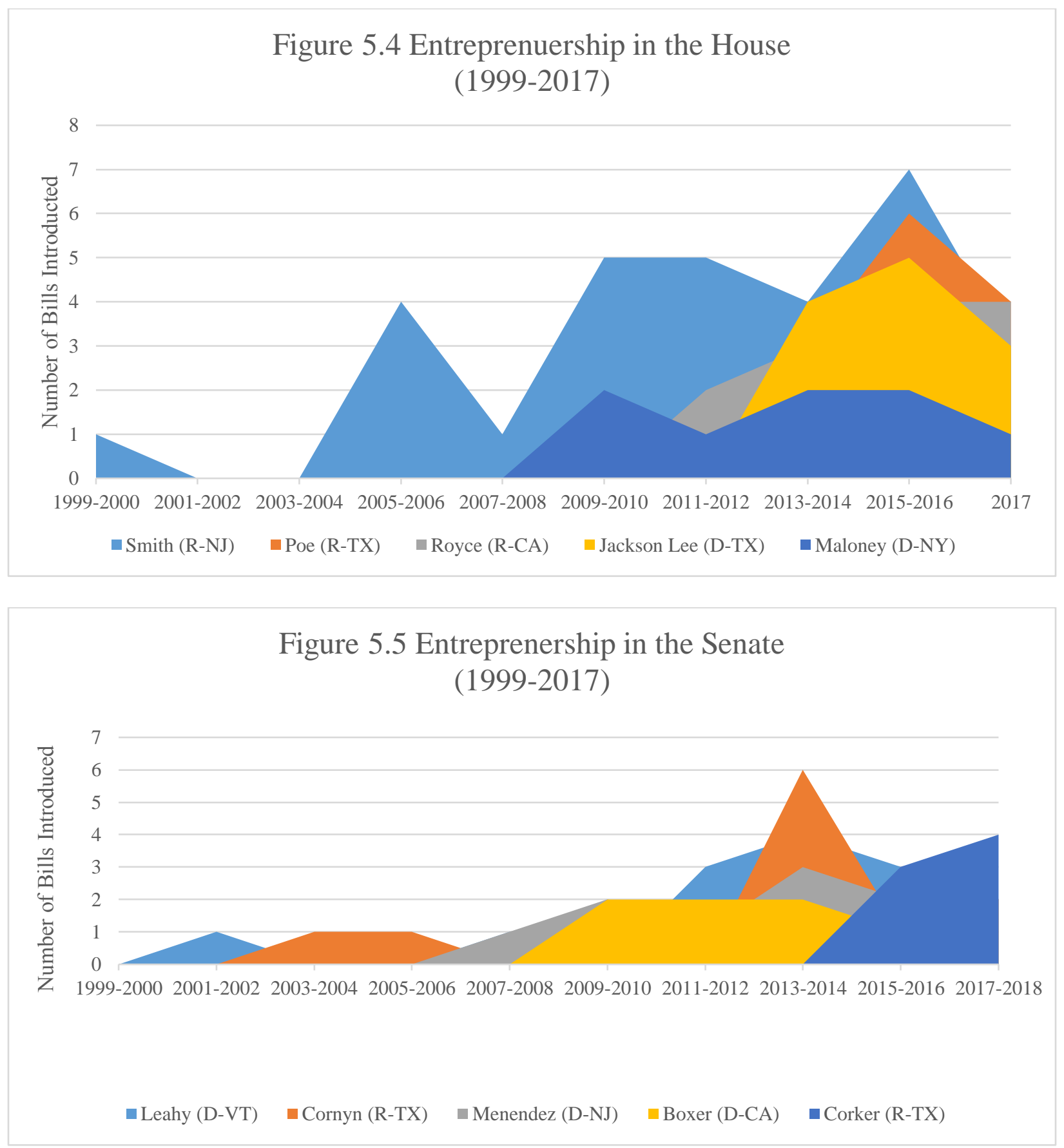


Though there seems to be a clear policy entrepreneur in Christopher Smith (R-NJ) in the House, other members of Congress are active in the area after 2009. (Wawro, 2001; Davidson and Oleszek,2004). House Bill 3244, The Trafficking Victims Protection Act (2000) was introduced by Christopher H. Smith (R-NJ). It had 37 co-sponsors across both chambers, 19 Republicans, 17 Democrats, and 1 Independent. It was referred and marked up by the House Committee on Foreign Relations and The House Judiciary Committee (H.R. 3244, 2000). During consideration of this legislation Christopher H. Smith (R-NJ) became the spokesperson for the legislation. Referring to this legislation as a piece of criminal justice reform in order to help halt the massive criminal activity of human trafficking. Proudly discussing the extreme criminal repercussions of the bill, Smith touted that the United States could become a world leader in combating human trafficking (Barron, 1999; Palmer, 2000; Palmer, 2000).

The next major alteration in human trafficking legislation came in 2005. Sponsored by Christopher H. Smith (R-NJ) with 103 bi-partisan co-sponsors, The Trafficking Victims Protection Act Reauthorization of 2005 (H.R. 972), strengthened the already strict criminal justice measures in the original act and sailed through the House Foreign Relations Committee. In addition to re-funding the existing program, bill made it possible for United States prosecutors to try federal contractors and United States employees overseas for acts of trafficking. It also allocated money to Homeland Security in order to help better combat human trafficking abroad and in the United States (H.R. 972, 2005; Speck, 2005).

Figure 5.6 details legislative referrals within the House (see Table 5.2 in the appendix for a detailed listing). Six committees receive the bulk of legislation, accounting for 10 referrals or more over the course of study. Foreign Affairs in the House is the dominant venue, accounting for 46 referrals. The Judiciary Committee is a close second with 37 referrals, the bulk of which occur after 2010, as do Homeland Security's 23 referrals. Interment players include Ways and Means (15 referrals), Armed Services (10 referreals) and Appropriations (9 referrals).

Figure 5.7 details legislative referrals within the Senate (see Table 5.3 in the appendix for a detailed listing). Four committees dominate the trafficking discussion in the Senate: Foreign Relations Committee (28 referrals) and Judiciary (27 referrals) enjoy an oligopoly of sorts, and mirror the foreign 
policy--legal policy dynamic in the House. Appropriations (17 pieces of legislation) and Homeland Security and Government Affairs (10 referrals) form the trafficking chorus in the Senate.

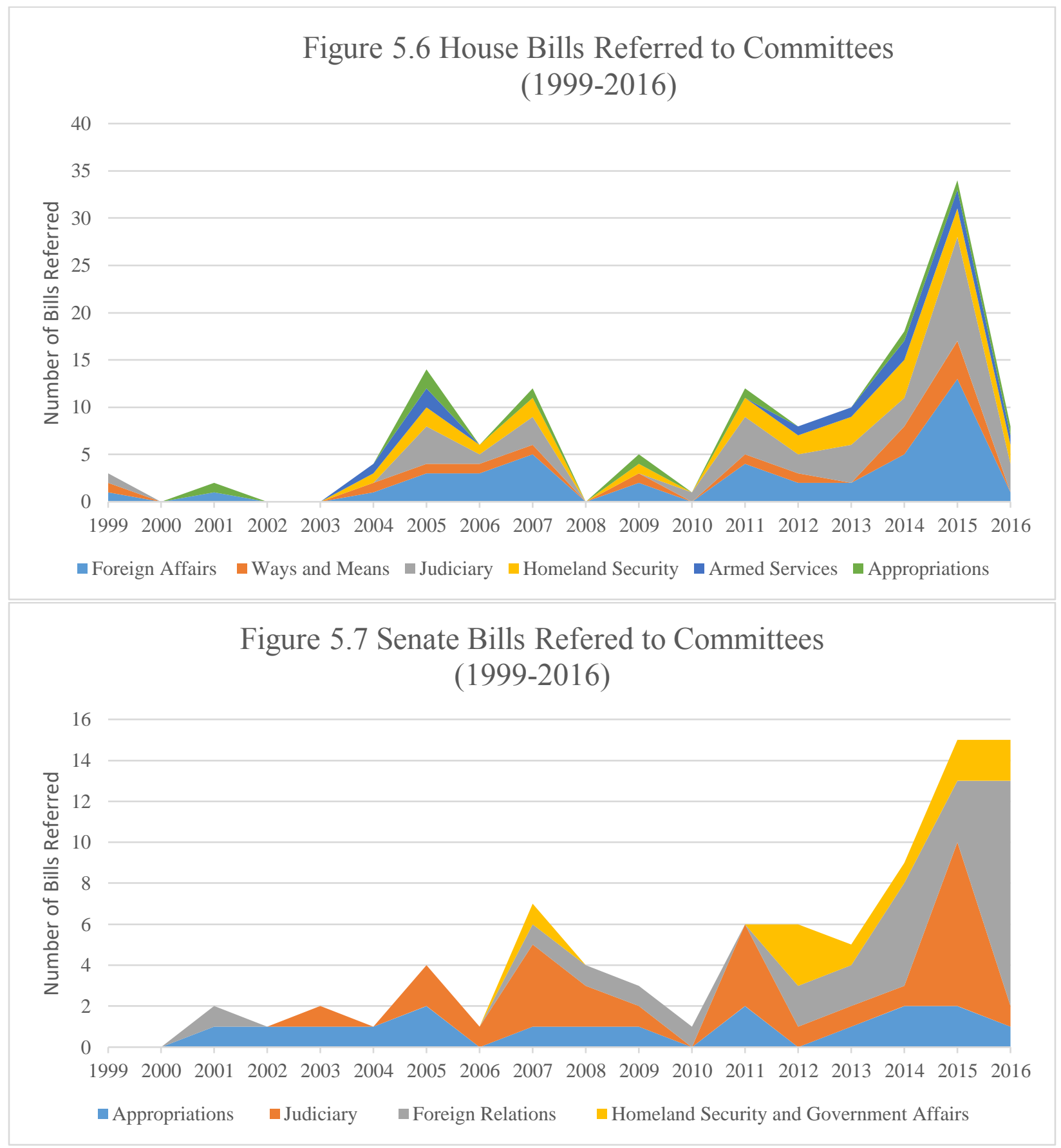

Figure 5.8 and 5.9 focus on committees that reported out trafficking legislation. Though a bill being referred to committee can tell a story, what happens in committee and whether a bill makes it out of committee is the real subject of interest. Focusing on committees that reported out legislation identifies 
the committees active in the creation of human trafficking legislation and framing the issue. Figure 5.8 confirms that the Committee on Foreign Affairs was initially in control of the issue in the House, with Judiciary becoming a player in 2010. This is no real surprise since the policy entrepreneurs discussed earlier, Christopher R. Smith (R-NJ), Ted Poe (R-TX), and Edward Royce (R-CA), are all members of Foreign Affairs. Sheila Jackson-Lee (D-TX), another entrepreneur, is a ranking member of the Judiciary Committee, which explains its involvement after 2010 and the increasing focus on the implementation of criminal justice protocols set up by the original legislation, and refined in all of the reauthorizations that followed. With the split along partisan lines after 2011, more actors got involved in both introduction and referral activity, although Foreign Affairs and Judiciary still dominated the reporting of legislation to the floor (Barron, 1999; Palmer 2000, Speck, 2005; Cadei 2012).

The Senate is consistently less active than the House on the issue of human trafficking, although after the partisan split in 2011 there is an uptick in activity. Appropriations reported out the most legislation (14 bills), suggesting the Senate's preoccupation is with funding. As was the case in the House, Judiciary (13 bills) and Foreign Relations ( 7 bills) are the most active substantive committees, followed by Homeland Security (4 bills). 

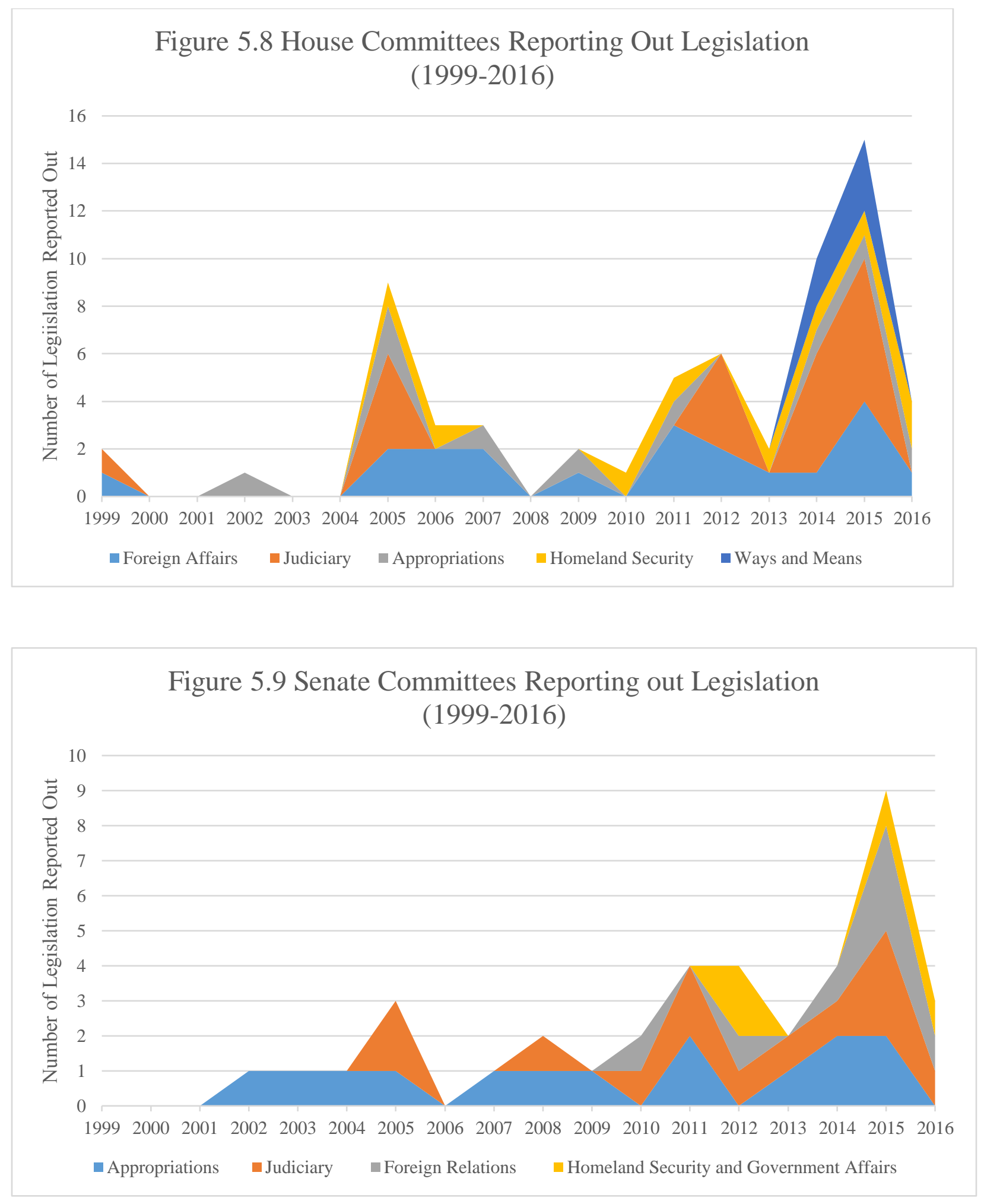


\section{Framing the Issue: Hearings and Commissions}

Committees are the institutional bedrock of the legislative process. They may promote new ideas and understandings, but may also act as roadblocks to congressional action (Deering and Smith, 1997). Which committees hold hearings is important, since different committees often take a different focus on an issue (Baumgartner and Jones 1993). This means committees are preoccupied with control of policy turf or jurisdiction (Baumgartner and Jones 1993, King 1994, Worsham 1997). There are two different ways that committees are assigned jurisdiction. The first is through statutory jurisdiction, under which congressional rules assign policy jurisdiction to particular committees. The second, common law jurisdiction, is established by committees themselves, who by holding non-legislative hearings establish a precedent with regard to policy jurisdiction not written into the rules of the chamber (King, 1994).

Although committees are the bedrock of the policy and legislative processes, there is an alternative route to shaping policy—congressional commissions. Congressional commissions are temporary entities created by Congress to help investigate problems whose jurisdictional assignment is blurred or overlapping. Commissions mostly serve as a guide to the Congress to deal with issues that don't necessarily fit with preexisting jurisdictional boundaries. They can also serve as alternative sources of information and as a means of developing expertise on new problems and issues (Glassman and Straus 2015). Legislators choose to form commissions to avoid two hazards of policymaking. First, they provide a way for legislators to explore different interests and even investigate and give legislative advice without the risk of being attached to an unpopular policy come re-election (Weaver 1987; Dean 1969; Mayhew 1974). Second, since commissions don't report out legislation, they enable commission members to avoid the deadlock of voting, unlike committees, and are thus able to provide an environment for consensus building (Glassman and Straus 2015). Commissions are often the means used by entrepreneurs to raise awareness of an issue. Because they are composed of both congressional members and outside experts, they raise not just congressional attention, but public attention and the attention of expert communities (Glassman and Straus, 2015; Campbell, 1998). 
I then compare frames, and witnesses to committee venue to determine if committees prefer particular frames, or favor particular interests. Figure 5.10 tracks hearing activity over time in the House, Senate and by commission. Figure 5.10 indicates that the House dominated hearings on the topic of human trafficking, holding 55 hearings over the span of 1999-2017, followed by the Senate with 21 hearings, and joint commissions with 15 hearings. Figure 5.11 shows that the Committee on Foreign Affairs (previously the Committee on International Relations) holds the majority of hearings dealing with trafficking, followed by the Committee on Oversight and Government Reform, followed by the Committee on Homeland Security. Compared to the House, the Senate holds few hearings, Figure 5.12 shows that the Senate Committee on Foreign Relations appears to be the lead actor, followed by the Committee on the Judiciary, and then the Committee on Homeland Security.

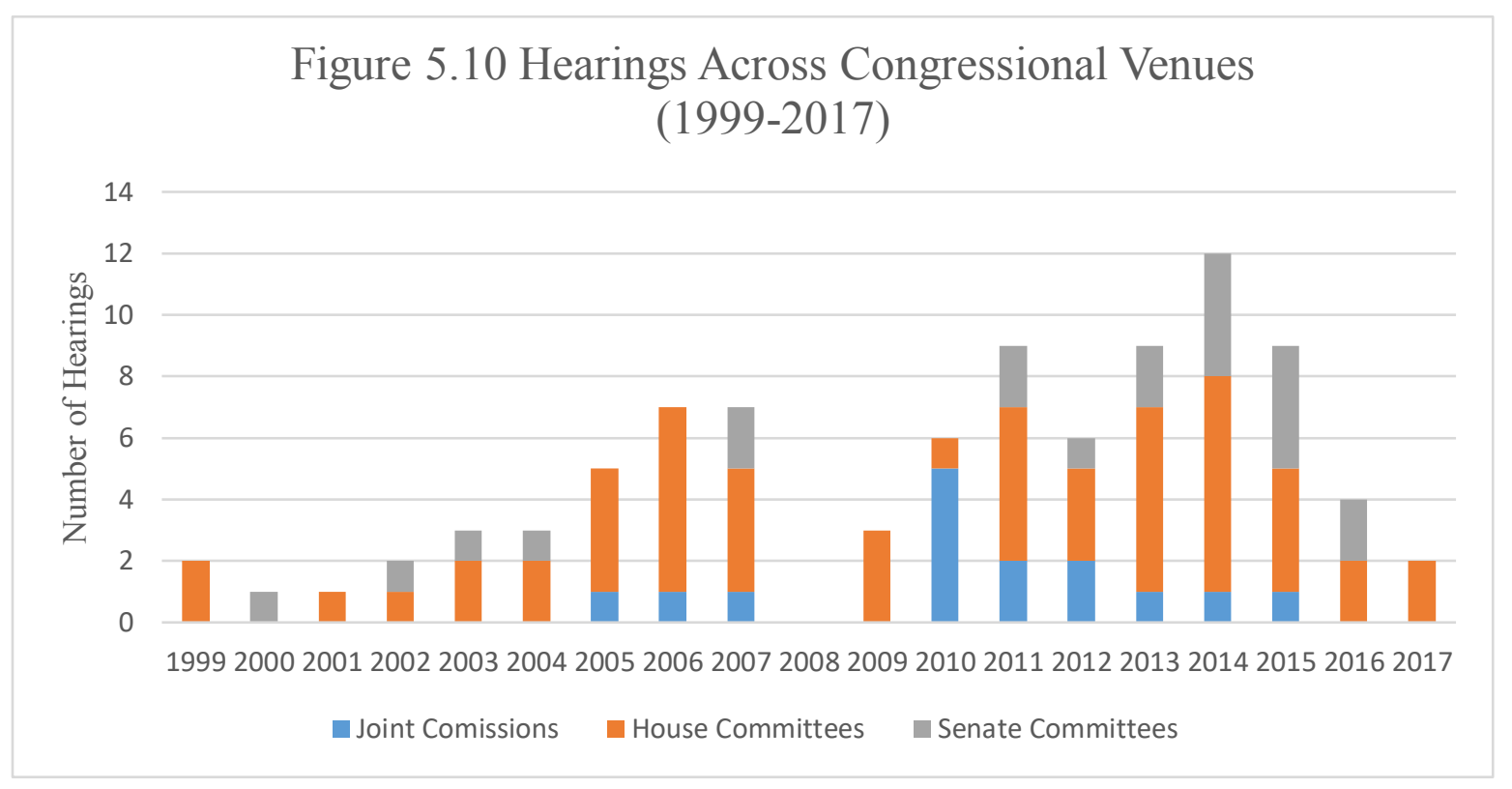


Figure 5.11 House Hearings

(1999-2017)
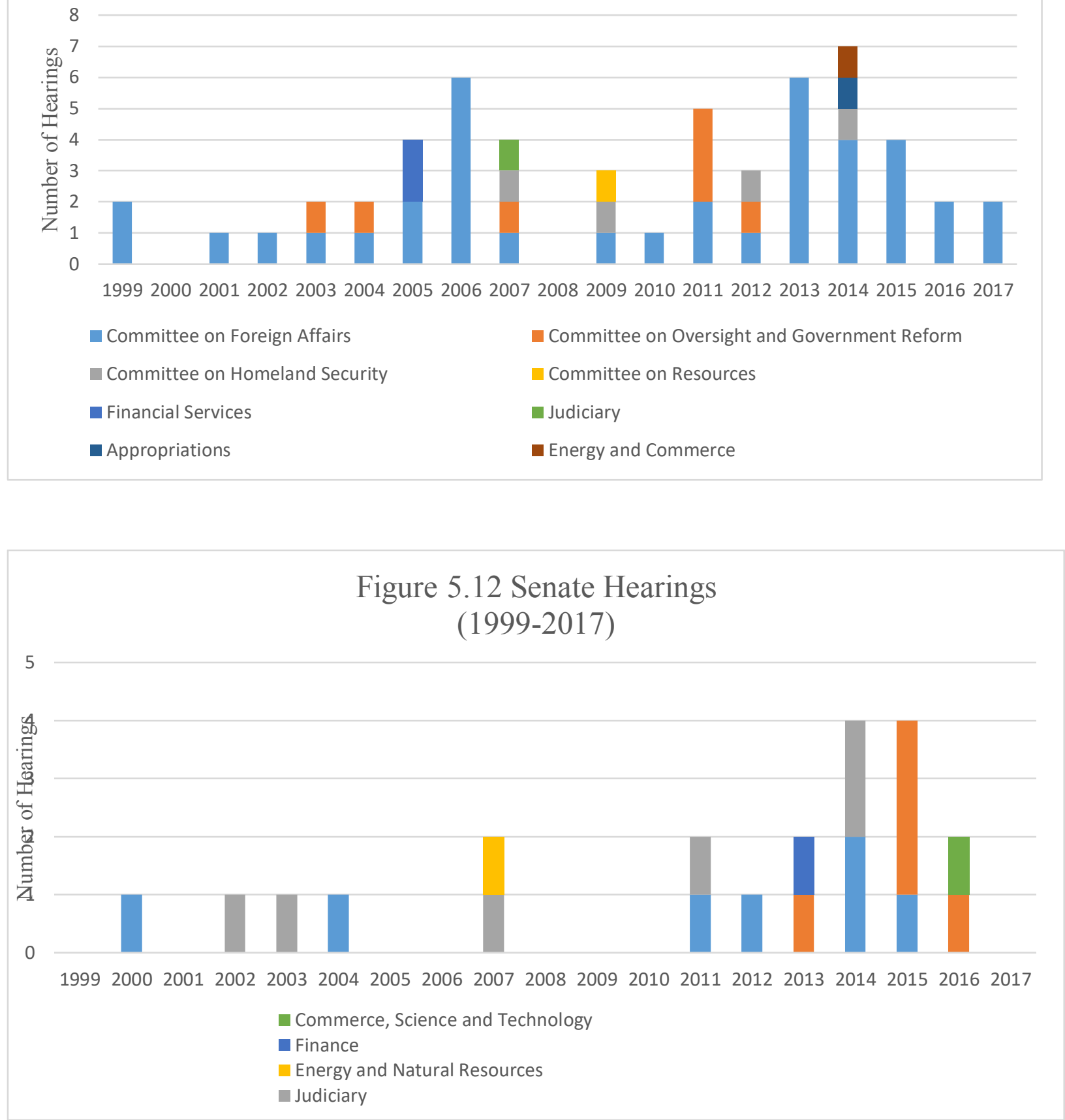


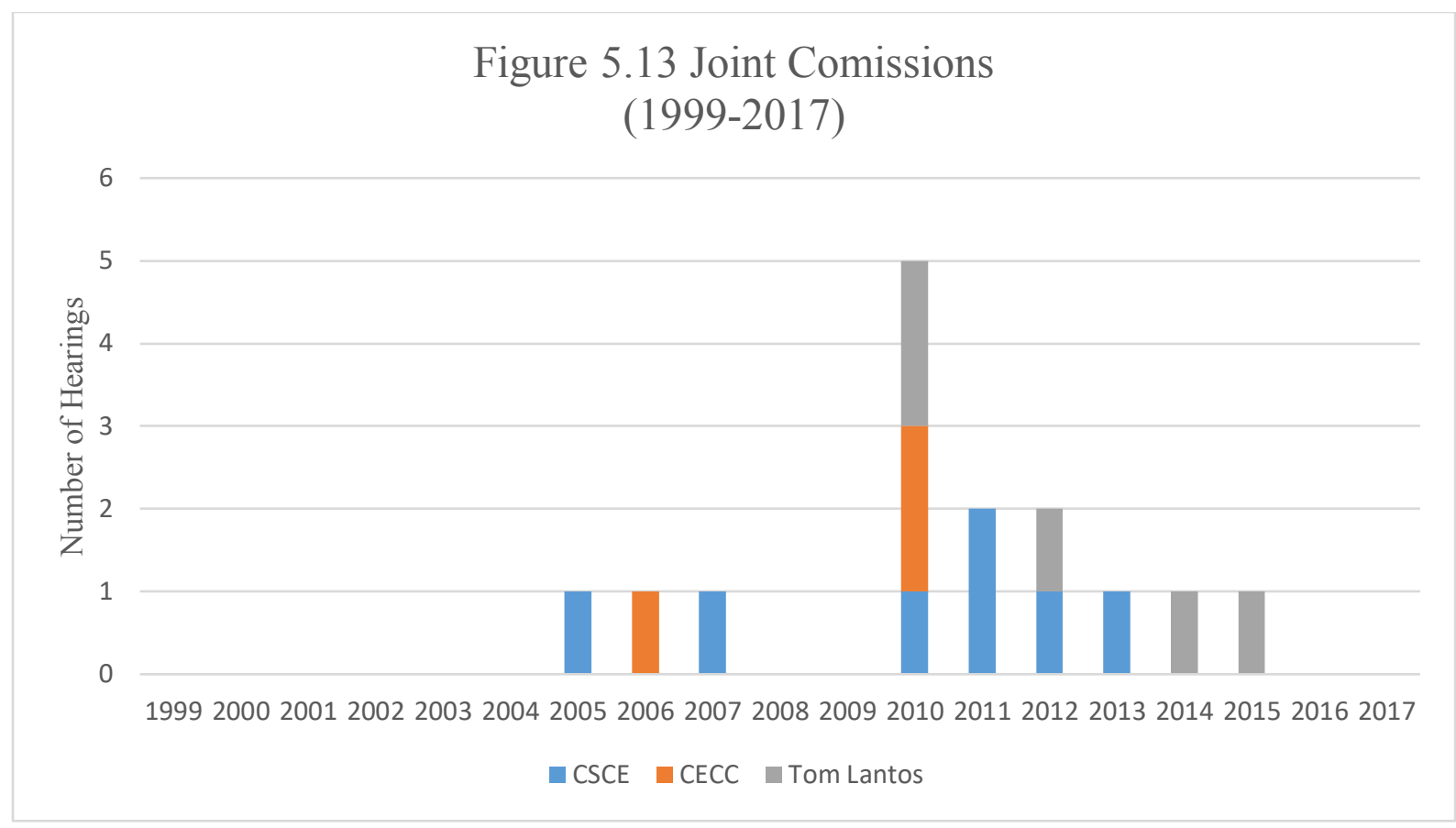

The most active commission player is the Joint Commission on Security and Cooperation in Europe (CSCE) with 7 hearings between 1999 and 2017 (see figure 5.13). It is co-chaired by the Foreign Affairs Committee's Christopher Smith (R-NJ), one of the entrepreneurs identified in the previous section. The CSCE is a joint commission that focuses on facilitating international cooperation between Europe, Eurasia, and North America on issues that deal with military, security, and human rights. This commission was also the first congressional body to hold a hearing on human trafficking. The Tom Lantos Human Rights Commission, previously the Congressional Human Rights Caucus, is another leading commission in the discussion of trafficking, holding 5 hearings between 2000-2017. Formed to promote human rights enshrined in the Universal Declaration of Human Rights, it is open to any interested member and co- chaired by a member from each party. The Congressional-Executive Commission on China, which as its name suggests, focuses on the US-China relationship, rounds out the list of top commissions performers, holding 3 hearings dealing with human trafficking.

Surprisingly, there was little attention given to human trafficking before the passage of the TVPA in 2000. There were only four hearings on the topic of human trafficking between the years of 1950-2000, mirroring the lack of legislative activity discussed in the previous section. Unlike other policies that 
involve a good deal of softening up before legislation is passed, congressional attention was surprisingly low before the passage of the act. That said, after passage of the TVPA attention picks up, with a total of ninety- two hearings by committees and commissions between 2001 and 2017.

As stated previously, Congressional committees use hearings as information sessions. To truly understand committee dynamics, it is imperative to look inside those hearings to understand how the issue it being framed. To do this I use Proquest Congressional to track hearing and commission activity dealing with human trafficking. In addition to tracking hearing activity, I coded hearings to identify how the issue was being framed, a variation of coding the tone of the hearing (Hardin, 2002; Baumgartner and Jones 2002). When compiling the data it was clear that some hearings had more than one topic, or frame to define the issue of human trafficking, in those cases each frame was recorded. Figure 5.14 tracks hearing topics across all venues between 1999-2017. I identify six topics (frames) that tend to dominate the discussion over time:

(1) Child trafficking, this frame was coded when a hearing focused on the implications of trafficking in minors for sexual or other forms of forced labor.

(2) Crime prevention, this frame was coded when a hearing discussed the role law enforcement both domestic and international had in the ending of human trafficking. These instances can be focused on what policies have worked or failed in combating trafficking.

(3) Forced Labor, this frame was coded when the hearing specifically focused on indentured servitude or debt bondage. A key distinction to make is that throughout the hearings there were often times hearings would mention slavery, but it was framed in the context of sex work- these cases would be coded under sexual slavery/prostitution.

(4) Implementation, this frame was coded when hearings discussed the expressed successes and failures of the TVPA.

(5) Sexual slavery and prostitution, this frame is the most interesting, because Congress specifically coded any mention of sex trafficking under "prostitution." The terms were used 
interchangeably throughout hearings. Any discussion of sexual slavery or sex work will be coded under this topic.

(6) Immigration - this frame was used when hearings discussed how human trafficking could affect immigration.

I am also interested in who attends hearings. Those who study witnesses at hearings argue that the composition of witnesses tells one something about the subsystem dynamics in play, who benefits from congressional attention, policy learning, and winners and losers in the process (Baumgartner and Jones 1993, 2002, 2005; May et al, 2009; Sabatier and Jenkins-Smith 1999; Worsham 1997, 2012). Using the affiliation found in the abstracts, witnesses were placed in one of eleven categories:

(1) Human rights experts, were coded if they were people who were focused on the individual impact of human trafficking. These persons were often heads or member of NGOs, and had done years of field work helping victims. These experts could be focused on children or adult victims of human trafficking, labor or sex trafficking victims.

(2) Law enforcement, there were persons that were involved in either part of the criminal justice system, be it members of the Department of Justice (DOJ), police officers, or immigration enforcement.

(3) Members of the State Department, were coded separately because out of all government officials they were the most prevalent. The State Department under the TVPA was granted many of the responsibilities for making sure the TVPA was implemented correctly.

(4) Trafficking survivor, these witnesses has survived human trafficking and also benefited from the TVPA.

(5) Other government officials, many different areas of the government are active in the implementation of the TVPA. An example would be a representative Health and Human Services who often times implement the social services aspect of human trafficking. Any government official that was not a member of the State Department or the Department of Justice were coded under this. 
(6) Legal expert, were coded when lawyers outside of the DOJ were involved in the hearing process.

(7) Journalist, was used to code members of the media who had specific expertise in covering human trafficking related problems.

(8) Medical expert, human trafficking poses a great public health risk, particularly through the spread of sexually transmitted diseases. Medical experts such as doctors and nurses would often testify to the risks associated with human trafficking.

(9) Labor expert, these witnesses were concerned with labor trafficking and the extent of forced labor and indentured servitude that exists.

(10) Transportation officials, these witnesses were flight attendants, train conductors, airline pilots who are often the first to suspect or witness a trafficking victim. Over the years the TVPA has set aside specific funds for training for the transportation industry to be the first line of defense.

(11) Economics expert, these witnesses were brought in to discuss the economic role human trafficking has both on the US economy and the global economy.

\section{Framing the Issue: Topics of Discussion at Hearings}

Figure 5.14 (all hearings over time), 5.15 (joint commissions), 5.16 (Senate committees), and 5.17 (House committees) track the different frames (areas of focus) utilized in the congressional discussion of human trafficking. As my examination of hearings progressed, it became clear that particular labels and frames were routinely used in hearings. These were relatively straightforward to code and often were directly correlated to the keywords Congress used to identify the hearing. Others contained a more nuanced discussion and generated both a good deal of discussion and conflict. For example, and probably the most contentious area that was discussed as a topic, was sex trafficking and prostitution. Which frame is used has a good deal to do with the way in which policy dealing with the 
issue is written. Much of the criticism of the TVPA came from the manner in which it framed sex work as a morality issue, often by reference to prostitution.

While each of the four human trafficking hearings held before the passage of the TVPA focused on the sex trafficking of women and children and the international dimensions of the problem, with some additional consideration of the forced labor aspect of trafficking in the Senate Committee on Foreign Relations and mention in two hearings of trafficking as a human rights concern, after passage of the TVPA the focus varies over time and venue. Two of these hearings were held by the House Committee on International Relations (with the primary focus sex trafficking of women and children), and one each by Senate Committee on Foreign Relations (which focused on sex trafficking, forced labor, law enforcement policy and social service needs of victims) and the Commission on Security and Cooperation in Europe (which focused on sex and labor trafficking of women and children). As the figures demonstrate these frames continued to shape the way in which Congress discussed human trafficking even after the passage of the TVPA.

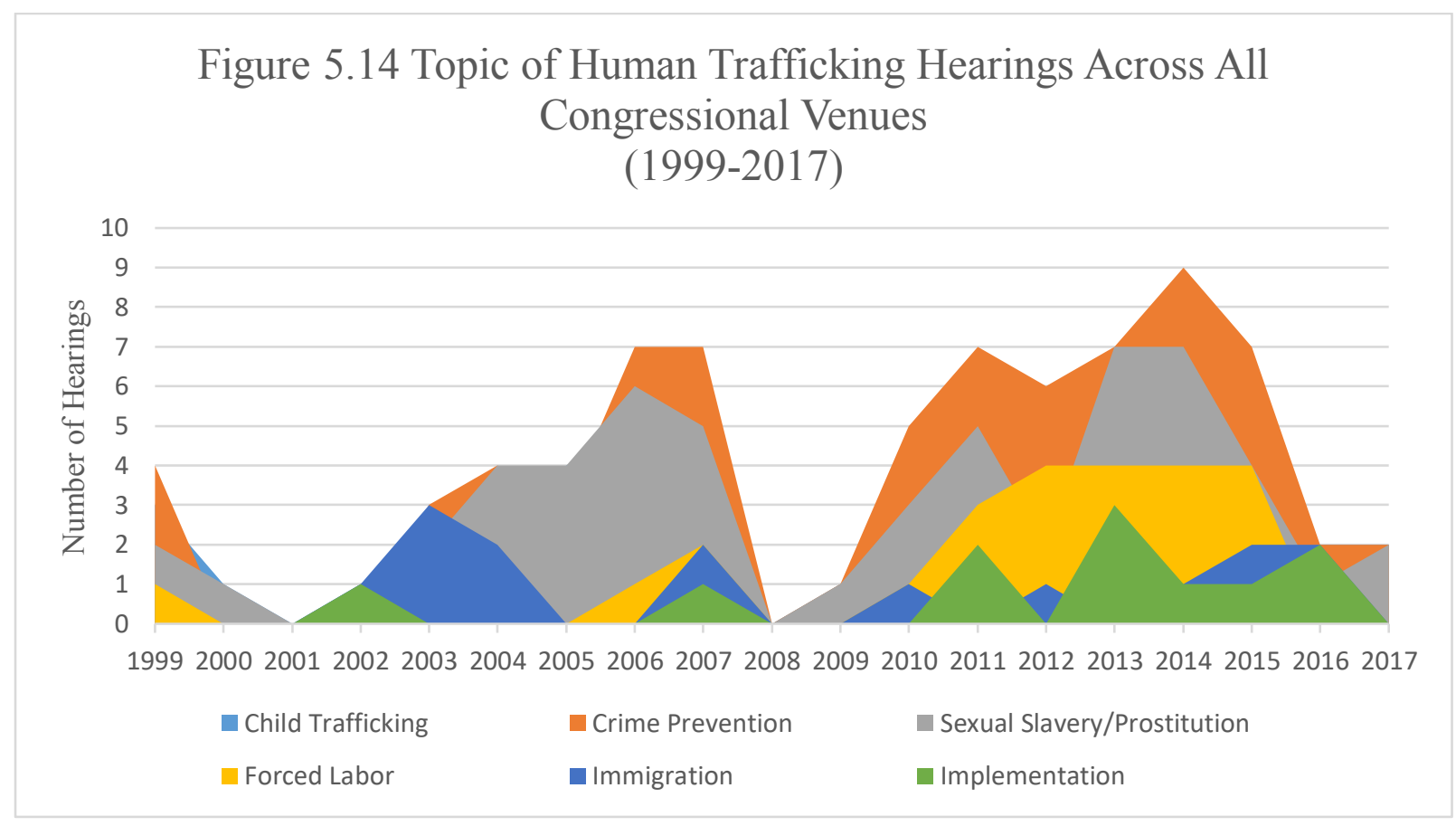



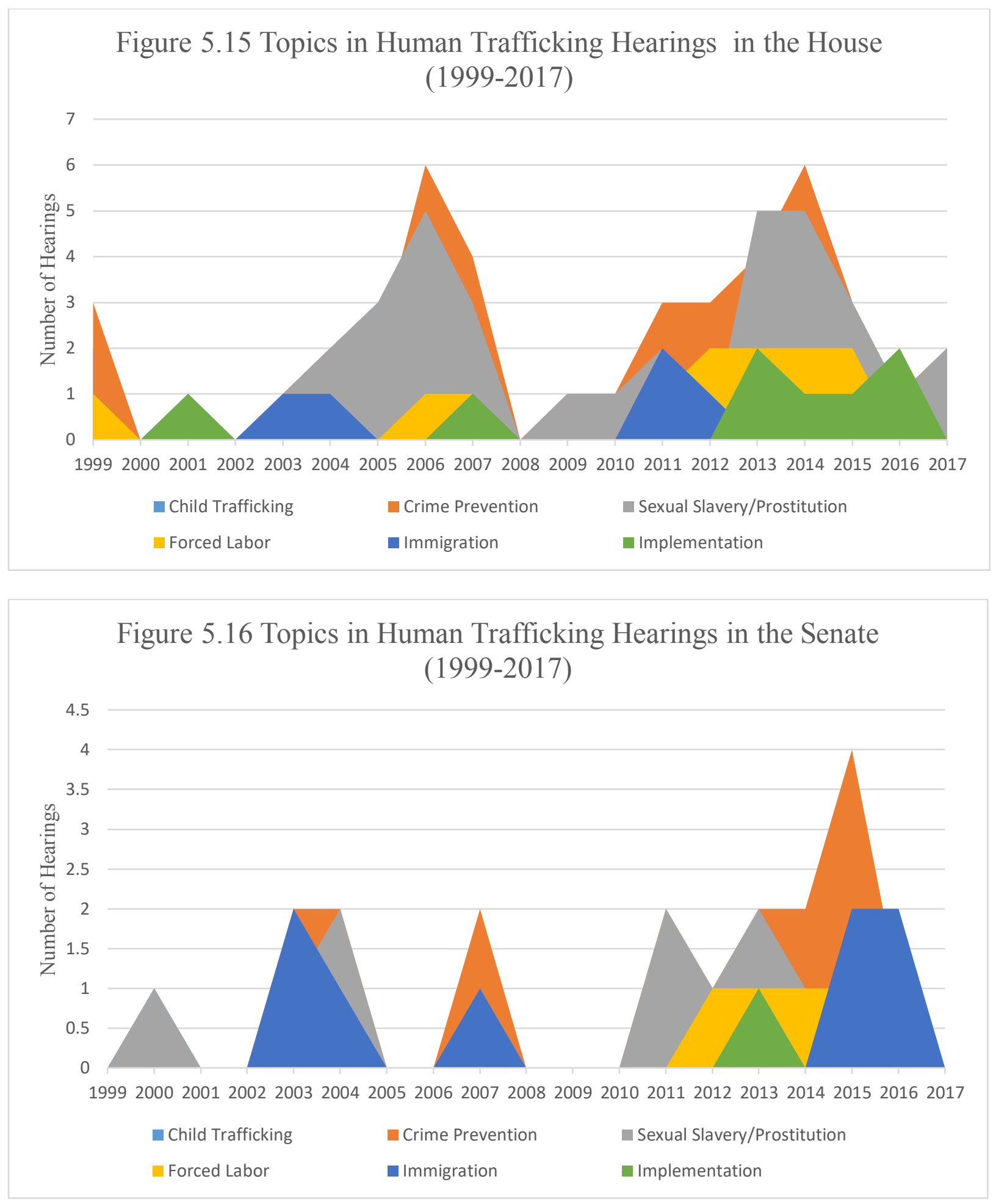


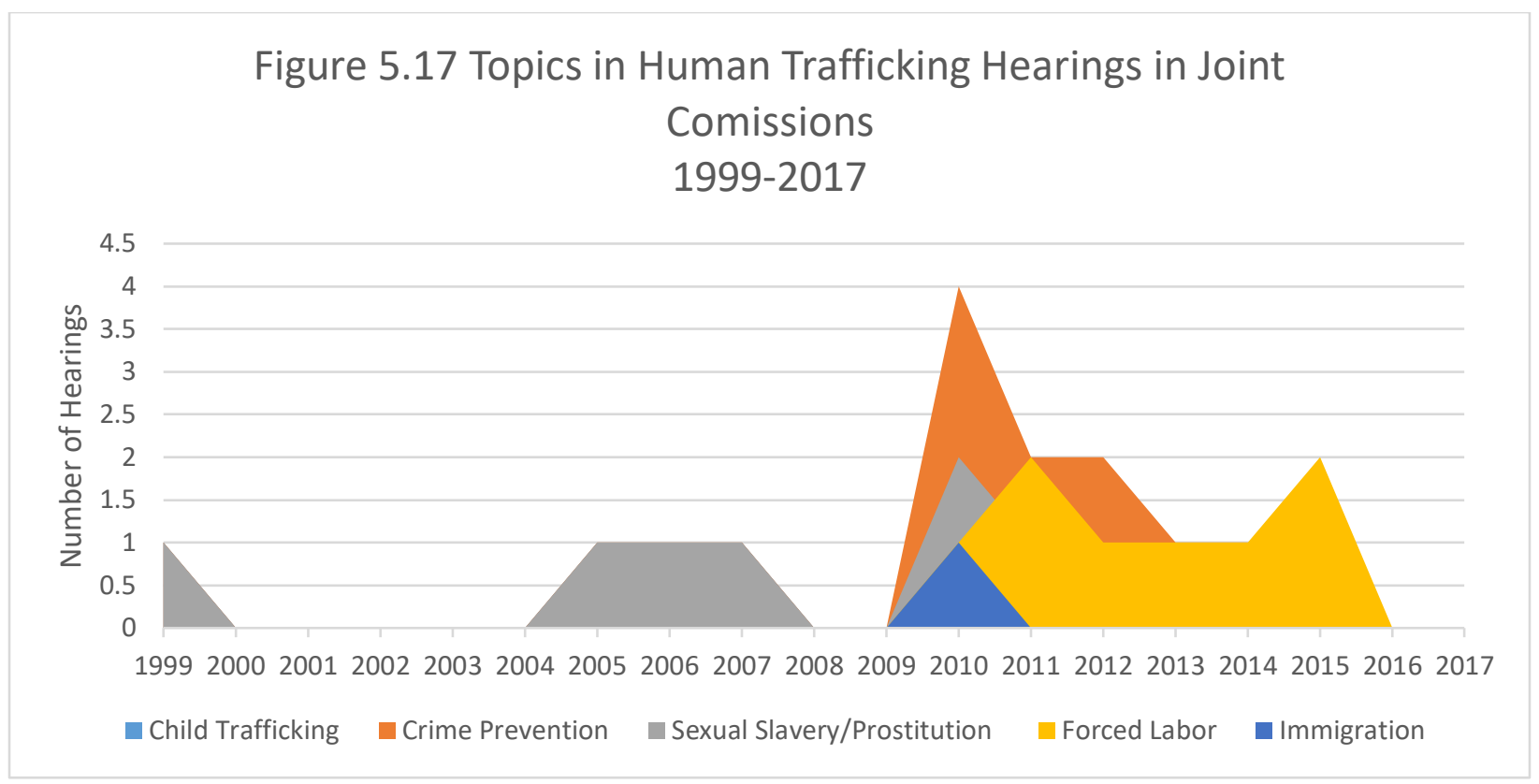

Although there are six identifiable topics throughout the hearings, it becomes clear that crime prevention becomes the dominant frame across all three venues. Crime prevention dominates the discussions of human trafficking by focusing on the role the criminal justice system. This correlates with the frame the media used to define human trafficking (see Chapter 4). Though criminal justice was the most prevalent topic, sexual slavery and prostitution become the second most used topic in these hearings. Focusing on sex trafficking as the main problem of human trafficking led these hearings to focus on that particular issue. Those two are clearly the main topic of hearings, what is something that is interesting over time is that forced labor, once absent from the discussion makes its way into hearings as the definition of trafficking begins to include more than just children and sex trafficking.

Figures 5.14-5.17 illustrate that although there is the dominant frame in criminal justice, sexual slavery/prostitution is a consistent focus, although it varies by venue and chamber. It is the topic in around 26\% of House hearings (see table 5.9), 23\% percent of Senate hearings (see table 5.7) and 24\% percent of the commission hearings (see table 5.7). After sexual slavery/prostitution, child trafficking is the third most active topic of human trafficking. It is the topic in around $23 \%$ of House hearings (see table 5.9), $17 \%$ percent of Senate hearings (see table 5.8) and $16 \%$ percent of the commission hearings (see table 5.7). 
Although sexual slavery and prostitution are a seeming constant in the trafficking discussion, the data suggest that the congressional focus is constantly shifting. So, for example, labor trafficking gains particular interest in the House beginning in 2010 and in the Senate during 2011. It also crops up in the commission discussions, but not as consistently as it does in committee. The human rights dimension dominates the commission hearings, no surprise given their legislative origins, albeit the CongressionalExecutive Commission on China does not focus on it nearly as much as the other two commissions (which might be due to the sensitivity of the Chinese to the topic of human rights in general). The Senate and House focus on human rights varies by committee, with the Committee on Homeland Security and Government Affairs giving it the greatest attention in the Senate, and Energy and Commerce taking the lead in the House. Forced labor is discussed in 9 percent of House hearings, 8 percent of Senate hearings, and in 21 percent of commission hearings.

What does the congressional focus on certain topics tell us about the role they played in issue formation of human trafficking as a problem? Congress decided to focus on a variety of issues, what they deemed to be the most important when they were identifying the problem of human trafficking. With their decision to discuss sexual slavery and prostitution interchangeably allowed them to draft legislation framing the two topics as one issue, often times not considering the impact on victims. Congress also decided to delineate between the three forms of trafficking, child trafficking, sex trafficking, and labor trafficking, all of which gained different amounts of attention. One of the most important areas that was discussed was human rights violations. Human rights violations are salient and a way to attract attention and support for action.

\section{Witnesses}

Tracking witnesses who appear at hearings allows one to say something about the source of expertise sought out by committees, as well as identify important players in the field and who was considered to be experts in issue definition and policy recommendations. Where a committee obtains its information on an issue allows one to predict how they will frame the issue and the types of solutions they 
will adopt in legislation. The most frequently appearing witness in all settings are human rights experts (see figures 5.18, 5.19, 5.20, and 5.21) These witnesses ranged from academics to members of the nonprofit community, all of whom emphasize the stark human rights abuses involved in human trafficking and the desperate need for effective policy to eliminate these abuses. Coming in a close second to those focused on human rights were members from the State Department who discussed human rights as well as efforts by other countries. Department of Justice (DOJ) and law enforcement officials were a minor presence, as were human trafficking victims.

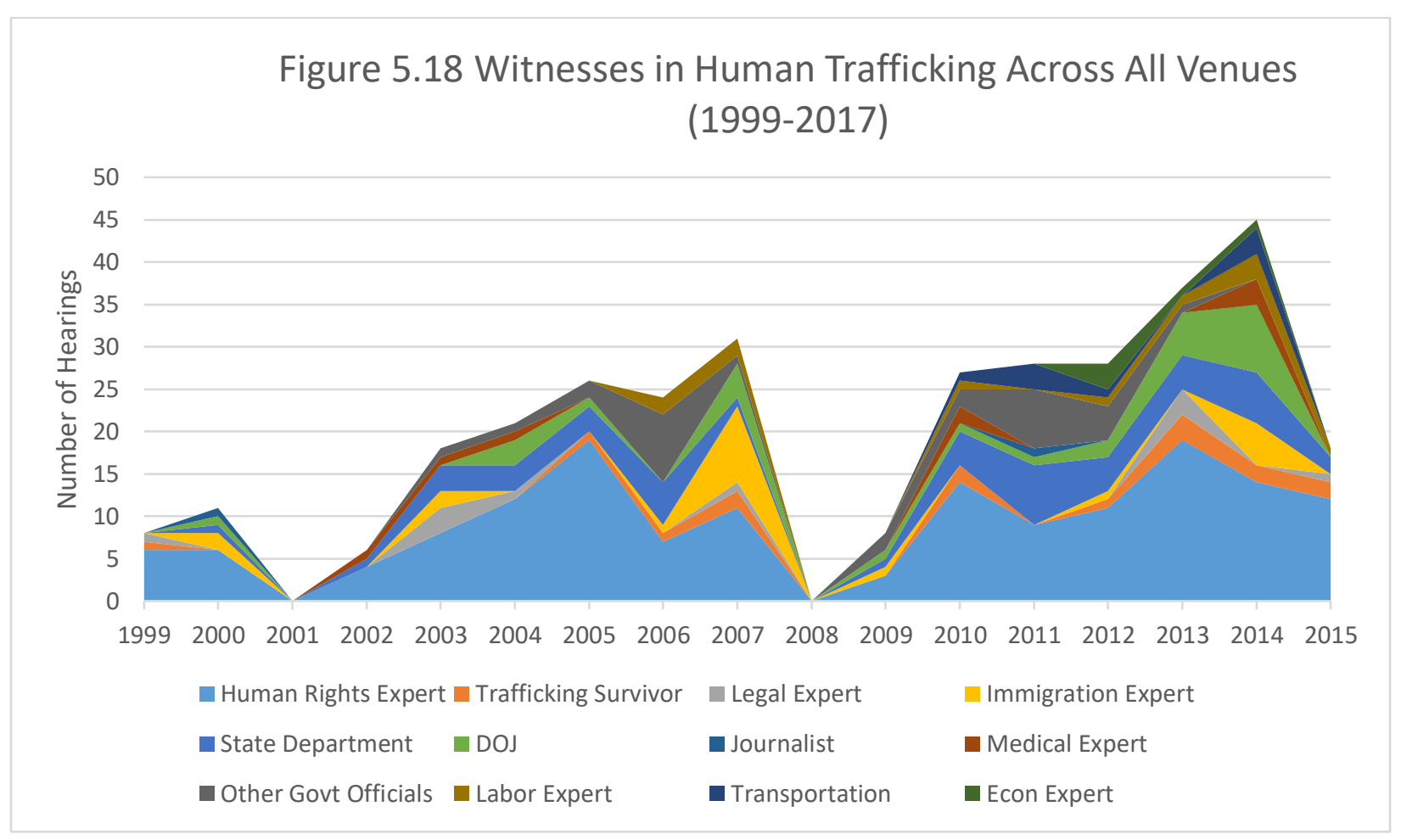




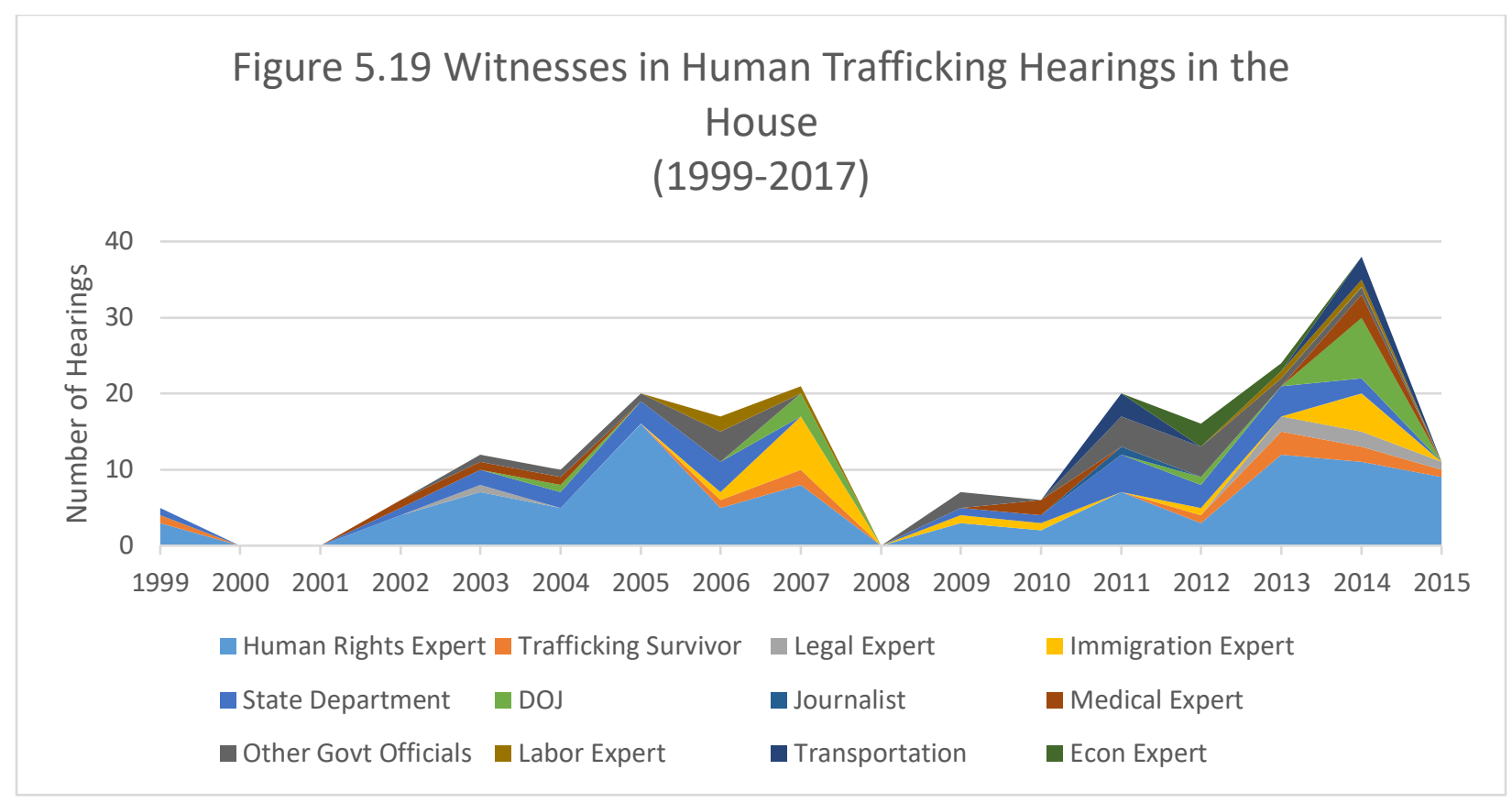

Figure 5.20 Witnesses in Human Trafficking Hearings in the Senate

(1999-2017)

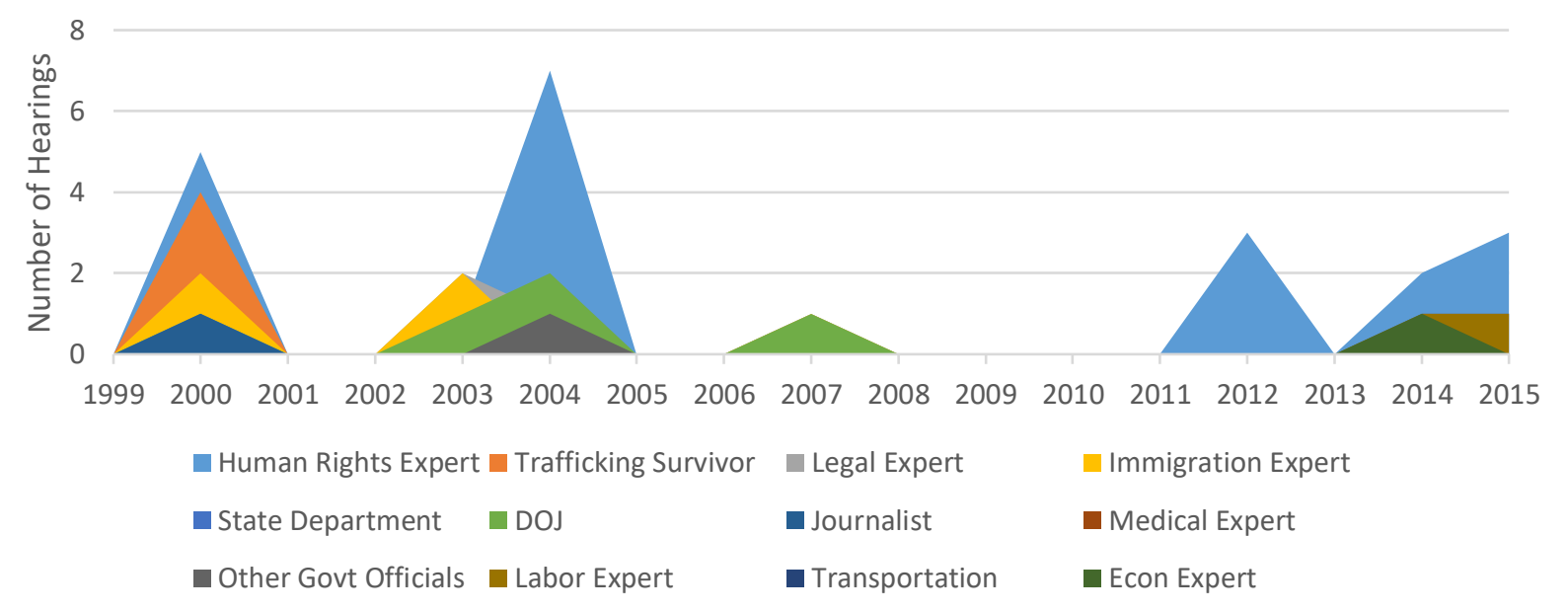




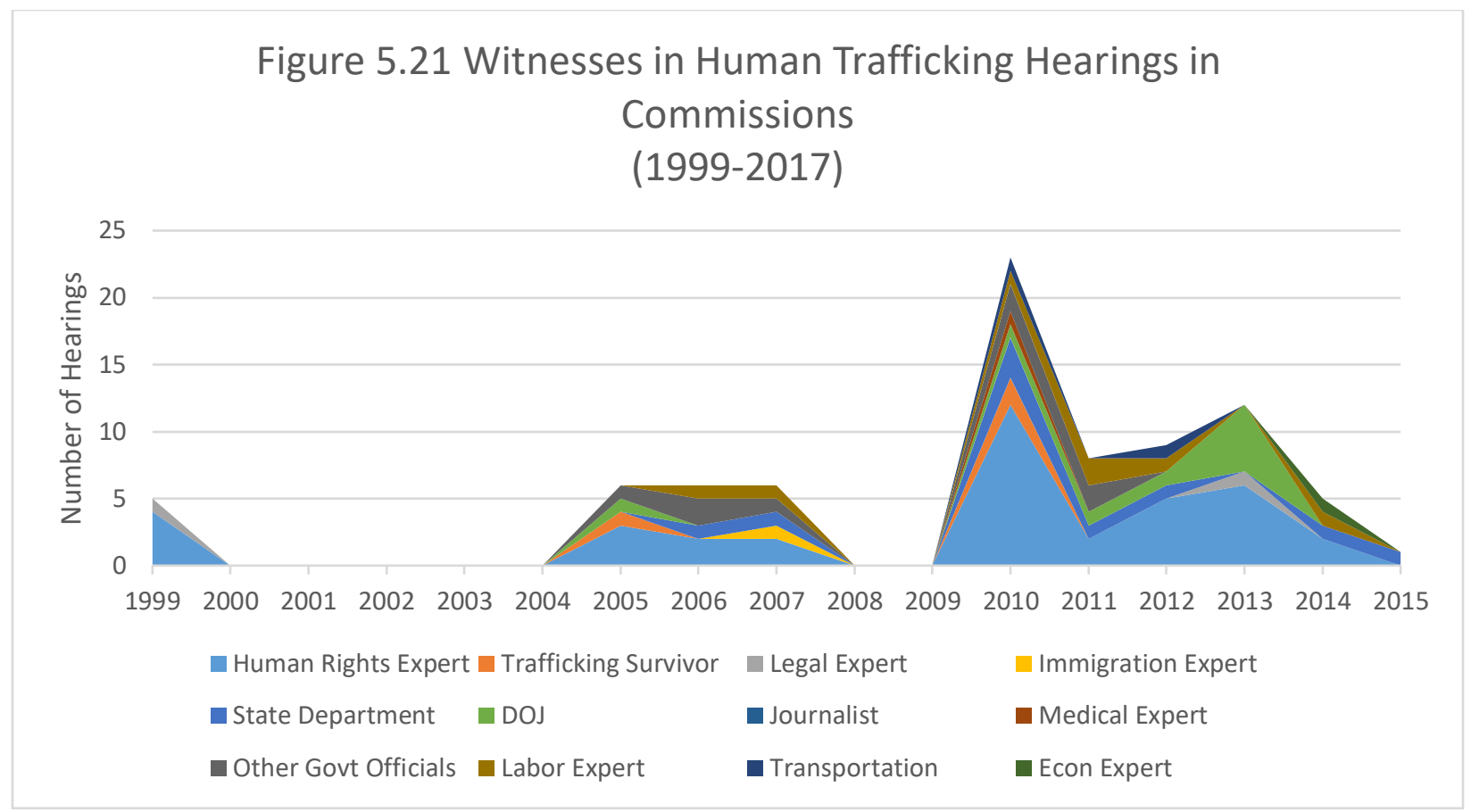

Figure 5.18 indicates that human rights experts are asked to attend hearings and share their expertise more often than other witnesses across all venues. Even when hearings are distinguished by venue-House, senate, and Commission — human rights experts are the most prevalent witness type. After human rights experts, State Department officials made up $14 \%$ of witnesses in the House, $8 \%$ in the Senate, and $11 \%$ in joint commissions. DOJ/Law Enforcement personnel constitute $6 \%$ of witnesses in the House, $10 \%$ in the Senate, and $11 \%$ in commissions. The other 9 witness types do not constitute a significant percentage of any of the three venues.

Witnesses that were asked to participate in hearings on human trafficking provide information as to the creation of legislation. It does not match up directly with the topic of hearings. The most used topic was one of criminal justice and crime prevention, with that information it would be expected that most of the witnesses would be members of the law enforcement community. Though that does not line up, it does explain other components of the TVPA. As mentioned previously in this Chapter there are many different parts of the TVPA, though there are criminal justice aspects there are also social services 
provided to victims of human trafficking (Barron, 1999). The many different facets of the TVPA would imply that there would be different focuses throughout the hearings.

\section{Conclusion}

Human trafficking suddenly moved onto the Congressional radar in the late 1990s. Seemingly out of nowhere, Christopher Smith sponsored a bill that became the Trafficking Victims Protection Act (TVPA) (Barron, 1999; Palmer, 1999). The TVPA, while a multi-faceted bill, tends to stress the criminal punishment of traffickers within the United States. No doubt because the media portrayed human trafficking as a criminal justice issue, Congress too stressed the criminal aspects of trafficking, even though the bulk of witnesses were human rights experts, who tend to think beyond the bounds of criminal law. It appears that when their testimony was filtered through the Foreign Relations committee the frame that dominated was the criminality of human trafficking, a frame easily assumed by Judiciary when they took up the issue after 2010. 


\section{Chapter 6- Sanctions as a Tool to Halt Human Trafficking}

\section{Introduction}

This research focuses on the effectiveness of the TVPA as the first legislation in the world to address all forms of domestic and international human trafficking. The TVPA was passed on October 28, 2000 which was one month before the United Nations Protocol to Prevent, Suppress and Punish Trafficking in Persons. The UN Protocol to Prevent, Suppress and Punish Trafficking in Persons was passed by the General Assembly on November 15, 2000. However, it was not authorized to "enter into force," until December 25, 2003 (United Nations, Treaty Collection, 2000). This international agreement is a supplement to the United Nations

Convention against Transnational Organized Crime which was passed in 2000. This international agreement was deemed to have the first "mutually agreed upon" definition of human trafficking.

The United Nations defines human trafficking as:

The recruitment, transportation, transfer, harboring, or receipt of persons by improper means (such as force, abduction, fraud, or coercion) for an improper purpose including forced labor or sexual exploitation (United Nations Department of Organized Crime, 2017).

At a glance it may not appear that this definition is any different than that found in the TVPA which defines human trafficking as:

(a) sex trafficking in which a commercial sex act is induced by force, fraud, and coercion, or in which the person induced to perform such act has not attained 18 years of age; or (b) the recruitment, harboring, transportation, provision or obtaining of person for labor or services, through the use of force, fraud or coercion for the purpose of subjection to involuntary servitude, peonage, debt bondage, and/or slavery (H.R. 3224, 2000). However the UN definition of human trafficking differs greatly from the TVPA. Under the United Nations definition, victims have vastly more avenues for legal and social protection. The UN definition does not explicitly leave out persons that have consented to illegal work or illegal actions in the process of being trafficked as does the TVPA. By wording the definition in 
such a way that includes all "force, abduction, fraud, or coercion," it provides much more leeway for individuals to seek justice than the limited definition of "force, fraud, and coercion" as found in the TVPA. A more precise way to compare these definitions is through a discussion of the legal frameworks of each definition (H.R. 3244, 2000; Protocol to prevent, Suppress and Punish Trafficking in Persons, Especially Women and Children, Supplementing United Nations Convention against Transnational Organized Crime, 2000; United Nations Office on Drugs and Crime 2017).

When comparing legal definitions, it is imperative that the means and the purpose of the legal precedent are examined. Both definitions involve recruiting persons, the movement of persons, harboring persons, or buying and selling of humans for the intention of trafficking them. Both definitions agree that the act of human trafficking is the same - meaning that they agree about the actions taken by traffickers that violate the law. The purpose, or reason for the crime, are also very similar throughout both definitions. They both define the purpose as exploitation either for sexual exploitation or labor exploitation even to the point of enslavement (H.R. 3244, 2000; Protocol to prevent, Suppress and Punish Trafficking in Persons, Especially Women and Children, Supplementing United Nations Convention against Transnational Organized Crime, 2000).

However, there is a difference in the two definitions when you examine them in the area of means precedent. The means of a law explains how an act becomes illegal. The TVPA claims that the act of trafficking persons becomes illegal when there is force, fraud, or coercion. This definition eliminates potential victims from any form of recourse or protection from the TVPA if they agreed to an illegal act (such as prostitution or illegal immigration). Under the TVPA definition, these individuals are not victims of human trafficking because they were not forced, 
coerced, or told fraudulent information. Unfortunately, this definition does not take into consideration those who may have been victims of recruiting, harboring, movement, or kidnapping (obtaining a person). The UN definition defines "human trafficking victim" in a way that, if adopted by a country, victims would have better access to legal recourse than the TVPA. The UN definition defines the means as threat or use of force, coercion, abduction, fraud, deception, abuse of power, or paying people in control of the victim. Under the UN definition, more victims are protected and able to seek legal recourse against their traffickers (Reiger, 2007; H.R. 3244, 2000; H.R. 3244, 2000; Protocol to prevent, Suppress and Punish Trafficking in Persons, Especially Women and Children, Supplementing United Nations Convention against Transnational Organized Crime, 2000; United Nations Department of Organized Crime, 2017).

Table 6.1 illustrates the differences between the two definitions in the both means and purpose between the TVPA and the UN.

Table 6.1

Legal Definition Difference Between the TVPA and the UN Protocol

\begin{tabular}{|c|c|c|c|}
\hline $\begin{array}{c}\text { International } \\
\text { Agreement }\end{array}$ & Act & Means & Purpose \\
\hline TVPA & $\begin{array}{c}\text { Can be defined as } \\
\text { recruiting, } \\
\text { harboring, moving, } \\
\text { or obtaining a } \\
\text { person }\end{array}$ & $\begin{array}{c}\text { Through force, } \\
\text { fraud, or coercion }\end{array}$ & $\begin{array}{c}\text { Involuntary servitude, } \\
\text { debt bondage, slavery } \\
\text { or sexual exploitation }\end{array}$ \\
\hline $\begin{array}{c}\text { United Nations } \\
\text { Protocol }\end{array}$ & $\begin{array}{c}\text { Recruitment, } \\
\text { transportation, } \\
\text { transfer, harboring } \\
\text { or receipt of persons }\end{array}$ & $\begin{array}{c}\text { Threat or use of } \\
\text { force, coercion, } \\
\text { abduction, fraud, } \\
\text { deception, abuse } \\
\text { of power or } \\
\text { vulnerability, or } \\
\text { giving payments } \\
\text { or benefits to a } \\
\text { person in control } \\
\text { of the victim }\end{array}$ & $\begin{array}{c}\text { Exploitation, which } \\
\text { includes exploiting } \\
\text { the prostitution of } \\
\text { others, sexual } \\
\text { exploitation, forced } \\
\text { labor, slavery or } \\
\text { similar practices and } \\
\text { the removal of organs }\end{array}$ \\
\hline
\end{tabular}


(H.R. 3244, 2000; Protocol to Prevent, Suppress and Punish Trafficking in Persons, Especially Women and Children, Supplementing United Nations Convention against Transnational Organized Crime, 2000)

\section{International Diffusion}

As previously noted, the TVPA was the first piece of legislation enacted in an attempt to combat human trafficking both domestically and internationally. Although it was the first internationally to address human trafficking, international diffusion took hold and it was soon followed by a flurry of countries adopting anti-human trafficking policies. Though there was not comprehensive human trafficking law until 2000, aspects of human trafficking had been outlawed throughout history. In 1904, the International Agreement for the Suppression of White Slave Traffic attempted to end the white slave trade. This focus was on how to end the sale of women for purposes of prostitution throughout Europe and the United States. This protocol was adopted by the League of Nations and then adapted and renamed The 1949 Convention for the Suppression of Traffic in Persons and Exploitation of Prostitution of Others by the United Nations. The 1949 protocol made owning a brothel illegal and the renting of property that becomes a brothel a criminal activity. In 1979, The Convention on the Elimination of all Forms of Discrimination Against Women (CEDAW) made prostitution and trafficking of women an illegal act. CEDAW forced countries who adopted it to eliminate trafficking and prostitution and encouraged them to have policies in place to reach that goal. Although the CEDAW was strongly worded, in reality, it only focused on sex trafficking and was difficult to enforce. In 1989, the Convention of the Rights of the Child was signed almost unanimously by all countries in the United Nations. This document made the selling, kidnapping, and trafficking of children illegal. This was amplified by the 1999 Convention to Eliminate the Worst Forms of Child Labor, which was brought by the International Labor Organization, making the trafficking of children illegal for the purposes of sex work (Defeis, 2004). 
The end of the Cold War brought with it the opening of borders and the intensification of globalization, resulting in an uptick in human trafficking. The trafficking of persons, which was once concentrated throughout Europe, is now dominated within the regions of Asia, Africa, and South America. The rise of human trafficking since the end of the Cold War left many countries ill-equipped to handle the influx of victims. In 1998, Argentina proposed a new convention to try and end trafficking in minors. Argentina's proposal was the first linkage of human trafficking to international criminal networks. This connection between human trafficking and international criminal networks led to it being adopted in the United Nations Convention against Transnational Crime (Defeis, 2004).

As noted earlier, there is a large difference between the UN Protocol to Suppress Trafficking and the TVPA. The definition of what trafficking persons meant was the most contentious part of the drafting of the UN Protocol. The main point of contention comes from whether or not all forms of prostitution should be protected or just forced prostitution. The United States felt strongly during negotiations that forced prostitution (as the TVPA defines) should be the only definition of sex trafficking acknowledged as human trafficking. A discussion of consent to determine the victims mattered greatly to the definition and creation of the UN Protocol. Many countries, as well as NGOs, focused on the victims claims that even consent at the beginning of trafficking does not mean consent could not be withdrawn at a later date. Those that consented to an illegal act could still be trafficked and should be protected by the law (Reiger, 2007)

The United Nations protocol consists of 172 parties and 117 signatories. One of the main components of both the TVPA and the UN Protocol was that, when adopted, a country was required to implement legal measures to halt the criminal activities involved in trafficking. As 
noted, the United Nations Protocol on Human Trafficking was entered into international law on November 15, 2000, but did not "enter into force" until December 25, 2003. During the 3 year time difference between signing and ratifying countries that were early adopters were encouraged to adopt punitive policies for traffickers as well as social services for victims. This time period was intended to allow countries adequate time to adjust their policies to be compliant with the UN Protocol. Throughout the past 16 years, 172 countries have ratified the treaty, including every permanent member of the United Nations Security Council (The United States, China, The Russian Federation, Great Britain, and France). There are 26 countries that have not ratified the UN Protocol. Those countries are Andorra, Aruba, Bangladesh, Bhutan, Burma, Comoros, Curacao, Iran, Kosovo, Macau, Macedonia, Marshall Islands, Nepal, North Korea, Pakistan, Palau, Papua New Guinea, Samoa, Sint Maarten, Solomon Islands, Somalia, South Sudan, Tonga, Vanuatu, and Yemen (Protocol to Prevent, Suppress and Punish Trafficking in Persons, Especially Women and Children, Supplementing United Nations Convention against Transnational Organized Crime, 2000). Although the TVPA also became law in 2000, it also did not provide any legal responses until 2003. This three-year time period was meant to allow states time to establish criminal justice policies as well as social services for victims of human trafficking (Protocol to Prevent, Suppress and Punish Trafficking in Persons, Especially Women and Children, Supplementing United Nations Convention against Transnational Organized Crime, 2000; Trafficking in Persons Report, 2001; H.R. 3244, 2000).

After the passage of the TVPA and the UN Protocol on human trafficking, the diffusion of human trafficking laws began as countries enacted various criminal laws to address these issues. However, as discussed in the US case, issue framing played an extremely influential role in the diffusion of this policy. Both the TVPA and the UN protocol, at least in part, frames 
human trafficking as a global criminal threat. The ability for punitive human trafficking policies to diffuse across borders, cultures, and development stages shows the strength of the frame adopted by the UN Protocol on Human Trafficking. Once human trafficking became a issue of crime that could happen in your back yard or community countries began adopting punitive policies. In Chapter Four I discussed how the media used certain frames to discuss human trafficking, such as law enforcement and policy, immigration/emigration, security, human rights and morality politics, and health concerns. Throughout these five frames, the most dominant frame in the US case was criminal justice. This is the exact frame that was used by the United Nations Protocol on Trafficking. In the end, the frames available in shaping the discussion of human trafficking across the world, criminal justice was able to grab the attention and lead to diffusion of human trafficking policy.

As international crime is seen as having a high level of negative externalities, solutions to problems like this become popular within countries that do not want to be affected by them. By framing the trafficking of humans as a problem with negative externalities persuaded countries to want to adopt measures to eliminate the problem. Linking human trafficking with international criminal rings threatened countries with a litany of other problems such as violence, drug trafficking, illegal immigration, and fraud was able to garner enough attention from world policy makers to make them concerned. Once this frame became used by international actors and governments, it began to spread as an international criminal issue which helped influence other countries to adopt similar policies (Lloyd et al, 2012; Defies, 2004, Finnemore and Sikkink, 1998).

When looking at the new norms regarding human trafficking that emerged in the postCold War period, I can utilize the norm life cycle developed by Finnemore and Sikkink (1998). 
Norms are often defined as acceptable behaviors by actors within a given situation. Though there is debate over what a norm is, particularly throughout international relations scholarship, there is agreement on the distinction of norms in the international system. For a norm to emerge on the international scene they must go through a three-step process. The first step is norm emergence. Norms are created through policy entrepreneurs. Policy entrepreneurs are individuals that take a stance against an ill in the world and bring light to the problem it creates. Building off the policy entrepreneurs in public policy literature were discussed and defined in Chapter Five, by seeing how and if that entrepreneur tries to spread the new policy outside of the United States. I claimed in Chapter Five that Representative Christopher Smith was the first and most prominent actor in creating the TVPA. The difference with norm life cycles through both the United States and the United Nations acted as these entrepreneurs in the issue of human trafficking. Both were responsible for dramatizing the issue and creating the frame that comes to dominate the discussion. In the instance of human trafficking, it was the framing of the issue in such a way that placed the focus on criminal justice rather than a country's views on the human rights components. Human trafficking was seen as affecting a country's economy, citizens, and crime, making it an important geopolitically issue.

The second stage is marked by a tipping point, which often takes the form of a cascade, in which powerful actors within the system accept and use the frame. Examples of this would be when a major actor like the United Nations, the European Union, or the United States adopts a policy. Such action influences others - either through soft or hard power- to also adopt the new norm, which results in a cascade and the norm becomes socialized throughout the world. Below this research will highlight four countries and their status of human trafficking protections, there will be a clear delineation around 2013 when almost every country begins to adopt some form of 
human trafficking legislation. One of the most important parts of the UN Protocol on Human Trafficking was the requirement of a country that ratified it, to adopt legislation to criminalizing it, as well as set up social services to help victims of human trafficking. Thus, as countries ratified the UN Protocol on Human Trafficking it led to the adoption of anti-trafficking policies all over the globe (Protocol to Prevent, Suppress and Punish Trafficking in Persons, Especially Women and Children, Supplementing United Nations Convention against Transnational Organized Crime, 2000; Lloyd et al2012; Defies, 2004). Norm internalization, the final stage in the cycle, occurs when the new norm becomes engrained in the life of most actors within the system. Those who do not adopt the norm are outsiders and as such are subject to penalties and ostracism adopted by most governments and international law (Finnemore and Sikkink, 1998 ).

\section{Sanctions as Punishment for Non-Compliance}

Although it is important to have international norms, it is also important for those norms to be enforced. After anti-human trafficking legislation became standard, international actors began to look for a way to punish those who did not adopt the same norm (Finnemore and Sikkink, 1998). Though this research has discussed in detail the domestic portions of the TVPA, this chapter is focused on the international and foreign policy implications of this legislation. Starting in 2001, The Trafficking in Persons Report is an annual report that describes the state of trafficking throughout the world. Each country in the world receives attention in a written report that explains their successes and failures in the area of combating human trafficking. Countries that are successful are deemed as allies in the fight against trafficking, while those that are unsuccessful are subject to sanctions by the United States. In the creation of this report, the State Department played many roles. The first was to explain the current issue of human trafficking internationally. Each year, the report explains the state of trafficking throughout the world, paying attention to criminal reports and if the act of trafficking is increasing or decreasing 
within each country. The report is also reports on the distinction between destination countries as well as countries where victims are sourced. The reports also track criminal prosecutions of major trafficking rings, while citing which policies were efficient at prosecuting criminals and which were not (Trafficking in Persons Report, 2017)

Chapter 5 briefly discusses the international component of this legislation, but it is not comprehensive. The TVPA itself is not strong enough to stop the worldwide problem of human trafficking. Christopher Smith (R-NJ) stated in press briefings and interviews that the United States would have to pressure other countries into adopting anti-human trafficking legislation. Though at the time it was hugely unpopular with President Clinton, the TVPA gave the executive branch the power to identify and punish countries that did not make strides against human trafficking in their own country. Congress decided that sanctions would be the best tool to pressure other countries to adopt similar provisions as the TVPA and the UN Protocol. Although sanctions were deemed the best tool, compromises with President Bush resulted on no sanctions placed on trade and the President's ability to waive these sanctions (Barron, 1999; Palmer 2000).

The Trafficking in Persons Report places countries performance on combatting human trafficking into three distinct tiers. Tier 1 is comprised of countries that are proactive at combatting trafficking - they have their own legislation and they have signed onto the UN Protocol to end human trafficking. Typically, the countries that are on Tier 1 are early adopters of the UN Protocol, states that are developed both economically and politically and have a strong commitment to prosecuting traffickers. Countries that have been on the Tier 1 list often are the United Kingdom, France, Germany, and Canada. The Trafficking in Persons Reports claims that these countries are what others should strive to be and are theoretically the most important allies in the fight against human trafficking. 
Tier 2 consists of countries that have made some strides in combatting human trafficking but have not reached the level of success as those in Tier 1. In between Tier 2 and Tier 3 is the Tier 2 watch list, which is comprised of countries that have been removed from the Tier 3 list for progress made on combatting human trafficking. However, to monitor this progress they will remain on the watch list for one year. Countries can also find themselves on the Tier 2 watch list if they are not providing adequate evidence that they are implementing policies needed to combat human trafficking, or the number of trafficking victims has increased from previous years.

Tier 3 countries are taking no legal actions to combat human trafficking or is either ignoring or promoting human trafficking and have more than 100 reported cases of human trafficking each year. These countries are subject to sanctions for all "non-humanitarian, nontrade-related foreign" assistance (Chaung, 2006, p. 452). Tier 3 countries are further defined as those that do not meet four important components. First, they are not prosecuting or punishing extreme violations of human trafficking. Second, when human trafficking involves children or sexual assault the punishment is incommensurable with the crimes committed. Third, having knowledge of instances of human trafficking and not addressing the issue or allowing them to go unpunished. Fourth, the government within Tier 3 countries fail to make a serious effort to eliminate human trafficking within and outside of their borders. The TVPA provides a remedy for countries to be removed from the Tier 3 list if they improve their approach to human trafficking within 90 days of the release of the report and if they fail to comply they are subject to unilateral sanctions by the President of the United States (Trafficking in Persons Report, 2001; Chaung, 2006). This portion of the chapter will focus on the effectiveness of these sanctions combatting human trafficking. 
Countries that fall under the Tier 3 category are subject to sanctions if they fail to comply with demands by the United States within 90 days of being identified under Section 110 of the TVPA. However, under Section 110 there are four subsections that allow the President to use discretion in the application of sanctions. Figure 6.2 provides Section 110 and the subsections that address the Presidential discretion in sanctioning countries designated as Tier 3 countries.

\section{Table 6.2}

\section{Powers Granted to the President in the TVPA to Sanction Non-Compliant Countries}

(1)Section 110 (D) (1) States that the President is able to sanction a country by withholding all nonhumanitarian and nontrade related assistance.

(A) The President can restrict nonhumanitarian and nontrade related assistance until they comply with the expectations of the TVPA

(ii) in a case where sanctions are already existed the President can cut any funding that may exist for cross cultural and educational practices that are meant to promote relations between the United States and the country in question.

(B) The President can instruct members of international banks and foreign assistance agencies to not send or help with development issues within the country.

(2) Section 110 (D)(2) The President can decide not to impose further sanctions on countries that are already being sanctioned due to human rights violations of another degree.

(3) Section 110 (D)(3) is a waiver the President can give to States that come into compliance within 90 days of being placed on the Tier 3 list.

(4) Section 110 (D)(4) is a waiver the President can use if there is a reason to believe that restricting nonhumanitarian and nontrade related assistance would infringe on a countries ability to halt human trafficking

(H.R. 3244, 2000)

The range of discretion varies from not imposing sanctions because it may slow down progress in a country's attempt to comply with the TVPA to not sanctioning a country because it would ultimately impact the most vulnerable members of that society, which, in turn, may make their citizens more vulnerable to human trafficking. The use of this discretion could be a great 
geopolitical strategy and appears to be especially the case in the use of Section 110 (D)(4)(1)(B), in which the President can decide to not sanction a Tier 3 country because of the invested interests of the United States. Unfortunately, like many forms of discretion, this practice has the potential of harming the cause it was intended to help.

Even if applied evenly and fairly, sanctions may not be the best tool to fight human trafficking. Economic sanctions have become increasingly popular since the end of the Cold War. With the 1990s move towards international cooperation, the ability for governments to enact unilateral, bilateral, and multilateral sanctions became a way for countries to try and influence behavior. This has become particularly true for issues that use to not make the radar such as humanitarian abuses or environmental degradation. Though sanctions were used more frequently in the 1990s it was not without its criticism. Sanctions are intended to be a short-term solution to try and influence behavior of other states, but do not have the best track record (Weiss, 1999). In a study done by Neuenkirch and Neumeier, in 2015 it shows that United Nations sanctions are effective at halting economic growth more so than US unilateral sanctions. As stated before, the TVPA allows the United States to unilaterally sanction a country for violating protocol. Though, not ineffective this policy may not apply the pressure needed to actually effect change.

Even if unilateral sanctions are able to damage the economies of countries being pressured, they have the tendency to not affect the violators of the policies that often. Sanctions can take many forms, but often sanctions tend to hurt the most vulnerable groups in society. Women, children, and the poor are more likely to feel the effects of sanctions through lack of food, humanitarian aid, or redistribution of wealth. Successful sanctions, like those applied to South Africa during the apartheid were not happening in a vacuum. On top of sanctions there 
were other acts of diplomacy and foreign relations that in combination with sanctions were effective at changing their policies. In other countries were all there was sanctions (Haiti), there were zero changes to policy. (Weiss, 1999; Neuenkirch and Neumeier, 2015).

Women, children and the poor are the most vulnerable members of society. They are more likely to be harmed by sanctions as well as are more likely to be trafficked. This creates a potential for policy disaster. If the most vulnerable members of society are going to be harmed, there is no way to ensure that victims of trafficking will not directly face ramifications for their countries behavior. In particular sanctions harm humanitarian efforts by both governments and NGOs, if sanctions are active on a country, it will make it more difficult to put the TVPA standards of protection, prevention, and prosecution in effect (Weiss, 1999).

Although sanctions could provide a valuable tool in combating human trafficking, it may not be as effective when both the ranking system of the TVPA and the application of the sanctions are arbitrary. As an example, what the State Department or the President deem to be significant progress in combating human trafficking is not something that is easily quantifiable. Since the President has full discretion over the sanctioning process their decision can come strictly from their world view or geopolitical interests. The research here analyzes if sanctions were in fact an effective tool at combating human trafficking abroad.

\section{Methods}

In this chapter, I examine the State Department's Trafficking in Persons Reports from 2003 to 2016 to ascertain the countries that were placed on the Tier 3 list and the Presidential decision for each of those countries. It will specifically address which countries were sanctioned and which were not. The decision on whether to sanction a country or not sanction a country 
were resolved in Presidential memos which will be cited below for the years 2003-2016. (Note the sanctioning provision of the TVPA did not go into effect until the year 2003.)

By examining Trafficking in Persons Reports from 2001-2016 data collected on which countries were designated Tier 3 by the State Department, this research will specifically note countries that were subject to sanctions from 2003-2016. A list of countries who have been in Tier 3 can be found in Tables 6.1-6.13 in the appendix. Using the information provided in the Trafficking Victims Reports and the annual Presidential Determinations on which countries would receive human trafficking sanctions under Section 110 of the TVPA, countries were placed into one of four categories.

1) Sanctions: a country fully sanctioned via Section 110 (D)(1).

2) Sanctions with exceptions: a country sanctioned, but through exceptions for either democracy promotion or cross-cultural educational programs to help increase relations between them and the United States. Section 110 (D)(2)(ii) allowed the president to strengthen sanctions or alleviate sanctions under this provision.

3) Sanctions would harm progress: a country deemed to have vulnerable populations too high to sanction due to fear that those sanctions would increase human trafficking. The President is granted full discretion in this matter under Section 110 (D)(4).

4) Sanctions hurt national interest: a country that is geopolitically important to the United States either through natural resources, allies in the War on Terror, or provides some geopolitical significance. The President is granted full discretion in this matter under Section 110 (D)(4)(1)(B).

This research is highlighting one country that consistently fell within each of the four categories listed above to ascertain if sanctioning (or lack of sanctioning) was helpful in combating human trafficking. First, Cuba will be examined as a country that was consistently 
sanctioned by the United States. Second, Venezuela will be examined as a country that had sanctions with exceptions. Third, Sudan/ South Sudan will be examined as a country given an exception to the sanctions as there was a fear those sanctions would lead to the worsening of trafficking. Finally, Saudi Arabia will be examined as a country that was not sanctioned as a concern existed that sanctions would harm United States national interest.

\section{Case Studies}

\section{Cuba}

Cuba is both a source and destination country for victims of human trafficking. Cuba is afflicted by all forms of trafficking: sex trafficking, child trafficking, and labor trafficking. Cuba is explicitly impacted by child trafficking for sexual exploitation. Cuba was ranked on the Tier 3 list by the Trafficking in Persons Report from 2003-2014, and moved to the Tier 2 Watchlist in 2015 and 2016. Cuba was systemically sanctioned by the United States during the years of 20032014 (Trafficking in Victims Report, 2003-2016).

The Trafficking Victims Protection Act outlines three ways each country can meet the standards set by the legislation. These three ways are prosecution, prevention, and protection. Prosecution refers to the way in which the country criminally deals with human traffickers and if their legal code is set up in a way to substantially convict these criminals. Cuba had within their legal code a provision that states that trafficking of persons for the use of prostitution is illegal. An important caveat to Cuba is that prostitution is legal for anyone above the age of 16 . Prostitution in Cuba is a state-run and regulated industry, meaning that sex tourism is often promoted by the government itself. The Trafficking in Victims reports from 2003-2005 claimed that the state promotion of sex tourism, particularly of those below the age of 16, had made Cuba an incubator for sex trafficking, particularly of children. Cuba reported no attempts or 
prosecutions of human traffickers between 2003 and 2013. Although there may have been criminal prosecutions, the Cuban government failed to report that information (Trafficking in Victims Report, 2003-2016).

Protection is another area in which Cuba fails to meet the minimum standards of the TVPA. Protection refers to what programs or policies governments have in place to keep victims of human trafficking safe, and providing necessary social services. Cuba did not provide social services to victims of human trafficking. They sometimes offered "reeducation" programs for women and child prostitutes, but there is no actual safety net for persons who have been victims of trafficking. Another problem with the Cuban system is that when there are crack downs of prostitution or human trafficking, the victims are often criminalized for their participation in these acts. Cuba also does not allow NGOs, who often assist victims, into their country. Cuba also limits free speech and freedom of the press, so journalists cannot promote or talk about the problems of human trafficking that are facing Cuba, including limited information on the human trafficking sanctions placed on them by the United States (Trafficking in Victims Report, 20032016).

Cuba failed to report any progress in the area of preventing human trafficking as well. From 2003-2013 Cuba did not provide any required information to the United States to avoid being sanctioned. Although prostitution is legal in Cuba they did not provide any information on steps being taken to avoid human trafficking, or exploitation of minors. Cuba during these years never recognized human trafficking as a problem they were facing. The Trafficking in Persons report claims that it took many years (until 2015) for Cuba to even recognize that human trafficking happened both within and outside of their country. In 2015, Cuba had failed to report or keep statistics on human trafficking or even admit that human trafficking was a problem, 
perceiving the sanctions as an attempt by the United States to control their domestic policy. Cuba claimed that the United States should focus on its own problem of human trafficking before they tried to legislate other countries actions (Smith, 2014; Trafficking in Victims Report, 20032016).

In the Trafficking in Persons report of 2015 and 2016, Cuba moved up to the Tier 2 Watchlist. This move to the Tier 2 Watchlist shows that there was a proactive effort by Cuba to change its human trafficking policy. In 2014 under President Obama it was announced that the United States would restore full diplomatic ties with Cuba. After than announcement and diplomacy Cuba begins to enact comprehensive and punitive human trafficking legislation (Baker 2014; Trafficking in Persons Report, 2016). The 2015 report claims that there was a dramatic change in the prosecution of human trafficking within Cuba. Cuba reported in both 2015 and 2016 that they had prosecuted over 10 cases per year, most of them focused on child trafficking within the sex industry. Cuba during these years also put in place police training to help prosecute as well as protect victims of human trafficking. Throughout 2015 and 2016 Cuba also stopped arresting and prosecuting victims of human trafficking. Cuba set up a national hotline for victims to access, as well as citizens who felt they had information on potential human trafficking problems (Trafficking in Victims Report, 2003-2016).

Though there was progress throughout 2015-2016, Cuba is still faced with the problem of labor trafficking. The Trafficking in Persons reports during this two-year time period shows some improvement in prosecution, protection, and prevention, it still shows that the Cuban government has made no improvements in the area of labor trafficking. In addition, Cuba is also a source country for victims, particularly human smuggling victims. Many Cubans choose to flee the closed political and economic situation of their country, often at the hands of a trafficker. 
Once these citizens reach their destination country they are then indebted to their trafficker.

Though Cuba has made some progress, there are still many areas in which they are not attempting to combat human trafficking as required by the TVPA (Trafficking in Victims Report, 2003-2016).

Sanctions did not seem to have any affect on human trafficking policy in Cuba. They were sanctioned from 2003-2014, and those sanctions never influenced them to change their policies. Only when relations began to thaw was there any admittance to the issue of human trafficking affecting Cuba.

\section{Venezuela}

Venezuela is a both a source and destination for human trafficking. Brazil intelligence once claimed that there are 10 designated routes through Venezuela that major international criminal networks used to transport persons for sex and labor trafficking (Trafficking in Victims Report, 2003). Similar to Cuba, sex work is a legal enterprise that is regulated by the government. Sex tourism particularly that of minors was a major contributing factor to Venezuela being placed in the Tier 3 list(Trafficking in Victims Report, 2003-2016).

Venezuela moved the most among the possible tiers determined by the TVPA in the period between 2003 and 2016. During these thirteen years, Venezuela moved from Tier 3 to the Tier 2 Watchlist, only to find itself back on the Tier 3 list. In 2003, Venezuela was firmly placed in Tier 3, since Venezuela had no policy to combat trafficking in any form and had no prosecutions or arrests of human traffickers. During this time, Venezuela was showing no signs of cooperating with either the United States or the United Nations on ending their role in human trafficking (Trafficking in Victims Report, 2003-2016).

In 2004, Venezuela passed the Naturalization and Immigration Law which made trafficking for the purposes of sex work illegal. The same year they also passed the Child 
Protection Act which was intended to protect children from trafficking and other forms of violence. It is important to note that corruption at all levels of the legal system is dominate in Venezuela and even when arrests or crackdowns happen they do not always end up in prosecutions (Trafficking in Victims Report, 2003-2016).

In 2005, Venezuela shows signs of complying with the TVPA. They passed the Organic Law Against Organized Crime which was intended to target human traffickers. In addition they initiated a state run information campaign on the dangers of human trafficking. State run television showed advertisements on human trafficking prevention, pamphlets and posters were produced and distributed by the Venezuelan government, and, for the first time, law enforcement received training on the crime of human trafficking. Although these actions were a major step in combating human trafficking, they proved not to be truly effective as the enforcement and punishments were extremely lax (Trafficking in Victims Report, 2003-2016)

In 2007 Venezuela shifted drastically in the way it dealt with human trafficking. They passed the Right of Women to a Violence Free Life. This bill explicitly inhibited human trafficking of women and children. This was the first piece of legislation that directly addressed human trafficking by the Venezuelan government, it was perceived as both strict and containing severe punishments. This piece of legislation provided a penalty of up to15-20 years in prison fo the trafficking of persons. In addition, it targeted both the domestic and international aspects of human trafficking. With the Right of Women to a Violence Free Life in legal code, 2008 Venezuela moved off of the Tier 3 list for the first time and is placed on Tier 2 Watchlist. Venezuela stayed on the Tier 2 Watchlist until 2016 (Trafficking in Victims Report, 2003-2016) For one year (2011), Venezuela moved back to Tier 3, even though the Right of Women to a Violence Free Life was intact, there were hardly any arrests or prosecutions. One of the main 
reasons the Venezuelan government was seen as not complying with the United States or the United Nations in the area of human trafficking is that they failed to collect and report data on arrests and prosecution of traffickers. Without accurate data it is impossible for outside countries or agencies to know if the laws in place are effective in combating human trafficking. For the next five years Venezuela moves back and forth from Tier 3 to Tier 2 Watchlist (2012,2013 Tier 2 Watchlist; 2014-2016- Tier 3). The shift in 2012 and 2013 form Tier 3 to the Tier 2 Watch list was the result of the amendment of men and boys to the Right of Women to a Violence Free Life legislation. Venezuela like Cuba faces an uphill battle in complying fully with the TVPA as they refuse to acknowledge labor trafficking, and in that refusal, fail to enact specific policies to address that prevalent problem (Trafficking in Victims Report, 2003-2016).

Sanctions did not appear to have any effect on Venezuela's human trafficking policies. Though some tensions eased with the end of the Bush Administration and the beginning of the Obama Administration the threat of limited sanctions did not seem to influence their policy decisions. Though they were proactive in passing policies, they did not have the infrastructure in place to see those policies through to implementation. Being sanctioned with exceptions did not seem to scare or influence them to make anti-trafficking policy at the forefront of their decisionmaking process.

\section{Saudi Arabia}

Saudi Arabia is both a source and destination country for human trafficking. Unlike the other countries discussed in detail most of the human trafficking offenses that happen in Saudi Arabia are labor trafficking. Saudi Arabia remained on the Tier 3 list from 2005-2014. Although they remain on the Tier 3 list during this time period, they did not receive sanctions at any point. This is the result of the geopolitical significance of Saudi Arabia. Saudi Arabia has massive oil 
reserves and is head of the Oil and Petroleum Exporting Countries (OPEC) which controls oil prices throughout the world. Saudi Arabia is also a military ally in a region that is typically hostile to Western influence (Shupac, 2016).

In 1962, Saudi Arabia banned the practice of slavery, but has failed to enact specific legislation addressing human trafficking. Although this ban of slavery existed instances of abuse of migrant workers remained and controls the narrative of human trafficking in Saudi Arabia. Saudi Arabia faces accusations of failing to protect their citizens who abuse migrant workers. The TVPA reports that Saudi Arabia failed to protect its migrant workers from unsafe working conditions, violence and slave labor (failing to pay workers). Saudi Arabia responded to these allegations and the lack of specific legislation by claiming that Sharia Law inherently made both sex and labor trafficking illegal (Trafficking in Victims Report, 2003-2016).

Although Saudi Arabia did not feel they needed any further legislation to address the issue of human trafficking, they were active in the area of protection and prevent protocols. Saudi Arabia had "Welfare Camps" for women and children who were victims of human trafficking. Though these camps existed there was no infrastructure in place to identify victims, to provide specific services to help victims, or to provide legal recourse. In addition, Saudi Arabia during this was actively engaged with other countries in combating he problems associated with human trafficking. They worked jointly with the United Nations and Yemen to help stop child trafficking. They worked with the governments of the Philippines and Sri Lanka, in providing information on human trafficking to migrants that would become laborers in Saudi Arabia. In addition, prominent religious leaders within Saudi Arabia give speeches and encouraged Imam's throughout the country to explain how the abuse of employees violated the Quran (Trafficking in Victims Report, 2003-2016) 
In 2009 Saudi Arabia caved to international pressure and created a National Plan to Combat Trafficking. In this legislation they placed real punishments for violators of trafficking. Violators could receive up to 15 years in prison or a fine up to $\$ 266,500$ dollars. Although the Saudi government enacted strong legislation in the area of human trafficking, it becomes clear the legislation will not be enforced in a serious way. Reports from the TVPA reports show that Saudi Arabian officials typically tried to get victims to settle for monetary payments instead of pursuing criminal prosecution. Although the law was in place, many other countries took notice of the lack of enforcement limited their citizens from working in Saudi Arabia. As an example, India banned their female citizens under the age of 40 from becoming a migrant worker in Saudi Arabia due to the continued abuse of migrant workers (Trafficking in Victims Report, 20032016).

Although Saudi Arabia is slow in the prosecution of human traffickers and abusers of migrant workers they shift in compliance in 2014. In 2014 Saudi Arabia prosecuted 52 cases and punished 68 offenders for human trafficking. In 2015 and 2016 they arrested over 283 suspects and held many trials to convict abusers. In 2015 and 2016 the TVPA recognizes Saudi Arabia for making major progress in the prosecution of human trafficking, however there is no evidence that any progress was made in labor trafficking as the Saudi government insisted it was covered by Sharia Law (Trafficking in Victims Report, 2003-2016).

Saudi Arabia is an interesting case, they have appalling instances of human trafficking and slave labor but waited to adopt anti-trafficking policies. Being placed on the Tier 3 list seemed to encourage them to pass any new legislation until the norm was reaching the tipping point status. After many other countries throughout the world began punishing Saudi Arabia by not sending their citizens there to work was there a change to their policies. Saudi Arabia is too 
important of a geopolitical actor (Council on Foreign Relations, 2017) to sanction, even if they have committed awful human trafficking violations.

\section{Sudan/South Sudan}

Sudan is a source and destination country for human trafficking. Sudan suffers from both international traffic and domestic trafficking. Sudan suffers from almost every inconceivable impact of human trafficking. The TVPA reports that the worst forms of human trafficking occurs in Sudan. This ranges from the use of child soldiers, as well as the trafficking of child soldiers into Uganda to join the Lord's Resistance Army (LRA) in Uganda, to the abduction by neighboring tribes for sexual slavery. As the country of Sudan has been in involved in a major civil conflict for the majority of the past 13 years. This ongoing civil conflict appears to have exasperated all the negative impacts of human trafficking. Though they were placed on the Tier 3 list, Sudan never faced any sanctions due to the fact that it was felt they would be worse off if they were sanctioned (Trafficking in Victims Report, 2003-2016).

Throughout this tumultuous time Sudan does attempt, at times, to alleviate some of the negative impacts of human trafficking. In 2003, Sudan cut formal ties with the LRA as a means to help eliminate the trafficking of child soldiers. Although they cut ties with the L.R.A, the relationship and the trafficking of Sudanese children by the LRA continued. In 2006 Sudan took a stance against another form of child trafficking, trafficking for the purposes of camel jockeying in Qatar. Sudan not only made it illegal, they also informed citizens about the dangers and abuse that their children would face if trafficked for camel jockeying (Trafficking in Victims Report, 2003-2016).

Similar to Saudi Arabia, Sudan felt as if they did not need to create specific legislation to address human trafficking as they were perceived to be covered by Sharia Law. Though they 
thought that, they also cave to international pressure by sponsoring the Committee for the Eradication of the Abduction of Women and Children (CEAWAC). This committee was created in 2007 with the purpose of combating human trafficking for the purposes of sexual slavery. Although this Committee exists it does provide legal ramifications for violators of trafficking. This has resulted in the inability to halt trafficking, and for international pressures for a stricter act that provides appropriate legal actions for violators of human trafficking (Trafficking in Victims Report, 2003-2016).

Sudan was, and in many ways still is, in crisis so there was a lot of international attention paid to Sudan. Sudan had a large presence of development NGOs, as well as programs like UNICEF active in their country in an attempt to help alleviate some of the problems associated with the ongoing civil conflict. One of the ways these NGOs and international organizations helped Sudan was through setting up Joint Tribal Communities, which became a part of the CEAWAC. These Communities were used to try and settle disputes as well as criminalize forms of trafficking. In these tribal communities, trafficked persons were often returned to their villages, even if there was no punishment for the traffickers. Throughout the years CEAWAC was at times funded upwards of 1.8 million dollars, while other times it was not funded at all (Trafficking in Victims Report, 2003-2016).

In 2011, South Sudan became an independent country with its own set of human trafficking issues. From 2013-2015 South Sudan remained a part of civil conflict which resulted in the abduction and trafficking of persons in many different forms. This includes the sex trade, trafficking in child soldiers, and labor trafficking. South Sudan was also placed on the Tier 3 list but also not sanctioned as the concerns expressed by the United States government for Sudan applied to South Sudan as well. 
Sanctions would not have mattered in the case of Sudan/South Sudan. Civil conflict led to the rise of human trafficking for everything from child soldiers to sexual slavery. Economic sanctions would not have altered the state of trafficking within Sudan, though they did feel international pressure to adapt and changes policies over time much of that was for other forms of humanitarian aid.

\section{Discussion}

This chapter was designed to ascertain the effectiveness of the sanctioning provision of the TVPA in combating human trafficking abroad and addresses the ineffectiveness of the TVPA both domestically and internationally. The data above clearly illustrates that most of countries placed on the Tier 3 list were either given exceptions to the TVPA sanctions or were simply not sanctioned year after year. It would be difficult to accept that the inconsistencies and arbitrary way sanctions were or were not imposed did not impact the effectiveness of the TVPA abroad and ultimately leading to the international community not taking the sanctions seriously.

An excellent example of the arbitrary application of these sanctions was in 2003 . The countries that received full sanctions that year (Burma, Cuba, and North Korea) were those that were already sanctioned by the United States or had no diplomatic relationship with the United States. Although those countries could be seen as complicit in combating human trafficking, so were countries such as Sudan. However, when Sudan was addressing the crisis of pervasive genocide in Darfur, the United States (with sanctions already in place for humanitarian reasons and Sudan's ties to terrorist organizations), did not apply TVPA sanctions. Instead, the Bush Administration placed Sudan under the category of harming their progress in fighting human trafficking. The Sudanese government was accused of arming militias during this conflict that ultimately spread violence throughout the entire region. It would be difficult to assume that any 
extra funding given to the Sudanese government would have been used to combat human trafficking, particularly since the government itself was complicit if not actively involved in the violence. Not only was Sudan a permanent member of the United Nations Security Council, but China and Russia which were considered geopolitical assets to the United States, had strong ties to Sudan making unilateral sanctions even more unpopular. Additionally, the United States was not willing to take a stance on the crisis happening in Sudan and ultimately both of these issues were deemed more important than halting human trafficking in Sudan (Associated Press, 2012; Bush, 2003; Reuters, 2017).

Although the Trafficking in Persons Report is supposed to be unbiased, the lack of consistency in the way in which sanctions were placed on certain countries questions the credibility of the sanctioning process as a way to combat human trafficking. As an example, during the Bush Administration sanctions with exceptions were placed on Venezuela in all but one year. Even though the Venezuelan government provided information on the political steps they were enacting to combat human trafficking, as well as the detrimental impact of the loss of 1 billion dollars in loans and assistance on their progress in combatting human trafficking, they were consistently sanctioned (Jones, 2004; Stout, 2006; Reuters, 2017).

How can one justify sanctioning Venezuela but not Sudan? Even taking into account the undemocratic regime in Venezuela, the Sudanese government (also an undemocratic regime) was actively participating in the genocide of its own citizens. During this civil conflict in Sudan persons were trafficked throughout the country, as well as neighboring countries mainly for sexual exploitation. The abuses happening in Darfur even rose to the attention of the United States House of Representatives. Representative Frank Wolf from Virginia, during a 2004 meeting of the House of Representatives, railed on Sudan's complacency in sex trafficking of 
young women both in and out of their country (Tatum, 2010). However, the Sudan remained unsanctioned.

Another country that appears on the Trafficking in Person Report as a Tier 3 country consistently is Saudi Arabia. Although they are not placed on the Tier 3 list until 2005, they remain on the list for 10 years. During the 2005-2014 time period, Saudi Arabia was placed on this list for their extreme lack of human trafficking policies. Saudi Arabia is cited in the Trafficking in Persons Reports as a destination country with a large presence of indentured servitude. They are also cited as having prosecutorial practices that were extremely biased against victims by not allowing them to work after they filed a complaint and at the same time not allowing access to government assistance until the trial was over. This made it almost impossible for victims to be able to confront their abusers. In addition, the report claims that the Saudi Arabian government had put little to no effort in reforming their criminal justice system to help victims or to address human trafficking; however they were never sanctioned (Trafficking in Persons Report, 2005-2014).

Though Saudi Arabia would remain on Trafficking in Persons list for 10 years, there is no evidence they made any effort to change or reform their policies to benefit human trafficking victims or combat human trafficking. Both the Bush and Obama Administrations reported that Saudi Arabia was not sanctioned because of their continued support and military effort in the global War on Terror (Bush, 2005-2008). However Saudi Arabia is also a powerful international actor, particularly in natural resources. Saudi Arabia accounts for $40 \%$ of the world's petroleum exports and the risk of breaking ties by sanctioning them for violations of the TVPA would not be in the best geopolitical interest for the United States (Schiavenza, 2015). 
Notably, Saudi Arabia is removed from the Tier 3 list in 2015 by the Obama Administration. President Obama does not provide a specific reasoning for this removal and there is no evidence of progress in combatting human trafficking in Saudi Arabia had taken place. Although President Obama's administration increased the number of countries listed as Tier 3, they did not deviate in the application of full sanctions from the previous administration (Obama, 2008-2016).

The Obama Administration—like the Bush Administration—consistently overlooked violations of the TVPA in countries they perceived as allies in the War on Terror. This is evidenced by the three countries that appeared on the Tier 3 list that were never sanctionedSaudi Arabia (10 years), Kuwait ( 8 years), and Algeria ( 8 years). All three of these countries are reported to be destination countries for labor trafficking. Additionally, all three of these countries failed to provide victims timely prosecuting of their abusers or assistance from social services. Although Algeria and Kuwait spent some years on the Tier 2 watch list, Saudi Arabia spent 10 straight years on the human trafficking Tier 3 list without any repercussion at all (Trafficking in Persons Reports 2001-2016). If the TVPA has any hope of being taken seriously or of being effective on the international stage sanctions, it must be applied consistentlyregardless of the countries' geopolitical connection to the United States.

In additional to giving special provisions for allies, the ability to give a waiver to countries that may face economic hardship that would negative impact their ability to halt human trafficking is also a not consistent decision. Many of these countries that are on this list are developing countries or countries that are recently democratized or came to existence. Though looking out for vulnerable populations that would be likely hurt by sanctions is important in effective foreign policy, what makes one country's vulnerabilities more forgivable than others? 
What is the different between Eritrea which received many sanctions over the years and the Gambia? Geopolitical relations matter the most when it comes to handing out sanctions. Because the United States already had negative relations with Eritrea, they were sanctioned more than countries committing similar abuses. Venezuela is also an excellent example of this as they were sanctioned and had special provisions stopping foreign investment in their country due to lack of relationship with the US. When you read Venezuela's Trafficking Report it is not much different than others on the list that continued to get waivers over time. If all that matters is the United States' relationship with the country, why would any government take the threat of sanctions seriously? Not only were sanctions ineffective in halting human trafficking, they were often used as another means to punish those already punished.

\section{Conclusion}

The creation of the TVPA was intended to provide domestic and international remedies to the problem of human trafficking. Domestically the TVPA was intended to be a strong criminal justice legislation that punished traffickers, while provided necessary social services to their victims. Internationally the TVPA was supposed to apply pressure to countries who have lax human trafficking regulations (Barron, 1999; Palmer, 2000).

The way the TVPA was going to accomplish international pressure is through the ability to unilaterally sanctions countries that violated the worst forms of anti-trafficking legislation. Countries that did this were placed on a Tier 3 list, and could face sanctions within the same year of falling on this list. The President reserved the right to not sanction countries on the list, to sanction with exceptions, no sanction due to the fear of worsening financial desperation that exasperates trafficking, and not sanction because of national interest (Barron, 1999; Palmer, 2000; H.R. 3244, 2000). 
Throughout the 13 years' sanctions were available (2013-2016) very few countries actually faced full sanctions. One of them was Cuba, who experiences almost 10 years of human trafficking sanctions, it did not seem to speed up their adoption of policy. Venezuela was sanctioned with expectations for a majority of the past 13 years, and those not as strict as to what was applied to Cuba still resulted in the same outcome, policy changes happened when they happened and did not seem to be influenced by United States sanctioning policy. Saudi Arabia, who was a member of the Tier 3 list for over 10 years never received a sanction. Due to their geopolitical status, they did not fear the facing of any sanctions since it was clear early on in the TVPA that they would not face any restrictions due to their alliance with the United States.

Finally, Sudan/South Sudan, these two countries have been in the midst of conflict for a majority of the past 13 years. This conflict enhanced all forms of trafficking. Though they were violators of trafficking sanctions were not placed on them due to the fear it would make the situation worse for those who are most vulnerable. Sanctions were not used routinely enough to place legitimate fear in violators of trafficking policy, therefore sanctions were not an effective policy tool at halting human trafficking. 


\section{Chapter 7- Conclusion}

Although the act of human trafficking is not a new problem, its appearance on the public and government agendas was unusually sudden. This research borrows from public policy studies to understand the origins and passage of the TVPA. Most of the focus of the literature on the TVPA and human trafficking is in feminist legal studies, criminal justice, or sociology. This study provides a bridge between these and the field of public policy, with a focus on how the issue was framed by the media and Congress, which in turn shaped the manner in which it was implemented. The dominant theme in previous literature addressing human trafficking is that the TVPA is ineffective at providing any real, lasting solutions to the problem. As such, the TVPA presents a classic problem of implementation (Pressman and Wildavsky 1973). One of the main concerns throughout this research project was identifying the factors that played a role in the creation of the TVPA, since implementation problems are often at their heart associated with earlier stages of the policy process (VanMeter and VanHorn 1975; Rein and Rabinovitz 1978; Mazmanian and Sabatier 1983).

The discussion of human trafficking is a relatively recent phenomenon in both the American press and Congress. Indeed, congressional interest is non-existent until a year prior to the passage of the TVPA in 2000, while popular and professional media attention was sparse at best in the decade prior to the passage of the act. This study suggests trafficking did not involve the normal softening up process associated with agenda entrance, instead, because it was a valance issue the legislative process was quick. Some scholars argue the TVPA has been a massive public policy failure, which I suggest may be due to the speed of its passage. To be considered a victim under the TVPA, one could not have consented to any illegal activity at any point throughout the process and must cooperate fully with all attempts to prosecute their 
trafficker (Chacon, 2006; Sadruddin et. al, 2005). Clearly this framing of what constitutes a victim has left many unprotected, locked policy into a criminal justice mode, and produced less than ideal results from the vantage of a human rights and victim's rights perspective.

The TVPA contained by a domestic and international focus, with the latter clearly influencing the UN Protocol to Prevent, Suppress and Punish Trafficking in Persons which was passed following the enactment of the TVPA. A problem early on with the TVPA on the international stage was the disjuncture between the definition of trafficking and victims in the two acts. The UN definition does not explicitly leave out persons that have consented to illegal work or illegal actions in the process of being trafficked, as does the TVPA. This difference presented a mixed message to the international community, not to mention problems in the US. International diffusion of the UN Protocol was relatively swift eventually including 172 parties and 117 signatories (Protocol to Prevent, Suppress and Punish Trafficking in Persons, Especially Women and Children, Supplementing United Nations Convention against Transnational Organized Crime, 2000; Trafficking in Persons Report, 2001; H.R. 3244, 2000). Problems arose when US Presidents used their discretion to unilaterally sanction countries in a fashion that fit with the TVPA but not the UN Protocol. Even more damaging in terms of implementation was the tendency of the US to excuse behavior by allies that violated both acts. Presidents were allowed to overlook violations of the TVPA if citing an offender might endanger vital national security interests. This research illustrates that the inconsistences in the use of this provision by both the Bush and Obama Administrations has resulted in rendering the sanctioning provision ineffective in combatting human trafficking. The inconsistencies in the definition of human trafficking and the Presidents' use of Section 110 of the TVPA makes it difficult to assess the effectiveness of the TVPA on the international stage. 
This research adds to the literature on human trafficking in three ways. First, it examines the factors that played a role in the creation of the TVPA, as previous research has suggested that implementation problems are often at their heart associated with earlier stages of the policy process (VanMeter and VanHorn 1975; Rein and Rabinovitz 1978; Mazmanian and Sabatier 1983). Second, it studies the framing of human trafficking within the media and the impact of that framing on the effectiveness of the TVPA. Previous research suggests the framing of an issue is critical to understanding agenda setting and that choosing the right frame was often instrumental in moving an item from the public to the government agenda (Baumgartner and Jones 2009). This is particularly critical in the discussion of human trafficking. Not only does the issue never seem to have a consistent frame, but the multiple — often conflicting — frames make any attempt to attach a solution to the problem difficult. Schneider and Ingram (1993) also suggest that the way in which the media frames an issue and the target population of policy is an important part of setting the agenda. Third, it examines Section 110 of the TVPA and the impact of the arbitrary application of sanctions to countries failing to abide by the TVPA on the effectiveness of the TVPA.

Human trafficking research within political science (although limited to date) has the potential of expanding in several ways. First, while John Kingdon warns against looking for the origins of the ideas that shape any particular policy, the trafficking case is a story that demands such a search. Why Christopher Smith took up the issue is a good place to start, Interviews with staff, the congressman, and similar would no doubt shed light on the origins of the TVPA. Second, interviews with interest groups should also be used to get at the behind the scenes action in the policy making process. I know from this research that particular groups were regulars at hearings, what interviews could reveal is how the discussion started, who framed the issue, and 
why the criminal justice frame took hold. It would also be interesting to look into interest group activity after the passage of the TVPA, to see if they are trying to open a new dimension and why. Third, examining the court venue, given the criminal justice focus of the TVPA, would add an important piece to the puzzle that is the TVPA. What role did the courts and the legal system play in pushing this legislation? What were some of the problems the criminal justice and courts systems were having before the passage of the TVPA? Finally, there is a good deal of room for international relations research in human trafficking, with a focus on the construction and implementation of the Tier system.

I close with three modest policy recommendations. First, revise the TVPA victim definition so that it aligns with the UN definition. This would eliminate the inconsistencies in the international community and it would protect some of the most vulnerable victims of human trafficking. Second, include the victims of human trafficking in future oversight hearings, committee meetings or conferences dealing with trafficking, the TVPA, or the UN protocol. Rather than treat them as dependent (and too often deviant), they need to be represented in the policy process. Third, mandatory training for those charged with implementing any portion of the TVPA is a must. The issue of human trafficking is fairly new, the literature and media coverage is limited, and training must be readily available to all individuals enforcing the policy and those dealing with the victims of human trafficking. 


\section{Bibliography}

Abdelaziz, Khalid, and Ahmed Aboulenein; "Sudan Regrets U.S. Putting It on Trafficking List before Sanctions Dec." Reuters, Thomson Reuters, 5 Oct. 2017, www.reuters.com/article/us-sudanusa/sudan-regrets-u-s-putting-it-on-trafficking-list-before-sanctions-decision-idUSKBN1CA1S3 . Addelman, Richard. Verbrugge, Lois. Death Makes The News: The Social Impact of Disease on Newspaper Coverage. Journal of Health and Social Behavior. Vol. 41 No. 3. 2000. P. 347-367. Archibold, Randall. "Arizona-Mexico Discussion Focuses on Border Violence," New York Times. June 16, 2007

Baker, Peter. U.S. to Restore Full Relations With Cuba, Erasing a Last Trace of Cold War Hostility. New York Times. December 17, 2014.

Bales, Kevin and Soodalter, Ron, The Slave Next Door: Human Trafficking and Slavery in America Today. 2009

Bales, Kevin. Disposable People: New Slavery in the Global Economy. 2004

Barron, Walt. "Bill to Halt Human Trafficking." CQ Weekly November 13, 1999

Bauer, Thomas; McKercher, Bob. Sex and Tourism: Journeys of Romance, Love, and Lust. 2003.

Biesenbender, Sophie and Jale Tosun (2014).Domestic Politics and theDiffusion of International Policy Innovations:How Does Accommodation Happen?GlobalEnvironmental Change, Special Issue,DOI:10.1016/j.gloenvcha.2014.04.001

Bush, President George W., "Presidential Determination with Respect to Foreign Governments' Efforts Regarding Trafficking in Persons." U.S. Department of State, U.S. Department of State. 2003

Bush, President George W., "Presidential Determination with Respect to Foreign Governments' Efforts Regarding Trafficking in Persons." U.S. Department of State, U.S. Department of State. 2004 Bush, President George W., "Presidential Determination with Respect to Foreign Governments' Efforts Regarding Trafficking in Persons." U.S. Department of State, U.S. Department of State. 2005

Bush, President George W., "Presidential Determination with Respect to Foreign Governments' Efforts Regarding Trafficking in Persons." U.S. Department of State, U.S. Department of State. 2006

Bush, President George W., "Presidential Determination with Respect to Foreign Governments' Efforts Regarding Trafficking in Persons." U.S. Department of State, U.S. Department of State. 2007

Bush, President George W., "Presidential Determination with Respect to Foreign Governments' Efforts

Regarding Trafficking in Persons." U.S. Department of State, U.S. Department of State. 2008

Cadei, Emily. "Culture Wars Claim Trafficking Law." CQ Weekly (April 30, 2012).

Campbell, Colton C. Creating an Angel: Congressional Delegation to Ad Hoc Commissions. Congress and The President. Vol. 25 Issue 2. Pages 161-182. 1998.

Carens, Joseph H. Nationalism and the Exclusion of Immigrants: Lessons From Australian Immigration Policy. In Mark Gibney (ed.), Open Borders? Closed Societies: The Ethical and Political Issues. Greenwood Press. 1988.

Chacon, Jennifer M. "Misery and Mypoia: Understanding the Failures of U.S. Efforts to Stop Human Trafficking." Fordham Law Review. Vol 74, No 6. 2006. pp 2977-3040.

Chapkis, Wendy. Trafficking, Migration, and the Law: Protecting Innocents, Punishing Immigrants. Gender and Soceity. 2003.

Children's Legal Rights Journal. Vol. 35 Issue. 1. 2015. Pp. 94-97.

Chuang, Janie. Beyond a Snapshot: Preventing Human Trafficking in the Global Economy. Indiana Journal of Global Legal Studies. Vol. 13. Issue 1. 2006. 
Clawson, H. J., Dutch, N., Solomon, A., \& Grace, L. G. (2009). Human trafficking into and within the United States: A review of the literature. Retrieved from the U.S. Department of Health and Human Services Web site: http://www.wunrn.com/news/2009/10_09/

10_05_09/100509_trafficking.htm

Clawson, H.J. et, al. "Estimating Human Trafficking into the United States: Development of a Methodology". US Department of Justice. Washington DC. 2006

Cobb, R. et. al. 1976. 'Agenda Building as a Comparative Political Process', American Political Science Review, Vol. 70, No. 1.

Council on Foreign Relations, Council on Foreign Relations. "Saudi Arabia." www.cfr.org/middle-eastand-north-africa/saudi-arabia.2017.

Dean, A. L. Ad hoc Commissions for Policy Formulation? In Cronin and Greenberg. (101-116). 1969.

Defeis, Elizabeth F. (2004) "Protocol To Prevent, Suppress And Punish Trafficking In Persons-A New Approach," ILSA Journal of International \& Comparative Law: Vol. 10 : Iss. 2 , Article 20.

Doezema, J. "Who gets to choose? Coercion, consent and the UN Trafficking Protocol". Gender and Development, Vol 10, No1. 2002.

Downs, Anthony, Up and Down with Ecology-the Issue-Attention Cycle , Public Interest, 28 (1972:Summer) p.38

Eckholm, Erik. Somalis in Twin Cities Shaken by Charges of Sex Trafficking, New York Times. Novemeber 23, 2010.

Farr, Kathryn. "Sex Trafficking: The Global Market in Women and Children."Worth Publishers. New York. 2005.

Farrell, Amy \& Fahy, Stephanie. (2009). The Problem of Human Trafficking in the US: Public Frames and Policy Responses. Journal of Criminal Justice. 37. 617-626.

Feingold, David A. Human Trafficking. Foreign Policy; Sep/Oct 2005; 150.

Feuer, Alan. U.S. Tells of Ocean Transfer in Smuggling of Immigrants. New York Times. June 14, 2005.

Finnemore, Martha, and Kathryn Sikkink. "International Norm Dynamics and Political Change." International Organization, vol. 52, no. 4, 1998, pp. 887-917.

Free the Slaves. Slavery Facts and Our Impact. www.freetheslaves.net. 2017

Fridkin, Kim. Kinney, Patrick. The Spectacle of U.S. Senate Campaigns. Princeton University Press. 1999

Friman, H. Richard, Reich, Simon. Human Trafficking, Human Security, and the Balkans. 2007.

Gozdziak, Elizbeta M., and Elizabeth A. Collett. "Research on Human Trafficking in North America: A Review of Literature." In Data and Research in Human Trafficking: A Global Survey. Edited by Frank Laczko and Elzbieta Gozdziak. Offprint of the Special Issue of International Migration Vol. 43, No. 1. 2005.

Greenhouse, Steven. "The Ugly Side of Free Trade." New York Times. May 2, 2006.

H.R. 3244, 2000. Trafficking Victims Protection Act. 106th Congress. 2000

H.R. 3254. Megan's Law. 2011.

H.R. 972. The Trafficking Victims Protection Act Reauthorization of 2005. 2005.

Hardin, John H. "Multiple Topics, Multiple Targets, Multiple Goals, and Multiple Decision Makers: Congressional Consideration of Comprehensive Health Care Reform." Policy Dynamics. The University of Chicago Press. 2002 
Hardy, V.L., Compton, K.D., \& McPhatter, V.S. (2013). Domestic minor sex trafficking: Practice implications for mental health professionals. Journal of Women \& Social Work, 28, 8-18.

https://treaties.un.org/Pages/ViewDetails.aspx?src=IND\&mtdsg_no=XVIII-12-a\&chapter=18\&lang=en. 2000.

Hughes, Donna M. "The 'Natasha' Trade: The Transnational Shadow Market of Trafficking in Women." Journal of International Affairs, vol. 53, no. 2, 2000, pp. 625-651.

International Organization for Migration. Counter-trafficking. https://www.iom.int/counter-trafficking. 2017.

Janie Chuang, The United States as Global Sheriff: Using Unilateral Sanctions to Combat Human Trafficking, 27 MICH. J. INT'L L. 437 (2006).

Janofsky, Michael. "Bush Assails Castro and Human Trafficking," New York Times July 7, 2004.

Jenkins-Smith, Hank, Sabatier, Paul. Evaluating the Advocacy Coalition Framework Journal of Public Policy Vol. 14, Issue 02. 1994.

Jones, B. D. and Baumgartner, F. R. Agendas and Instability in American Politics. University of Chicago Press. 1993.

Jones, B. D. and Baumgartner, F. R. Agendas and Instability in American Politics. University of Chicago Press. 2009.

Jones, B. D. and Baumgartner, F. R., Representation and Agenda Setting. Policy Studies Journal, 32. 2004

Jones, Bart. "Venezuela Says Sanctions by U.S. Are Part of Anti-Chavez Campaign."TribunedigitalBaltimoresun, 26 Sept. 2004, articles.baltimoresun.com/2004-0926/news/0409260226_1_human-trafficking-venezuela-sanctions

Jones, Bryan D, Tracy Sulkin, and Heather Larsen. 2003. "Policy Punctuations in American Political Institutions." American Political Science Review 97: 151-70.

Jones, M. D. and Jenkins-Smith, H. C. (2009), Trans-Subsystem Dynamics: Policy Topography, Mass Opinion, and Policy Change. Policy Studies Journal, 37: 37-58.

Joshi, Aiko. "The Face of Human Trafficking."Hastings Women's Law Journal. Volume 13. Issue 1. 2002

Kara, Siddarth. The Modern Business of Human Trafficking. 2009.

King, David C. The Nature of Congressional Committee Jurisdictions. The American Political Science Review, Vol. 88, No. 1 (Mar., 1994), pp. 48-62.

King, David C.. "Representation through Participation in Committee Hearings: Ways and Means

Committee Members and the 1978 Revenue Reform Act." Annual Meeting of the Midwest Political Science Association, Chicago, April 13, 1989.

Kingdon, James W. Agendas, Alternatives, and Public Policies. HarperCollins Publishers. 1984.

Kingdon, James W. Agendas, Alternatives, and Public Policies. HarperCollins Publishers. 1995.

Kinney, Edith C., Appropriations for the Abolitionists: Undermining Effects of the U.S. Mandatory Anti-Prostitution Pledge in the Fight Against Human Trafficking and HIV/AIDS (April 15, 2006). Berkeley Journal of Gender, Law \& Justice, Vol. 21, p. 158, 2006.

Kohm, Steven, Selwood, John. Sex Work and City Planning: Winnipeg's Red Light District Committee and the Regulation of Prostitution. Institute of Urban Studies. 2004.

Kristoff, Nicholas. "Seduction, Slavery, and Sex." New York Times. July 4, 2010.

Kristoff, Nicholas. Girls on our Streets. New York Times.May 6, 2009. 
Li, Pei. Cronkite News. http://cronkitenewsonline.com/2013/12/little-known-cumbersome-visa-fortrafficking-victims-is-chronically-underused/index.html. 2013.

Lichtblau, Eric. "Two Groups Charged With Abuse of Witness Law," June 27, 2005.

Lloyd, Paulette \& Simmons, Beth \& Stewart, Brandon. (2011). The Global Diffusion of Law:

Transnational Crime and the Case of Human Trafficking. SSRN Electronic Journal. . $10.2139 / \mathrm{ssrn} .2289428$.

Marquis, Christopher. "A Crackdown on the Traffic of Humans." New York Times. February 26, 2003. May, Peter J., Joshua Sapotichne and Samuel Workman. 2009. "Widespread Policy Disruption and Interest Mobilization." The Policy Studies Journal 37(4): 793-815.

Mayhew, David R. Congress The Electoral Connection. Yale University Press. 1974.

Mazmanian, Dan and Paul Sabatier, 1983. Implementation and Public Policy. Scott Foresman and Company. chpts 1,2 .

McCool, Daniel. The Subsystem Family of Concepts: A Critique and a Proposal. Political Research Quarterly. Vol. 52, No. 2. 1998.

Mintrom, M. 1997. "Policy Entrepreneurs and the Diffusion of Innovation." American Journal of Political Science 41: 738-70.

Mintrom, Michael. "Policy Entrepreneurs and the Diffusion of Innovation." American Journal of Political Science, vol. 41, no. 3, 1997, pp. 738-770.

Moore, Kelly Anne. "Take Al Qaeda to Court," New York Times. August 21, 2007

Morone, James. Hellfire Nation: The Politics of Sin in American History. 2003

Nelson, Barbara. Making An Issue of Child Abuse: Political Agenda Setting for Social Problems. University of Chicago Press. 1984.

Neuenkirch, Matthias. Neumeier, Florian. The impact of UN and US economic sanctions on GDP growth. European Journal of Political Economy, 2015, Vol. 40. Issue PA, pp. 110-125

Newman, Graeme R. "The Exploitation of Trafficked Women." US Department of Justice. Community Oriented Policing Services. Washington, DC. 2006

No Author. "Italian Police Free 113 Poles Living in Slave Labor Camps," New York Times. July 19 2006.

Obama, President Barack., "Presidential Determination with Respect to Foreign Governments' Efforts Regarding Trafficking in Persons." U.S. Department of State, U.S. Department of State. 2009

Obama, President Barack., "Presidential Determination with Respect to Foreign Governments' Efforts Regarding Trafficking in Persons." U.S. Department of State, U.S. Department of State. 2010

Obama, President Barack., "Presidential Determination with Respect to Foreign Governments' Efforts Regarding Trafficking in Persons." U.S. Department of State, U.S. Department of State. 2011

Obama, President Barack., "Presidential Determination with Respect to Foreign Governments' Efforts Regarding Trafficking in Persons." U.S. Department of State, U.S. Department of State. 2012

Obama, President Barack., "Presidential Determination with Respect to Foreign Governments' Efforts Regarding Trafficking in Persons." U.S. Department of State, U.S. Department of State. 2013

Obama, President Barack., "Presidential Determination with Respect to Foreign Governments' Efforts Regarding Trafficking in Persons." U.S. Department of State, U.S. Department of State. 2014 Obama, President Barack., "Presidential Determination with Respect to Foreign Governments' Efforts Regarding Trafficking in Persons." U.S. Department of State, U.S. Department of State. 2015 
Obama, President Barack., "Presidential Determination with Respect to Foreign Governments' Efforts Regarding Trafficking in Persons." U.S. Department of State, U.S. Department of State. 2016 Oleszek, Walter J. Congressional Procedures and the Policy Process. CQ Press. Washington, D.C. 1996. Palmer, Elizabeth. "House Panel Approves Bill To Punish Trafficking of Humans and Assist Victims" CQ Weekly. April 8, 2000.

Palmer, Elizabeth. "House Panel Approves Bill To Punish Trafficking of Humans and Assist Victims" CQ Weekly. May 13, 2000.

Paul Simon Public Policy Institute at Southern Illinois University Carbondale.1 May 2017, news.siu.edu/2017/05/050117par17072.php.

Pear, Robert. "Many Indigent Refugees to Lose Federal Assistance," New York Times, July 31, 2010.

Reiger, April. "Missing the Mark: Why the Trafficking Victims Protection Act Fails to Protect Sex Trafficking Victims in the United States" Harvard Journal of Law and Gender. Vol 30. 2007.

Rein, Martin and Francine Rabinovitz. 1978. "Implementation: A Theoretical Perspective" in Burnham, ed. American Politics and Public Policy. MIT Press.

Rogin, Josh. "Obama Waives Sanctions on Countries That Use Child Soldiers."Foreign Policy, Foreign Policy, 1 Oct. 2012, foreignpolicy.com/2012/10/01/obama-waives-sanctions-on-countries-thatuse-child-soldiers/.

Sadruddin, Hussein et. al. "Human Trafficking in the United States: Expanding Victim Protection

Beyond Prosecution Witness." Stanford Law and Policy Review. Vol 16, Issue 2. 2006. pp 379415.

Samarasinghe, Vidyamali. "Female Sex Trafficking in Asia." Routledge. New York. 2008.

Schattschneider, E. E. The Semisovereign People : A Realist's View of Democracy in America. New York, Holt, Rinehart and Winston, 1960.

Schauer, Edward J. and Elizabeth M. Wheaton. "Sex Trafficking into the United States: A Literature Review." Criminal Justice Review. Vol 31, No. 2, 2006. pp. 146-149

Schneider, Anne, and Helen Ingram. "Social Construction of Target Populations: Implications for Politics and Policy." The American Political Science Review, vol. 87, no. 2, 1993, pp. 334-347

Schneider, M., and P. Teske. 1992. "Toward A Theory of the Political Entrepreneur: Evidence from Local Government." The American Political Science Review 86: 737-747.

Schneider, M., P. Teske, and M. Mintrom. 1995. Public Entrepreneurs: Agents for Change in American Government. Princeton, NJ: Princeton University Press

Shupac, Joseph. "The Geopolitics of Saudi Arabia." Future Economics, 13 Nov. 2017, futureeconomics.com/2016/06/22/the-geopolitics-of-saudi-arabia/.

Simmons, Beth A., and Zachary Elkins. 2004. The globalization of liberalization: policy diffusion in the international political economy. American Political Science Review 98(1).

Simpson, Daniel. Bosnia Policeman Fired for Aiding Sex Traffic. New York Times. October 18, 2002

Smith, Laura. Around the World: U.S. Efforts to Combat Sex Trafficking of Minors in Cuba

Southern Illinois University. College of Mount Saint Vincent, Human Trafficking: Involuntary Servitude." 2 Nov. 2017, mountsaintvincent.edu/human-trafficking-involuntary-servitude/.

Speck, Mary. "Law Governing Human Trafficking Would Be Reauthorized Under Measure." CQ Weekly (December 26, 2005): 3406

Spetalnick, Matt, et al. "Exclusive: U.S. Sanctions Venezuelan Officials to Pressure Maduro - So." Reuters, Thomson Reuters, 26 July 2017, www.reuters.com/article/us-venezuela-politics- 
sanctions-exclusiv/exclusive-u-s-sanctions-venezuelan-officials-to-pressure-maduro-sourcesidUSKBN1AB1YP.

Stiglitz, Joseph. Globalization and It's Discontents. 2003

Stone, Deborah. Causal Stories and the Formation of Policy Agendas. Political Science Quarterly. Vol 104, No. 2. 1989.

Straus, Jacob R., Glassman, Matthew. E. Party and Procedure in the United States Congress. Rowman \& Littlefield Publishers. 2015.

Talbert, Jeffery C., et al. "Nonlegislative Hearings and Policy Change in Congress." American Journal of Political Science, vol. 39, no. 2, 1995, pp. 383-405.

Tatum D.C. (2010) The War in Darfur: Genocide on Our Watch. In: Genocide at the Dawn of the Twenty-First Century. Palgrave Macmillan, New York

Thomas, Dana. Terrors Purse Strings," New York Times. August 30, 2007

Thurber, James. 1991. "Dynamics of Policy Subsystems in American Politics." In Allen Cigler and Burdett Loomis, eds., Interest Group Politics, 3rd ed. Washington, DC: Congressional Quarterly Press.

Tuller, David, Fletcher, Laurel, Stover, Eric. "Freedom Denied: Forced Labor in California. Human Rights Center. University of California, Berkley. 2005.

United Nationals Organization on Drugs and Crime. Global Trafficking in Persons Report. 2014 United Nationals Organization on Drugs and Crime. Global Trafficking in Persons Report. 2015 United Nationals Organization on Drugs and Crime. Global Trafficking in Persons Report. 2017. United Nations Treaty Collection. a Protocol to Prevent, Suppress and Punish Trafficking in Persons, Especially Women and Children, supplementing the United Nations Convention against Transnational Organized Crime

United States Department of State. Trafficking in Victims Report. 2001

United States Department of State. Trafficking in Victims Report. 2002 United States Department of State. Trafficking in Victims Report. 2003 United States Department of State. Trafficking in Victims Report. 2004 United States Department of State. Trafficking in Victims Report. 2005 United States Department of State. Trafficking in Victims Report. 2006 United States Department of State. Trafficking in Victims Report. 2007 United States Department of State. Trafficking in Victims Report. 2008 United States Department of State. Trafficking in Victims Report. 2009 United States Department of State. Trafficking in Victims Report. 2010 United States Department of State. Trafficking in Victims Report. 2011 United States Department of State. Trafficking in Victims Report. 2012 United States Department of State. Trafficking in Victims Report. 2013 United States Department of State. Trafficking in Victims Report. 2014 United States Department of State. Trafficking in Victims Report. 2015 Van Meter, Donald S. and Carl E. Van Horn. 1975. "The Policy Implementation Process: A Conceptual Framework." Administration and Society. 6 (Feb): 445-88.

VL 13.IS - 1. Blackwell Publishing Ltd. 1999. 1-22.

Walker, Jack. Setting the Agenda in the US Senate: A Theory of Problem Selection. British Journal of Political Science. Vol. 7. Num. 4 1977. P.423-445. 
Wawro, G..Legislative Entrepreneurship in the U.S. House of Representatives. Ann Arbor: University of Michigan Press, 2000

Weaver R. Kent, "Is Congress Abdicating Power to Commissions?" Roll Call, February 12, 1989, pp. 5, 25.

Weiss, Thomas G.,Principles, Politics, and Humanitarian Action. Ethics \& International Affairs

Weitzer, Ronald. The Social Construction of Sex Trafficking: Ideology and Institutionalization of a Moral Crusade. Politics \& Society Vol 35, Issue 3. 2007.

Wheaton, Elizabeth, Schauer, Edward, Galli, Thomas. Economics of Human Trafficking. International Migration Vol. 48 Issue 4. 2010.

Wijers, M., and L. Lap-Chew. "Trafficking in Women: Forced Labour and Slavery-like Practices inMarriage, Domestic Labour and Prostitution." Foundation Against Trafficking, the Netherlands. Vol 20.1997.

William L.F. Felstiner, et al. "The Emergence and Transformation of Disputes: Naming, Blaming, Claiming ..." Law \& Society Review, vol. 15, no. 3/4, 1980.

Wilson, Jeremy. Dalton, Erin. Human Trafficking in the Heartland: Variation in Law Enforcement Awareness and Response Journal of Contemporary Criminal Justice. Vol 24, Issue 3, pp. 296 313

Wonders, Nancy A., and Raymond Michalowski. "Bodies, Borders, and Sex Tourism in a Globalized World: A Tale of Two Cities- Amsterdam and Havana." Social Problems, vol. 48, no. 4, 2001, pp. 545-571. JSTOR, JSTOR, www.jstor.org/stable/10.1525/sp.2001.48.4.545.

Wood, R. S. (2006), The Dynamics of Incrementalism: Subsystems, Politics, and Public Lands. Policy Studies Journal, 34.

Worsham, J. and Stores, C. (2012), Pet Sounds: Subsystems, Regimes, Policy Punctuations, and the Neglect of African American Farmers, 1935-2006. Policy Studies Journal, 40: 169-190.

Worsham, Jeffrey. Other people's money: Policy Change, Congress, and Bank Regulation. Westview Press. Boulder, CO. 1997.

Worsham, Jeffrey. Up In Smoke: Mapping Subsystem Dynamics in Tobacco Policy. Policy Studies Journal. Vol. 34 Issue 3. P. 437-452.2006. 


\section{Appendix Chapter Five}

\begin{tabular}{|c|c|}
\hline \multicolumn{2}{|c|}{$\begin{array}{c}\text { Appendix } \\
\text { Table 5.1 } \\
\text { Number of Introductions of Human Trafficking Legislation in the House and Senate } \\
(1999-2016)\end{array}$} \\
\hline $\begin{array}{c}\text { Members of the House of } \\
\text { Representatives }\end{array}$ & $\begin{array}{l}\text { Pieces of Human } \\
\text { Trafficking Legislation } \\
\text { Introduced }\end{array}$ \\
\hline Smith, Christopher H. [R-NJ] & 30 \\
\hline Poe, Ted [R-TX][15] & 14 \\
\hline Royce, Edward R. [R-CA] & 13 \\
\hline Jackson-Lee, Sheila [D-TX] & 12 \\
\hline Maloney, Carolyn B. [D-NY] & 8 \\
\hline Honda, Michael M. [D-CA] & 7 \\
\hline Franks, Trent [R-AZ] & 7 \\
\hline Sensenbrenner, F. James, Jr. [R-WI] & 7 \\
\hline Bass, Karen $[\mathrm{D}-\mathrm{CA}]$ & 7 \\
\hline Granger, Kay [R-TX] & 7 \\
\hline Lee, Barbara [D-CA] & 7 \\
\hline Lofgren, Zoe [D-CA] & 7 \\
\hline Chabot, Steve [R-OH] & 6 \\
\hline Wolf, Frank R. [R-VA] & 6 \\
\hline Berman, Howard L. [D-CA] & 5 \\
\hline Carter, John R. [R-TX] & 5 \\
\hline DeLauro, Rosa L. [D-CT] & 5 \\
\hline Engel, Eliot L. [D-NY] & 5 \\
\hline Lowey, Nita M. [D-NY] & 5 \\
\hline McCaul, Michael T. [R-TX] & 5 \\
\hline Ros-Lehtinen, Ileana [R-FL] & 5 \\
\hline Roybal-Allard, Lucille [D-CA] & 5 \\
\hline Schakowsky, Janice D. [D-IL] & 5 \\
\hline Wagner, Ann [R-MO] & 5 \\
\hline Beatty, Joyce [D-OH] & 4 \\
\hline Bordallo, Madeleine Z. [D-GU] & 4 \\
\hline Evans, Lane [D-IL] & 4 \\
\hline Fortenberry, Jeff [R-NE] & 4 \\
\hline Jackson-Lee, Sheila [D-TX] & 4 \\
\hline King, Peter T. [R-NY] & 4 \\
\hline Kolbe, Jim [R-AZ] & 4 \\
\hline Sanchez, Loretta [D-CA] & 4 \\
\hline
\end{tabular}


Serrano, Jose E. [D-NY] 4

Cao, Anh "Joseph" [R-LA] 3

Cuellar, Henry [D-TX] 3

Culberson, John Abney [R-TX] 3

Davis, Danny K. [D-IL] 3

Ellison, Keith [D-MN] 3

Foxx, Virginia [R-NC] 3

Grijalva, Raul M. [D-AZ] 3

Hultgren, Randy [R-IL] 3

Lungren, Daniel E. [R-CA] 3

McKeon, Howard P. "Buck" [R-CA] 3

Miller, Candice S. [R-MI] 3

Noem, Kristi L. [R-SD] 3

Paulsen, Erik [R-MN] 3

Polis, Jared [D-CO] 3

Reichert, David G. [R-WA] 3

Rogers, Harold [R-KY] 3

Young, C. W. Bill [R-FL] 3

Barrow, John [D-GA] 2

Black, Diane [R-TN] 2

Cohen, Steve [D-TN] 2

Conyers, John, Jr. [D-MI] 2

Curbelo, Carlos [R-FL] 2

Ellmers, Renee L. [R-NC] 2

Fattah, Chaka [D-PA] 2

Giffords, Gabrielle [D-AZ] 2

Gowdy, Trey [R-SC] 2

Green, Al [D-TX] 2

Heck, Joseph J. [R-NV] 2

Mack, Connie [R-FL] 2

Maloney, Sean Patrick [D-NY] 2

McDermott, Jim [D-WA] 2

Millender-McDonald, Juanita [D-CA] 2

Miller, George [D-CA] 2

Moore, Gwen [D-WI] 2

Norton, Eleanor Holmes [D-DC] 2

O'Rourke, Beto [D-TX] 2

Olson, Pete [R-TX] 2

Pearce, Stevan [R-NM] 2

Peters, Scott H. [D-CA] 2 


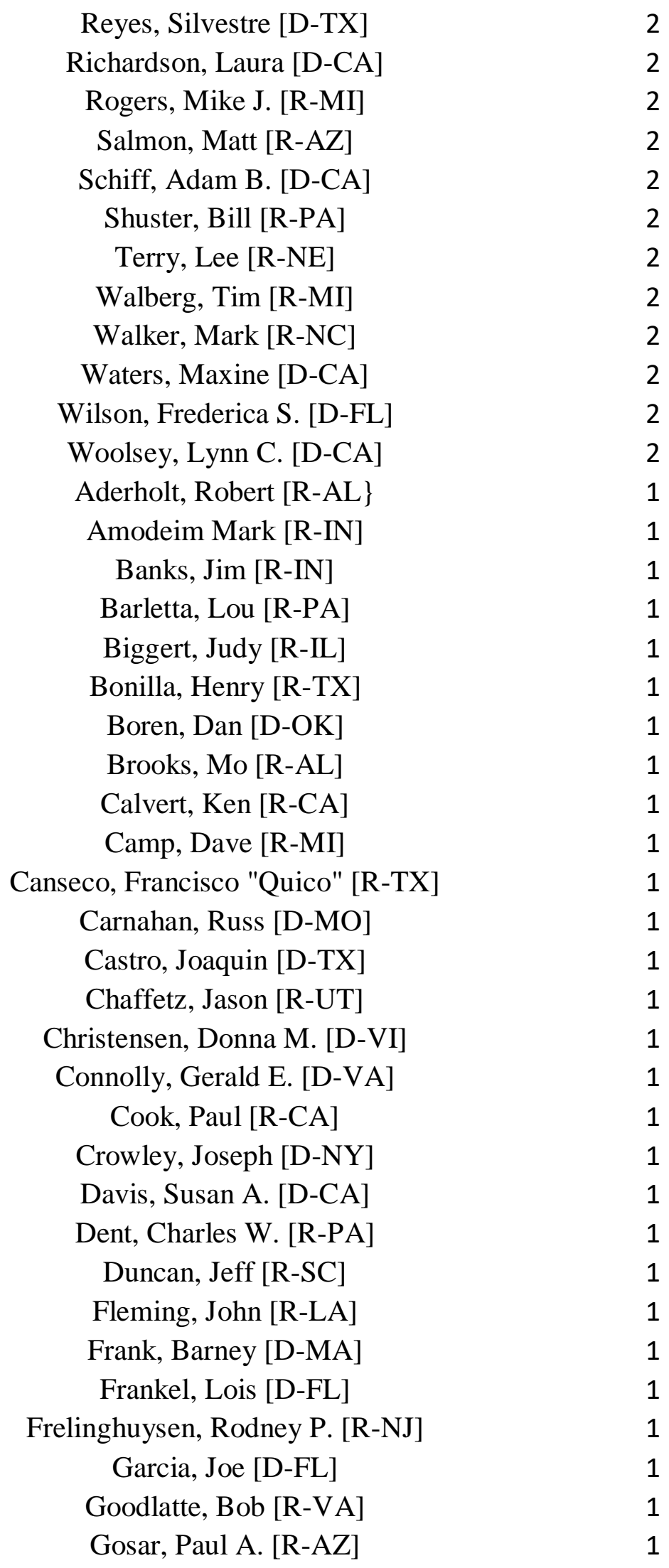




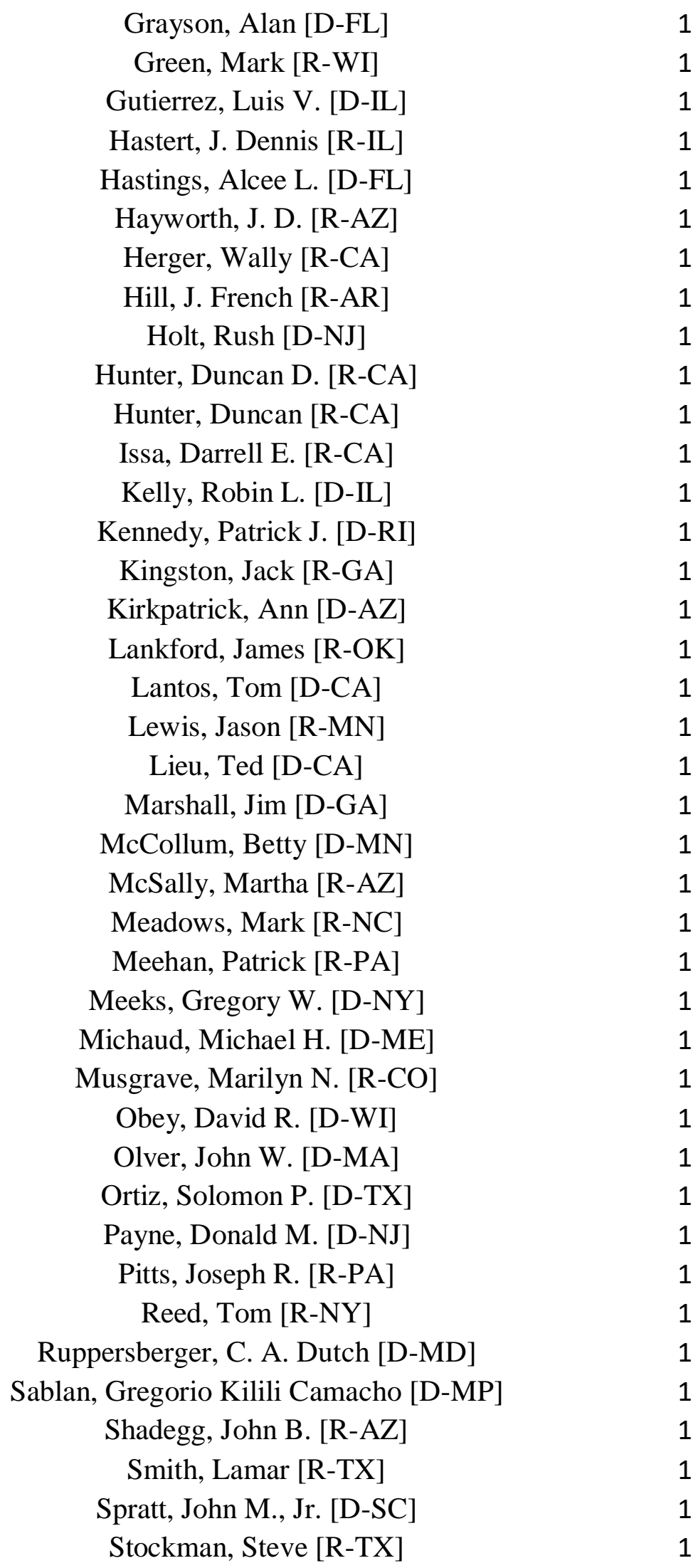


Thompson, Bennie G. [D-MS] 1

Thornberry, Mac [R-TX] 1

Tiberi, Patrick J. [R-OH] 1

Titus, Dina [D-NV] 1

Towns, Edolphus [D-NY] 1

Trott, David A. [R-MI] 1

Turner, Robert L. [R-NY] 1

Vargas, Juan [D-CA] 1

Wasserman Schultz, Debbie [D-FL] 1

Watson, Diane E. [D-CA] 1

Yarmuth, John A. [D-KY] 1

Yoho, Ted S. [R-FL] 1

$\begin{array}{cc}\text { Members of the Senate } & \begin{array}{c}\text { Pieces of Human } \\ \text { Trafficking Legislation } \\ \text { Introduced }\end{array}\end{array}$

Leahy, Patrick J. [D-VT] 12

Coryn, John [R-TX] 11

Menendez, Robert [D-NJ] 11

Boxer, Barbara [D-CA] 7

Bob, Corker [R-TN] 7

Feinstein, Dianne [D-CA] 6

Blumenthal, Richard [D-CT] 6

McCain, John [R-AZ] 6

Biden, Joseph R., Jr. [D-DE] 6

Wyden, Ron [D-OR] 6

Brownback, Sam [R-KS] 5

Coons, Christopher A. [D-DE] 5

Corker, Bob [R-TN] 5

Klobuchar, Amy [D-MN] 5

Portman, Rob [R-OH] 5

Baucus, Max [D-MT] 4

Cardin, Benjamin L. [D-MD] 4

Flake, Jeff [R-AZ] 4

Gillibrand, Kirsten E. [D-NY] 4

Grassley, Chuck [R-IA] 4

Hatch, Orrin G. [R-UT] 4

Johnson, Ron [R-WI] 4

Kirk, Mark Steven [R-IL] 4

Shaheen, Jeanne [D-NH] 4

Brown, Sherrod [D-OH] 3 
Cassidy, Bill [R-LA] 3

Heitkamp, Heidi [D-ND] 3

Landrieu, Mary L. [D-LA] 3

Nelson, Ben [D-NE] 3

Reid, Harry [D-NV] 3

Rubio, Marco [R-FL] 3

Schumer, Charles E. [D-NY] 3

Vitter, David [R-LA] 3

Akaka, Daniel K. [D-HI] 2

Collins, Susan M. [R-ME] 2

Graham, Lindsey [R-SC] 2

Levin, Carl [D-MI] 2

McCaskill, Claire [D-MO] 2

McConnell, Mitch [R-KY] 2

Mikulski, Barbara A. [D-MD] 2

Paul, Rand [R-KY] 2

Santorum, Rick [R-PA] 2

Sessions, Jeff [R-AL] 2

Alexander, Lamar [R-TN] 1

Allen, George [R-VA] 1

Barrasso, John [R-WY] 1

Boozman, John [R-AR] 1

Clinton, Hillary Rodham [D-NY] 1

Cochran, Thad [R-MS] 1

Conrad, Kent [D-ND] 1

Cruz, Ted [R-TX] 1

Domenici, Pete V. [R-NM] 1

Durbin, Richard J. [D-IL] 1

Durbin, Richard [D-IL] 1

Ernst, Joni [R-IA] 1

Hagel, Chuck [R-NE] 1

Heller, Dean [R-NV] 1

Hoeven, John [R-ND] 1

Isakson, Johnny [R-GA] 1

Kaine, Tim [D-VA] 1

Kennedy, Edward M. [D-MA] 1

Kerry, John F. [D-MA] 1

Lieberman, Joseph I. [ID-CT] 1

Nelson, Bill [D-FL] 1

Sanders, Bernard [I-VT] 1 
Sasse, Ben [R-NE] 1

Shelby, Richard C. [R-AL] 1 Specter, Arlen [R-PA] 1

Thune, John [R-SD] 1

Warren, Elizabeth [D-MA] 1

Webb, Jim [D-VA] 1

Wicker, Roger F. [R-MS] 1

Young, Todd C. [R-IN] 1 
Table 5.2

Legislation Referrals in the House of Representatives (1999-2016)

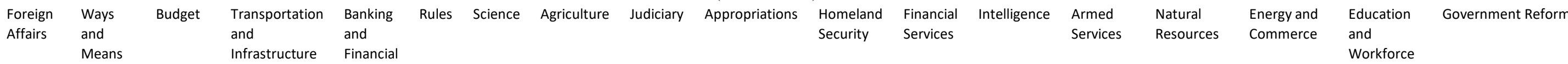

$\begin{array}{rr}1999 & 1 \\ 2000 & \\ 2001 & 1 \\ 2002 & \\ 2003 & \\ 2004 & 1 \\ 2005 & 3 \\ 2006 & 3 \\ 2007 & 5 \\ 2008 & \\ 2009 & 2 \\ 2010 & \\ 2011 & 4 \\ 2012 & 2 \\ 2013 & 2 \\ 2014 & 5 \\ 2015 & 13 \\ 2016 & 1 \\ & \end{array}$

1

Services

1

$\begin{array}{lllllll}1 & 1 & 1 & & 1 & 1\end{array}$ 
Table 5.3

Legislation Referrals in the Senate

(1999-2016)

\begin{tabular}{|c|c|c|c|c|c|c|c|c|c|c|}
\hline Appropriations & $\begin{array}{l}\text { Indian } \\
\text { Affairs }\end{array}$ & Judiciary & $\begin{array}{l}\text { Senate } \\
\text { Commerce, } \\
\text { Science, and } \\
\text { Transportation }\end{array}$ & $\begin{array}{l}\text { Small Business } \\
\text { and } \\
\text { Entrepreneurship }\end{array}$ & $\begin{array}{l}\text { Foreign } \\
\text { Relations }\end{array}$ & $\begin{array}{l}\text { Homeland } \\
\text { Security and } \\
\text { Government } \\
\text { Affairs }\end{array}$ & $\begin{array}{l}\text { Senate } \\
\text { Indian } \\
\text { Affairs }\end{array}$ & $\begin{array}{l}\text { Energy } \\
\text { and } \\
\text { Natural } \\
\text { Resources }\end{array}$ & $\begin{array}{l}\text { Armed } \\
\text { Services }\end{array}$ & Intelligence \\
\hline
\end{tabular}

1999
2000
2001
2002
2003
2004
2005
2006
2007
2008
2009
2010
2011
2012
2013
2014
2015
2016 Transportation

1

\begin{tabular}{|c|c|}
\hline 1 & \\
\hline 1 & \\
\hline 1 & \\
\hline 2 & \\
\hline 1 & \\
\hline 1 & \\
\hline 1 & \\
\hline 2 & 1 \\
\hline 1 & \\
\hline 2 & \\
\hline 2 & 1 \\
\hline 1 & \\
\hline
\end{tabular}

1
1
1

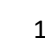


Table 5.4

Legislation Reported Out in the House

(1999-2016)

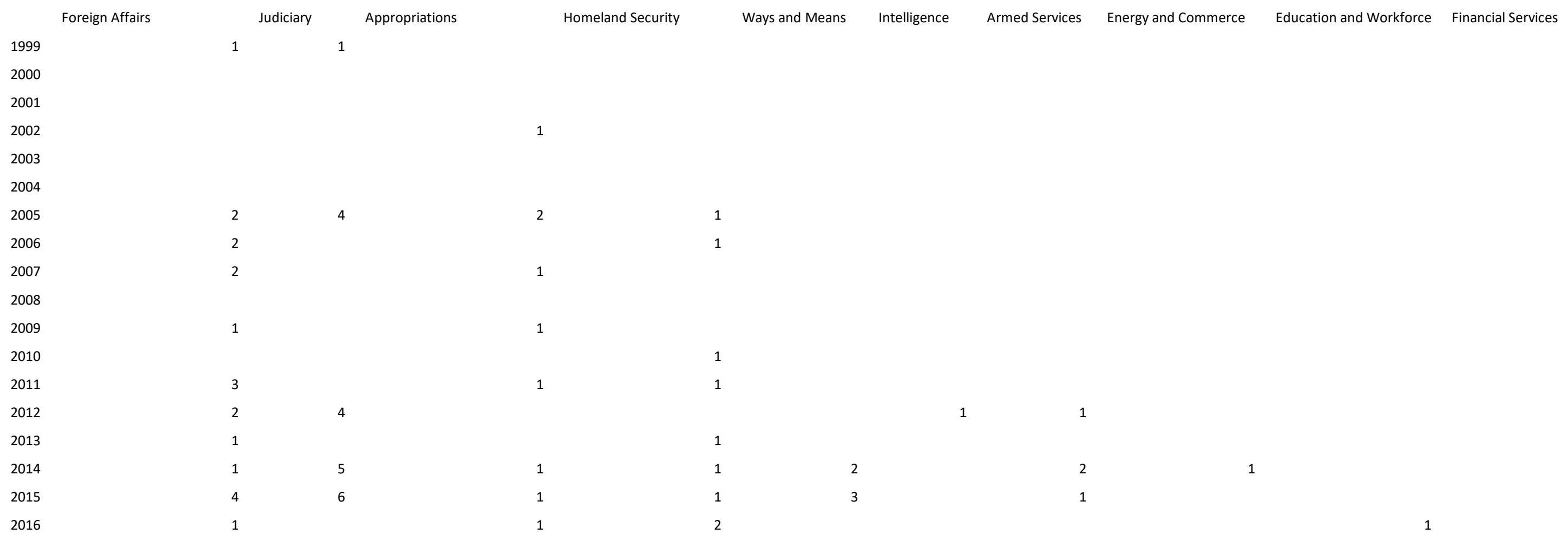


Legislation Reported Out in the Senate (1999-2016)

Appropriations Judiciary Foreign Relations Homeland Security and Government Affairs

Senate Indian Affair

Energy and Natural Resources

Armed Services Finance Commerce, Science, and Transportation 1999

2000

2001

2002

2003

2004

2005

2006

2007

2008

2009

2010

2011

2012

2013

2014

Table 5.6

Topic Dominace Over Time 


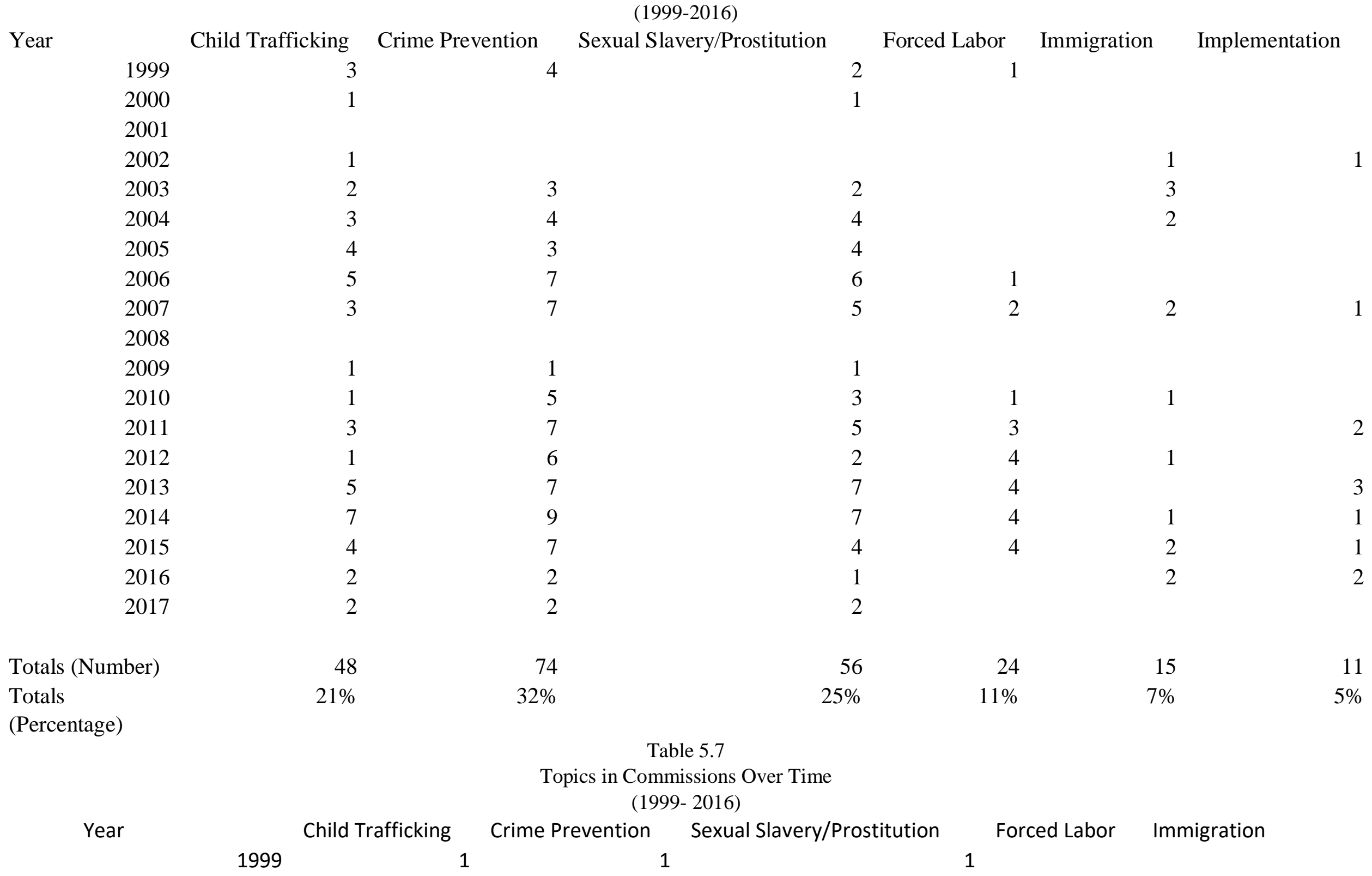


2000

2001

2002

2003

2004

2005

2006

2007

2008

2009

2010

2011

2012

2013

2014

2015

2016

2017

Total (Number)

Total (Percentage)

$\begin{array}{rr}1 & 1 \\ 1 & 1 \\ 1 & 1 \\ & \\ 1 & 4 \\ & 2 \\ 1 & 2 \\ 1 & 1 \\ & 1 \\ & \\ & \\ 6 & 14 \\ 16 \% & 37 \%\end{array}$

1

$\begin{array}{ll}1 & 1 \\ 1 & 1\end{array}$

$4 \quad 2$

21

1

$37 \%$

$24 \%$

8

$21 \%$

1

Table 5.8

Topic Dominance in the Senate Over Time (1999-2017) 


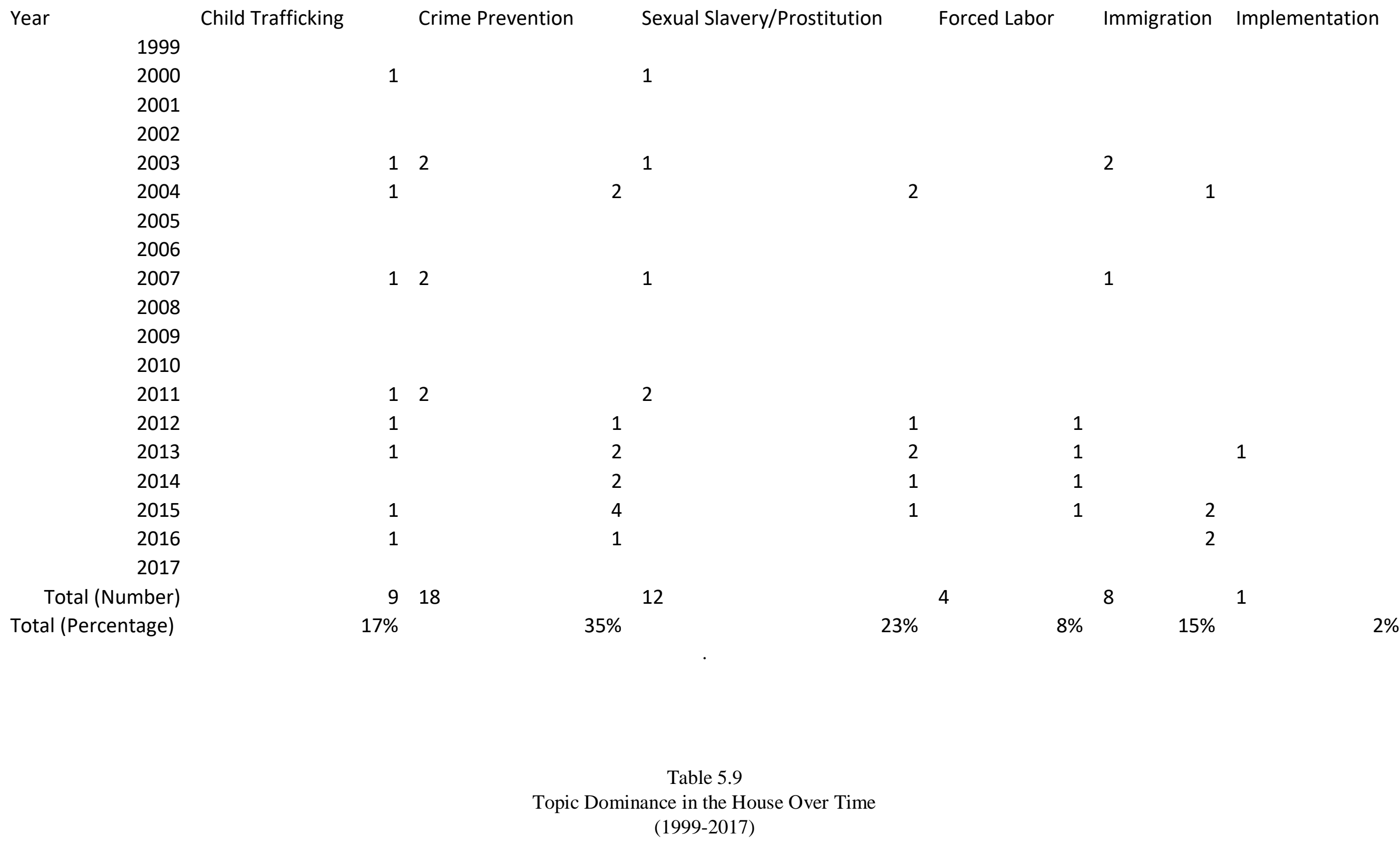




\begin{tabular}{|c|c|c|c|c|c|c|c|}
\hline \multirow[t]{19}{*}{ Year } & & Child Trafficking & Crime Prevention & Sexual Slavery/Prostitution & Forced Labor & Immigration & Implementation \\
\hline & 1999 & 2 & 3 & 1 & 1 & & \\
\hline & 2000 & & & & & & \\
\hline & 2001 & & & & & 1 & 1 \\
\hline & 2002 & & & & & & \\
\hline & 2003 & 1 & 1 & 1 & & 1 & \\
\hline & 2004 & 2 & 2 & 2 & & 1 & \\
\hline & 2005 & 3 & 2 & 3 & & & \\
\hline & 2006 & 4 & 6 & 5 & 1 & & \\
\hline & 2007 & 1 & 4 & 3 & 1 & 1 & 1 \\
\hline & 2008 & & & & & & \\
\hline & 2009 & 1 & 1 & 1 & & & \\
\hline & 2010 & & 1 & 1 & & & \\
\hline & 2011 & 2 & 3 & 2 & 1 & 2 & \\
\hline & 2012 & & 3 & & 2 & 1 & \\
\hline & 2013 & 3 & 4 & 5 & 2 & & 2 \\
\hline & 2014 & 6 & 6 & 5 & 2 & 1 & 1 \\
\hline & 2015 & 3 & 3 & 3 & 2 & & 1 \\
\hline & 2016 & 1 & 1 & 1 & & & 2 \\
\hline & 2017 & 2 & 2 & 2 & & & \\
\hline Total (Number) & & 31 & 42 & 35 & 12 & 8 & 8 \\
\hline Total (Percentage) & & $23 \%$ & $31 \%$ & $26 \%$ & $9 \%$ & $6 \%$ & $6 \%$ \\
\hline
\end{tabular}




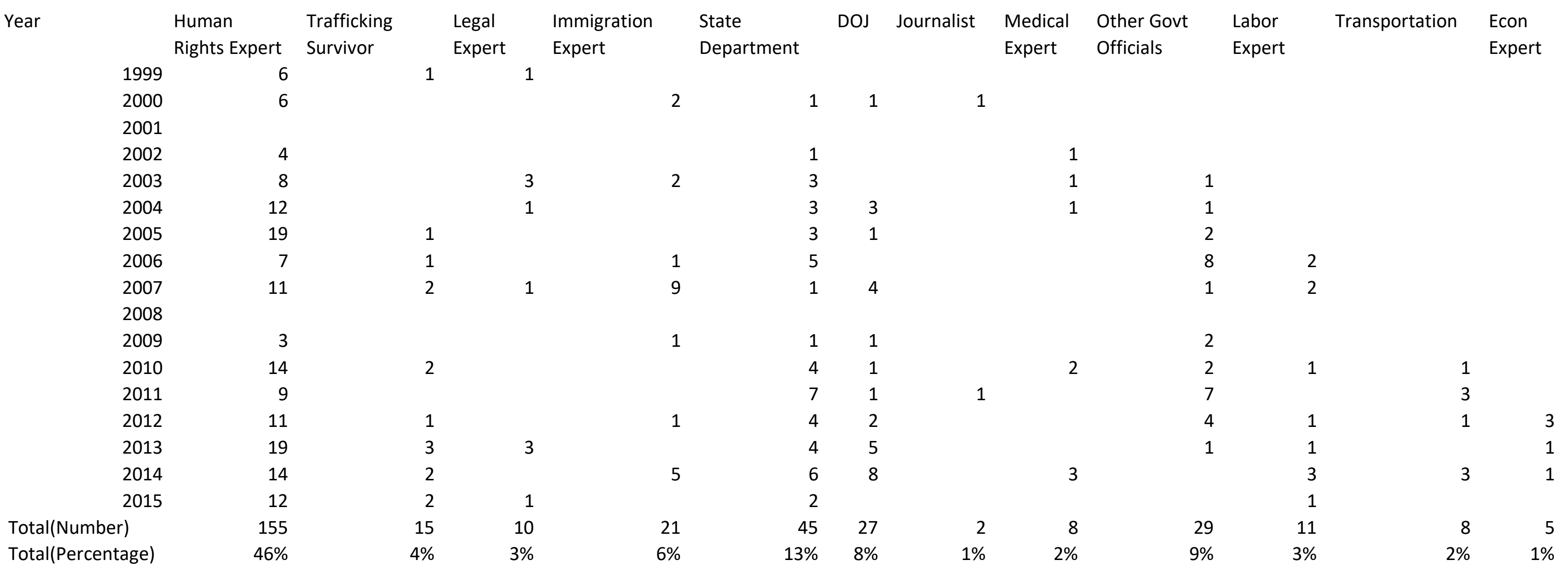




\begin{tabular}{|c|c|c|c|c|c|c|c|c|c|c|c|}
\hline Year & $\begin{array}{l}\text { Human Rights } \\
\text { Expert }\end{array}$ & $\begin{array}{l}\text { Trafficking } \\
\text { Survivor }\end{array}$ & $\begin{array}{l}\text { Legal } \\
\text { Expert }\end{array}$ & $\begin{array}{l}\text { Immigration } \\
\text { Expert }\end{array}$ & $\begin{array}{l}\text { State } \\
\text { Department }\end{array}$ & DOJ & $\begin{array}{l}\text { Medical } \\
\text { Expert }\end{array}$ & $\begin{array}{l}\text { Other Govt } \\
\text { Officials }\end{array}$ & $\begin{array}{l}\text { Labor } \\
\text { Expert }\end{array}$ & Transportation & $\begin{array}{l}\text { Econ } \\
\text { Expert }\end{array}$ \\
\hline 1999 & 4 & & 1 & & & & & & & & \\
\hline 2000 & & & & & & & & & & & \\
\hline 2001 & & & & & & & & & & & \\
\hline 2002 & & & & & & & & & & & \\
\hline 2003 & & & & & & & & & & & \\
\hline 2004 & & & & & & & & & & & \\
\hline 2005 & 3 & 1 & & & & 1 & & 1 & & & \\
\hline 2006 & 2 & & & & 1 & & & 2 & 1 & & \\
\hline 2007 & 2 & & & 1 & 1 & & & 1 & 1 & & \\
\hline 2008 & & & & & & & & & & & \\
\hline 2009 & & & & & & & & & & & \\
\hline 2010 & 12 & 2 & & & 3 & 1 & 1 & 2 & 1 & 1 & \\
\hline 2011 & 2 & & & & 1 & 1 & & 2 & 2 & & \\
\hline 2012 & 5 & & & & 1 & 1 & & & 1 & 1 & \\
\hline 2013 & 6 & & 1 & & & 5 & & & & & \\
\hline 2015 & & & & & 1 & & & & & & \\
\hline Total (Number) & 38 & 3 & 2 & 1 & 9 & 9 & 1 & 8 & 7 & 2 & 1 \\
\hline Total & $47 \%$ & $4 \%$ & $2 \%$ & $1 \%$ & $11 \%$ & $11 \%$ & $1 \%$ & $10 \%$ & $9 \%$ & $2 \%$ & $1 \%$ \\
\hline
\end{tabular}




\begin{tabular}{|c|c|c|c|c|c|c|c|c|c|c|}
\hline Year & Human Rights Expert & Trafficking Survivor & Legal Expert & Immigration Expert & State Department & DOJ & Journalist & Other Govt Officials & Labor Expert & Econ Expert \\
\hline 2000 & 5 & 4 & & 2 & 1 & 1 & 1 & & & \\
\hline 2001 & & & & & & & & & & \\
\hline 2002 & & & & & & & & & & \\
\hline 2003 & 1 & & 2 & 2 & & 1 & & & & \\
\hline 2004 & 7 & & 1 & & 1 & 2 & & 1 & & \\
\hline 2005 & & & & & & & & & & \\
\hline 2006 & & & & & & & & & & \\
\hline 2007 & 1 & & 1 & 1 & & 1 & & & & \\
\hline 2008 & & & & & & & & & & \\
\hline 2009 & & & & & & & & & & \\
\hline 2010 & & & & & & & & & & \\
\hline 2011 & & & & & & & & & & \\
\hline 2012 & 3 & & & & & & & & & \\
\hline 2013 & & & & & & & & & & \\
\hline 2014 & 2 & & & & 1 & & & & 1 & 1 \\
\hline 2015 & 3 & & & & 1 & & & & 1 & \\
\hline Total (Number) & 22 & 4 & 4 & 5 & 4 & 5 & 1 & 1 & 2 & 1 \\
\hline Total (Percentage) & $45 \%$ & $8 \%$ & $8 \%$ & $10 \%$ & $8 \%$ & $10 \%$ & $2 \%$ & $2 \%$ & $4 \%$ & $2 \%$ \\
\hline
\end{tabular}




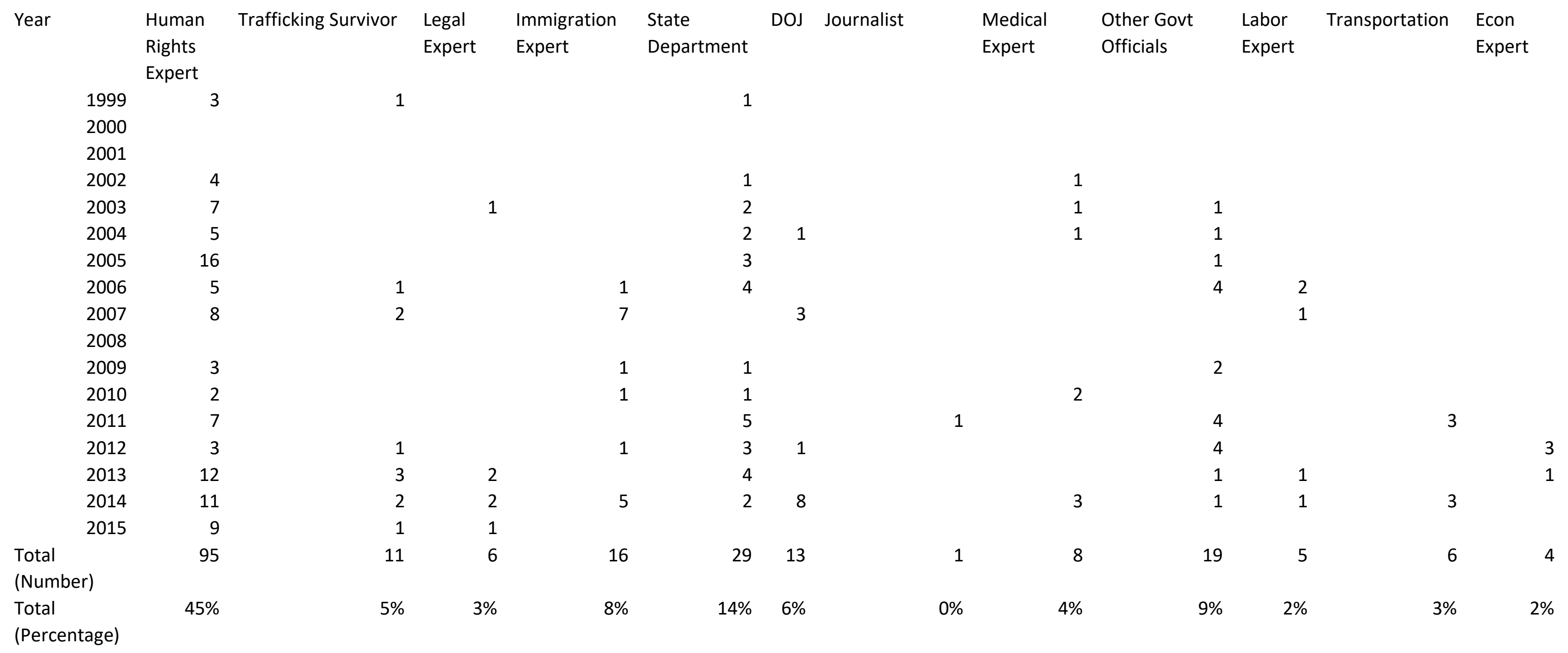




\section{Appendix Chapter Six}

Table 6.1 2001 Tier 3 Countries

$\begin{array}{lll}\text { Albania } & \text { Israel } & \text { Saudi Arabia } \\ \text { Bahrain } & \text { Kazakhstan } & \text { South Korea } \\ \text { Belarus } & \text { Lebanon } & \text { Sudan } \\ \text { Bosnia/Herzegovina } & \text { Malaysia } & \text { Turkey } \\ \text { Burma } & \text { Pakistan } & \text { United Arab Emirates } \\ \text { Democratic Republic of the } & \text { Qatar } & \text { Yugoslavia } \\ \text { Congo } & & \\ \text { Gabon } & \text { Romania } & \\ \text { Indonesia } & \text { Russia } & \end{array}$

Table 6.2 2002 Tier 3 Countries

Afghanistan

Burma

Cambodia

Kyrgyz Republic

Armenia

Greece

Qatar

Bahrain

Indonesia

Sudan

Belarus

Iran

Turkey

Bosnia/Herzegovina

United Arab Emirates

Table 6.3 2003 Tier 3 Countries

Belize

Bosnia/Herzegovina

Burma

Cuba

Dominican Republic

Table 6.4 2004 Tier 3 Countries

Bangladesh

Burma

Cuba

Ecuador

\section{Georgia}

Greece

Haiti

Kazakhstan

Liberia
Sudan

Suriname

Turkey

Uzbekistan
Equatorial Guinea

Guyana

North Korea

Sierra Leone

Table 6.5 2005 Tier 3 Countries

Bolivia

Burma

Cambodia

Cuba

Ecuador
Jamaica

Kuwait

North Korea

Qatar

Saudi Arabia
Sudan

Venezuela

Table 6.6 2006 Tier 3 Countries

Belize

Burma
Laos

North Korea
Syria

Uzbekistan
Togo

United Arab Emirates

Venezuela 
Cuba

Iran

Table 6.7 2007 Tier 3 Countries

Algeria

Bahrain

Burma

Cuba

Equatorial Guinea

Iran

Table 6.8 2008 Tier 3 Countries

Algeria

Burma

Cuba

Fiji

Iran

Table 6.9 2009 Tier 3 Countries

Burma

Chad

Cuba

Eritrea

Fiji

Iran
Saudi Arabia

Sudan

Kuwait

Malaysia

North Korea

Oman

Qatar

Saudi Arabia
Venezuela

Zimbabwe
Kuwait

Moldova

North Korea

Oman

Papua New Guinea
Sudan

Syria

Uzbekistan

Venezuela

Saudi Arabia

Sudan

Syria

Table 6.10 2010 Tier 3 Countries

Burma

Iran

Democratic Republic of the

Congo

Cuba

Dominican Republic

Eritrea
Malaysia

Mauritania

Niger

North Korea

Papua New Guinea

Saudi Arabia
Sudan

Swaziland

Syria

Zimbabwe

Table 6.11 2011 Tier 3 Countries

Algeria

Burma

Central African Republic

Democratic Republic of the

Congo

Cuba

Equatorial Guinea

Eritrea

Guinea-Bissau
Iran

North Korea

Kuwait

Lebanon

Libya

Madagascar

Mauritania

Papua New Ginea
Saudi Arabia

Sudan

Turkmenistan

Venezuela

Yemen

Zimbabwe 
Table 6.12 2012 Tier 3 Countries

Algeria

Central African Republic

Democratic Republic of the

Congo

Cuba

Equatorial Guinea

Eritrea

Table 6.13 2013 Tier 3 Countries

Algeria

Central African Republic

China

Democratic Republic of the

Congo

Cuba

Equatorial Guinea

Eritrea
Iran

North Korea

Kuwait

Libya

Madagascar

Papua New Guinea
Saudi Arabia

Sudan

Syria

Yemen

Zimbabwe
Guinea-Bissau

Iran

North Korea

Kuwait

Libya

Mauritania

Papua New Guinea
Russia

Saudi Arabia

Sudan

Syria

Uzbekistan

Yemen

Zimbabwe

Table 6.14 2014 Tier 3 Countries

$\begin{array}{ll}\text { Algeria } & \text { Iran } \\ \text { Demomocratic Republic of the } & \text { North Korea } \\ \text { Congo } & \\ \text { Cuba } & \text { Kuwait } \\ \text { Equatorial Guinea } & \text { Libya } \\ \text { Eritrea } & \text { Malaysia } \\ \text { The Gambia } & \text { Mauritania } \\ \text { Guinea-Bissau } & \text { Papua New Guinea }\end{array}$

Saudi Arabia

Syria

Thailand

Uzbekistan

Venezuela

Yemen

Zimbabwe

Table 6.15 2015 Tier 3 Countries

$\begin{array}{ll}\text { Algeria } & \text { The Gambia } \\ \text { Belarus } & \text { Guinea-Bissau } \\ \text { Belize } & \text { Iran } \\ \text { Burundi } & \text { North Korea } \\ \text { Central African Republic } & \text { Kuwait } \\ \text { Comoros } & \text { Libya } \\ \text { Equatorial Guinea } & \text { Marshall Islands } \\ \text { Eritrea } & \text { Mauritania }\end{array}$

Russia

South Sudan

Syria

Thailand

Yemen

Venezuela

Zimbabwe

Table 6.16 2016 Tier 3 Countries

$\begin{array}{ll}\text { Algeria } & \text { The Gambia } \\ \text { Belarus } & \text { Guinea-Bissau } \\ \text { Belize } & \text { Haiti }\end{array}$

Sudan

Suriname

Syria 


Burma
Burundi
Central African Republic
Comoros
Djibouti
Equatorial Guinea
Eritrea

Burma

Iran

North Korea

Marshall Islands

Mauritania

Papua New Guinea

Russia

South Sudan
Turkmenistan

Uzbekistan

Venezuela

Zimbabwe 